Florida International University

FIU Digital Commons

\title{
The The Relationships Between the Leadership Styles of Principals Assigned to Title I Middle Schools, Staff Longevity, School Climate, and Overall School Achievement
}

Anna L. Rodriguez

Florida International University, annarodriguez@dadeschools.net

Follow this and additional works at: https://digitalcommons.fiu.edu/etd

Part of the Curriculum and Instruction Commons, Educational Leadership Commons, Elementary and Middle and Secondary Education Administration Commons, and the Urban Education Commons

\section{Recommended Citation}

Rodriguez, Anna L., "The The Relationships Between the Leadership Styles of Principals Assigned to Title I Middle Schools, Staff Longevity, School Climate, and Overall School Achievement" (2019). FIU Electronic Theses and Dissertations. 3961.

https://digitalcommons.fiu.edu/etd/3961

This work is brought to you for free and open access by the University Graduate School at FIU Digital Commons. It has been accepted for inclusion in FIU Electronic Theses and Dissertations by an authorized administrator of FIU Digital Commons. For more information, please contact dcc@fiu.edu. 


\section{FLORIDA INTERNATIONAL UNIVERSITY}

Miami, Florida

\section{THE RELATIONSHIPS BETWEEN THE LEADERSHIP STYLES OF PRINCIPALS ASSIGNED TO TITLE I MIDDLE SCHOOLS, STAFF LONGEVITY, SCHOOL CLIMATE, AND OVERALL SCHOOL ACHIEVEMENT}

A dissertation submitted in partial fulfillment of

the requirements for the degree of

DOCTOR OF EDUCATION

in

EDUCATIONAL ADMINISTRATION AND SUPERVISION

by

Anna L. Rodriguez

2019 
To: Dean Michael R. Heithus

College of Arts, Sciences \& Education

This dissertation, written by Anna L. Rodriguez, and entitled The Relationships Between the Leadership Styles of Principals Assigned to Title I Middle Schools, Staff Longevity, School Climate, and Overall School Achievement, having been approved in respect to style and intellectual content, is referred to you for judgment.

We have read this dissertation and recommend that it be approved.

Delia C. Garcia

Liana Gonzalez

Thomas G. Reio

Peter J. Cistone, Major Professor

Date of Defense: March 26, 2019

The dissertation of Anna L. Rodriguez is approved.

Dean Michael R. Heithus

College of Arts, Sciences \& Education

Andrés G. Gil

Vice President for Research and Economic Development and Dean of the University Graduate School

Florida International University, 2019 
(C) Copyright 2019 by Anna L. Rodriguez

All rights reserved. 


\section{DEDICATION}

For my beloved angel, my grandmother, Maria M. Navas, who taught me love, humility, and resilience. The heavens are blessed to have her... 


\section{ACKNOWLEDGMENTS}

Nine years after taking the first step towards this great academic milestone, it is truly gratifying to have finally realized this feat. Without the support, encouragement, and guidance of my major professor, Dr. Peter J. Cistone, I could not have completed this process. His motivation, and above all, patience, prompted me to recommit many times to this journey when I was ready to throw in the towel.

Dr. Delia C. Garcia was also an invaluable member of my committee who never gave up on me throughout all these years. It was her work and vision through the Creating Latino Access to a Valuable Education (CLAVE) Grant award that afforded me, along with other Hispanic educational leaders, the opportunity to pursue and realize this dream.

A special thank you is also in order for Dr. Liana Gonzalez who agreed to join my committee when one of the members retired. Her insight and encouragement made my final product stronger and was thoroughly appreciated.

Every project is accompanied by a "behind the scenes" champion. This study could not have been possible without the work of Dr. Thomas Reio. He was not only instrumental in the data analysis process, and in the development of the methodology, but he was the sustenance, the unwavering benefactor, and the coach that prompted me to successfully run the last leg of this nine-year race.

Almost a decade ago, a cohort of ten educational leaders began this journey together. We sat in many classes and study sessions together. Many of these cohort members finished this journey years ahead of me, yet they have continued to push me to 
finish. I would like to thank Dr. Blanca Correa-Cespedes, Dr. Cory Rodriguez, and Dr. Mirta Segredo for never losing faith in me.

I would also like to thank the 30 principals and 290 teachers who graciously participated, therefore making the completion of this investigation possible. I would be remised if I didn't thank one very special mentor, and supporter, my boss, Ms. Barbara A. Mendizábal. Her understanding and educational insight contributed to the final product immensely. As well, I would like to thank Jesus Tellechea for his assistance, no matter the time of day.

Finally, I would like to acknowledge my family. My grandmother, Maria M. Navas, was with me when I was first accepted into the program. It was her dream to be present in the audience when I walked across the stage, this fourth time. As God willed it, she now not only will be present, but will walk beside me, as my guardian angel, as I receive that diploma. To my mother and father, Gloria and Pedro Rodriguez, thank you for instilling in me the great work ethic that has served as the backbone of my academic career and this dissertation. To Renette: thank you for your unwavering support. 


\section{ABSTRACT OF THE DISSERTATION \\ THE RELATIONSHIPS BETWEEN THE LEADERSHIP STYLES OF PRINCIPALS ASSIGNED TO TITLE I MIDDLE SCHOOLS, STAFF LONGEVITY, SCHOOL CLIMATE AND OVERALL SCHOOL ACHIEVEMENT \\ by}

Anna L. Rodriguez

Florida International University, 2019

Miami, Florida

Professor Peter J. Cistone, Major Professor

The achievement gap stands as one of the top priorities framing educational policy through the past half-century. The middle school level amplifies this gap especially in urban areas. The role of principal leadership in closing the achievement gap is key.

The purpose of this study was to examine the relationships between the leadership styles of principals assigned to Title I middle schools, staff longevity, school climate, and overall school achievement. The researcher applied a non-experimental, ex-post facto research design to investigate the research hypotheses. Utilizing the Google Survey Platform, 290 staff members across 30 middle schools within a large urban school district in southeast Florida, completed a survey which included questions related to longevity, and the Multifactor Leadership Questionnaire (MLQ Form 5x). Results of the school district's School Climate Survey, Staff Form, were employed to gauge school climate.

Hierarchical linear regression analyses revealed several significant positive associations between transformational leadership and numerous of the academic areas 
explored (e.g., reading learning gains of the lowest quartile, math proficiency, and social studies proficiency). In contrast to what was predicted, transactional leadership, also positively predicted some of the academic achievement factors evaluated (e.g., math proficiency, and math learning gains). Staff longevity negatively predicted school grade. Staff climate positively predicted math proficiency, and math learning gains. On the other hand, staff climate negatively predicted school grade, the three factors related to reading achievement (e.g., proficiency, learning gains, and learning gains of the lowest quartile), and social studies proficiency.

New research questions arose as a result of the investigation. Further research is recommended that examines the leadership variables explored within a larger sample, and in other geographical areas with similar demographics. As well, additional research is suggested involving staff longevity and school climate alongside a measure of collective instructional efficacy where urban schools are concerned. 


\section{TABLE OF CONTENTS}

CHAPTER $\quad$ PAGE

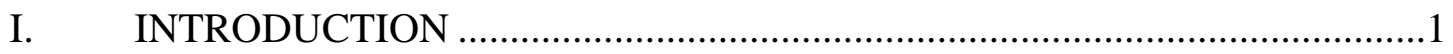

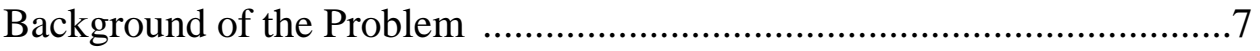

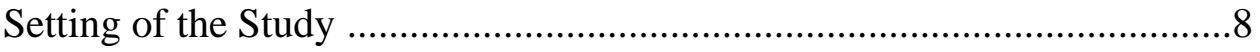

Purpose and Significance of the Study ……………………………….....

Theoretical Framework ...........................................................................11

Assumptions and Delimitations ...............................................................12

Definitions and Operational Terms ………………………………….....13

II. REVIEW OF THE LITERATURE ……………....................................18

Achievement Gap in the United States ...................................................18

Middle Schools and the Achievement Gap ..............................................28

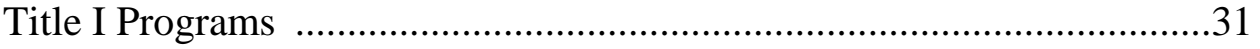

Educational Reforms ............................................................................34

Principal Leadership and Student Achievement .........................................38

Full-Range-of-Leadership Model and Principal Leadership .....................48

School Climate, Leadership, and Student Achievement .............................51

Staff Longevity, Leadership, and Student Achievement ...........................54

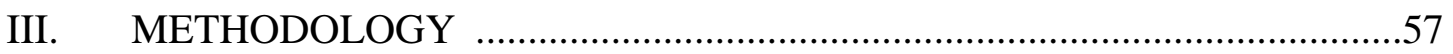

Research Questions …………………………………………….....58

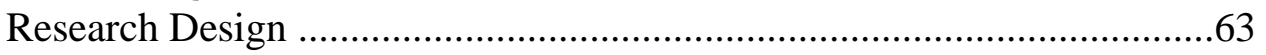

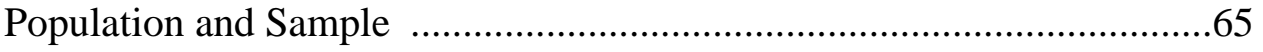

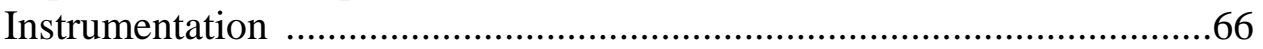

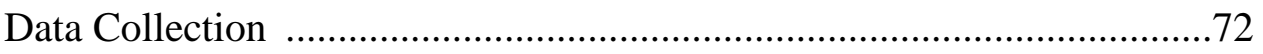

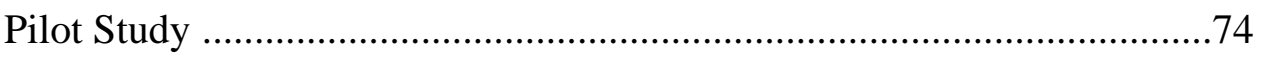

Statistical Analysis …………………………………......................

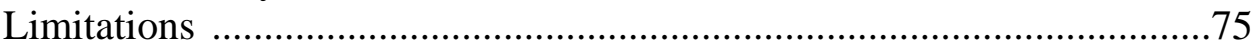

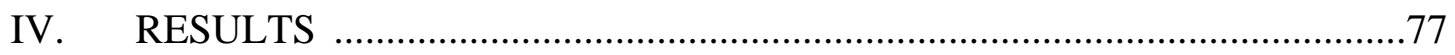

Demographics of the Sample …………………………………….......

Descriptive Statistics ..............................................................................

Results of Testing the Research Hypotheses ……………………….......92

Summary of Results ..........................................................................130

V. SUMMARY, CONCLUSIONS, AND IMPLICATIONS ............................133

Summary of the Study …………………………………...................133

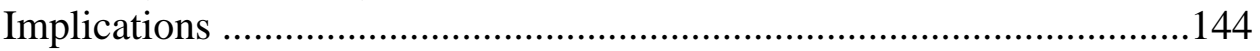

Suggested Further Research ..............................................................147

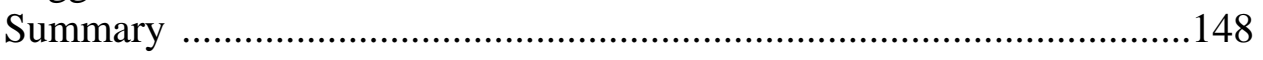




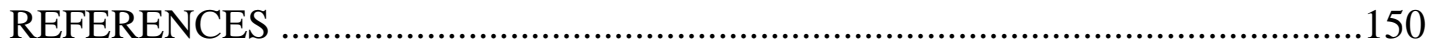

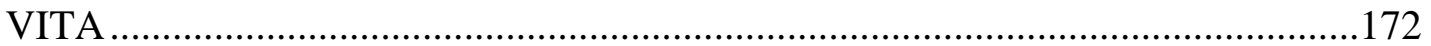




\section{LIST OF TABLES}

TABLE

PAGE

1. Average Scale Scores for Long Term Reading............................. 24

2. Average Scale Scores for Long Term Mathematics........................ 25

3. Components of the Full-Range-of-Leadership Model.......................... 50

4. Florida School Grading Scale $\ldots \ldots \ldots \ldots \ldots \ldots \ldots \ldots \ldots \ldots \ldots \ldots \ldots \ldots \ldots \ldots \ldots \ldots, \quad 65$

5. Transformational Leadership Constructs and Item Statements................... 69

6. Transactional Leadership Constructs and Item Statements .................. 70

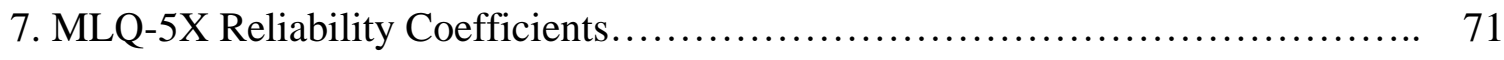

8. Participating Schools Demographics................................... 81

9. Summary of Scores on the MLQ Form $5 X(\mathrm{~N}=290) \ldots \ldots \ldots \ldots \ldots \ldots \ldots \ldots \ldots \ldots \ldots$

10. Summary of School Climate Staff Survey Results $(\mathrm{N}=30) \ldots \ldots \ldots \ldots \ldots \ldots \ldots \ldots$

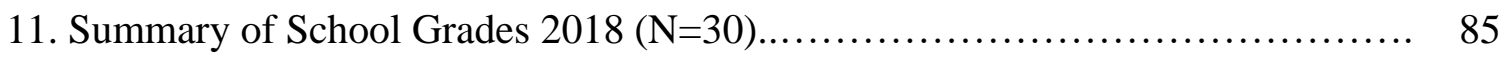

12. Summary of Changes Involving Specific Academic Factors Evaluated $(\mathrm{N}=30) \ldots 91$

13. Intercorrelations of MLQ-5X Leadership Factors, School Grade, Staff Climate,

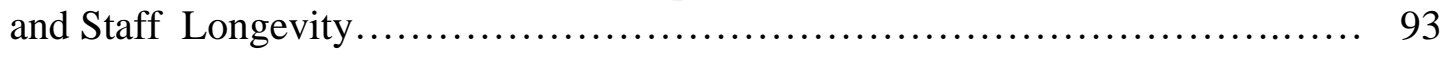

14. Summary of Hierarchical Multiple Regression Analysis for Transformational Leadership Variables Predicting School Grade (N=290)................... 95

15. Summary of Hierarchical Regression Analysis for Transformational Leadership

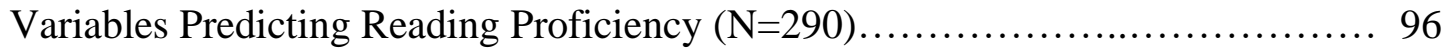

16. Summary of Hierarchical Regression Analysis for Transformational Leadership

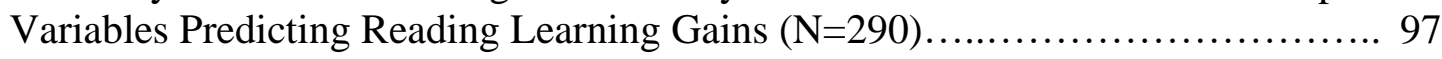

17. Summary of Hierarchical Regression Analysis for Transformational Leadership Variables Predicting Reading Learning Gains of the Lowest Quartile ( $\mathrm{N}=290) \ldots . . .98$ 
18. Summary of Hierarchical Regression Analysis for Transformational Leadership Variables Predicting Math Proficiency $(\mathrm{N}=290)$.

19. Summary of Hierarchical Regression Analysis for Transformational Leadership

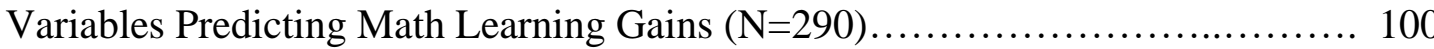

20. Summary of Hierarchical Regression Analysis for Transformational Leadership Variables Predicting Math Learning Gains of Lowest Quartile (N=290)

21. Summary of Hierarchical Regression Analysis for Transformational Leadership Variables Predicting Science Proficiency (N=290).

22. Summary of Hierarchical Regression Analysis for Transformational Leadership Variables Predicting Social Studies Proficiency $(\mathrm{N}=290)$.

23. Summary of Hierarchical Regression Analysis for Transactional Leadership Variables Predicting School Grade (N=290)... 104

24. Summary of Hierarchical Regression Analysis for Transactional Leadership Variables Predicting Reading Proficiency $(\mathrm{N}=290)$

25. Summary of Hierarchical Regression Analysis for Transactional Leadership Variables Predicting Reading Learning Gains ( $\mathrm{N}=290)$.

26. Summary of Hierarchical Regression Analysis for Transactional Leadership Variables Predicting Reading Learning Gains of Lowest Quartile ( $\mathrm{N}=290)$

27. Summary of Hierarchical Regression Analysis for Transactional Leadership Variables Predicting Math Proficiency (N=290)

28. Summary of Hierarchical Regression Analysis for Transactional Leadership Variables Predicting Math Learning Gains $(\mathrm{N}=290)$....

29. Summary of Hierarchical Regression Analysis for Transactional Leadership Variables Predicting Math Learning Gains of Lowest Quartile ( $\mathrm{N}=290)$

30. Summary of Hierarchical Regression Analysis for Transactional Leadership Variables Predicting Science Proficiency $(\mathrm{N}=290)$

31. Summary of Hierarchical Regression Analysis for Transactional Leadership Variables Predicting Social Studies Proficiency $(\mathrm{N}=290)$....

32. Summary of Hierarchical Regression Analysis for Staff Longevity in Predicting School Grade $(\mathrm{N}=290)$ 
33. Summary of Hierarchical Regression Analysis for Staff Longevity in Predicting Reading Proficiency $(\mathrm{N}=290)$.

34. Summary of Hierarchical Regression Analysis for Staff Longevity in Predicting

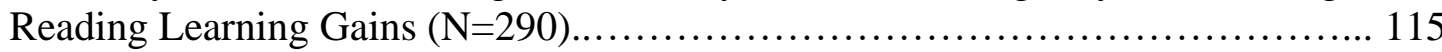

35. Summary of Hierarchical Regression Analysis for Staff Longevity in Predicting

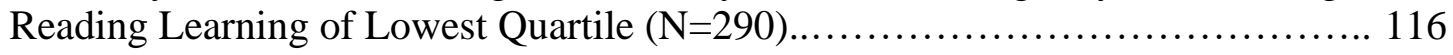

36. Summary of Hierarchical Regression Analysis for Staff Longevity in Predicting

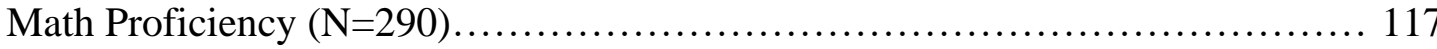

37. Summary of Hierarchical Regression Analysis for Staff Longevity in Predicting

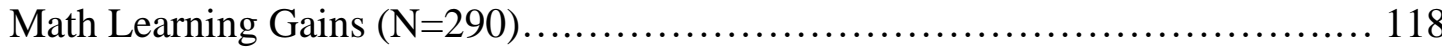

38. Summary of Hierarchical Regression Analysis for Staff Longevity in Predicting

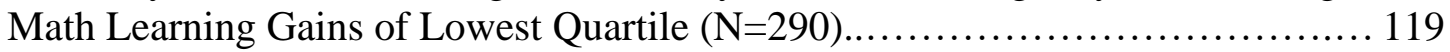

39. Summary of Hierarchical Regression Analysis for Staff Longevity in Predicting Science Proficiency $(\mathrm{N}=290)$

40. Summary of Hierarchical Regression Analysis for Staff Longevity in Predicting

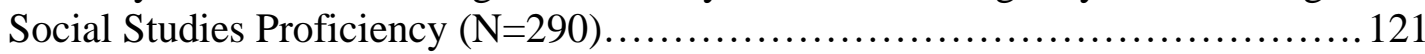

41. Summary of Hierarchical Regression Analysis for School Climate in Predicting School Grade $(\mathrm{N}=290)$.

42. Summary of Hierarchical Regression Analysis for School Climate in Predicting Reading Proficiency $(\mathrm{N}=290)$

43. Summary of Hierarchical Regression Analysis for School Climate in Predicting

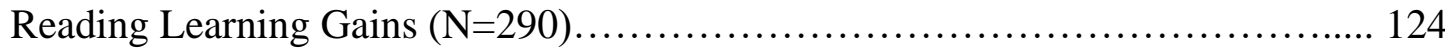

44. Summary of Hierarchical Regression Analysis for School Climate in Predicting

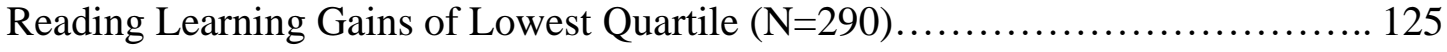

45. Summary of Hierarchical Regression Analysis for School Climate in Predicting

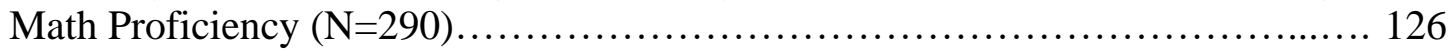

46. Summary of Hierarchical Regression Analysis for School Climate in Predicting Math Learning Gains $(\mathrm{N}=290)$.

47. Summary of Hierarchical Regression Analysis for School Climate in Predicting Math Learning Gains of Lowest Quartile $(\mathrm{N}=290)$. 
48. Summary of Hierarchical Regression Analysis for Multifactor Leadership Variables and School Climate in Predicting Science Proficiency (N=290)....

49. Summary of Hierarchical Regression Analysis School Climate in Predicting Social Studies Proficiency $(\mathrm{N}=290)$. 


\section{CHAPTER I}

\section{INTRODUCTION}

"American Public Education is "beyond all other devices of human origin, the great equalizer of the conditions of men- -the balance-wheel of social machinery."

-Horace Mann, 1848

In 1983, the National Commission on Excellence in Education released a report on the state of American education entitled A Nation at Risk. According to the findings, the nation's schools were being battered by a rising tide of mediocrity, and "if an unfriendly foreign power had attempted to impose on America the mediocre educational performance that" existed, it may have been "viewed as an act of war" (The National Commission on Excellence in Education, 1983, p. 33). The findings, when compared to international peers, highlighted the inadequate assessment results of American students, as well as, the insufficient academic outcomes produced by students educated in America's urban public schools (Eberts, Hollenbeck, \& Stone, 2002). Considering the overall discontent for the United States (U.S.) education system, various reforms were enacted in the years that followed, holding schools accountable for student academic progress (Vinovskis, 2015).

A number of educational reforms have been imposed over the past 30 years, however, a substantial educational disparity has developed, known as the achievement gap (Darling-Hammond, 2010). Reducing or closing the achievement gap has emerged as a crucial mission of the American Public Education System (Darling-Hammond, 2010). According to the National Center for Education Statistics, a long-term trend of the average 13-year-old middle school student reported that in 2012 Blacks and Hispanics 
trailed behind their White counterparts by 23 and 21 average scale score points respectively in reading, and by 29 and 22 points in mathematics (National Center for Education Statistics,2018). According to the Stanford Education Data Archive, when school districts are compared across the United States, the achievement gap is still wide, as Black students trail behind their White counterparts by four to five grade levels, considering the National Assessment of Educational Progress (NAEP) (Sparks, 2016). While the White-Black, and White-Hispanic achievement gaps were 30-40\%, they have declined since the 1970s; nonetheless the gaps are still considered large, as they range from 0.5 to 0.9 standard deviations (National Center for Education Statistics,2012).

Two in ten students who hail from low-socioeconomic families are educated in schools that have minimized the achievement gap (Cities, 2016). Public schools are accountable for equally and adequately educating all students, irrespective of national origin, race, postal code, social economic status, religion, political beliefs, sexual orientation, or disability (Noguera, 2003). Increased legislation has created heightened urgency centered on student achievement, as many students fail to meet expected academic levels (Bottoms \& O'Neill, 2001). Increased accountability efforts have incited augmented interest in the relationship between effective school leadership and student achievement (Fullan, 2002). As such, a new breed of school principal is essential to ensure the increased accountability that accompanies reform efforts are properly carried out (Bottoms \& O'Neill, 2001).

Principal leadership has been found to have a profound impact on instruction, for effective school-site leadership is regarded as crucial to the fruitful execution of reform (Cotton, 2003). Griffith (2004) studied the effect of principal leadership on student 
achievement and determined that some transformational characteristics do lead to increased educational outcomes. Beach and Reinhartz (2000) found that school leadership is crucial to fostering student achievement and formulating a clear vision of success for the complete educational program. The Mid-Continent Research Laboratory for Education and Learning (McRel) found a positive connection among school leadership and student achievement when it examined over 70 studies conducted in nearly 3,000 schools, housing 14,000 instructors and over one million students (Waters, Marzano, \& McNulty, 2003). According to Leithwood (1992) leadership takes a back seat only to direct classroom instruction when all school-related components that affect student learning are considered. Coincidentally, when principals take an active role in positively shaping culture accompanied by clear purpose, student achievement increases (Leithwood, Louis, Anderson, \& Wahlstrom, 2004; Wallace Foundation, 2013). As such, the question that remains is what do some principals do that others do not to produce such desirable results? Researchers have yet to agree upon a specific set of leadership behaviors that can effectively close the achievement gap (Bradbury, Corak, Waldfogel, \& Washbrook, 2015).

Principals who act in a transformational manner by positively revamping their respective schools, present great promise in successfully implementing the requirements necessary to positively impact student achievement and thereby minimize the achievement gap (Heck, 2014). Essentially, the vital element behind success stories is extraordinary leadership (Bierly \& Shy, 2013). The most successful principals are those who lead with efficiency, utilizing research-based approaches to tackle the plethora of issues that emerge daily and ultimately lead to enhanced outcomes (Hoy \& Miskel, 
2013). Characteristics found effective in producing positive outcomes in low achieving schools are more closely aligned to the tenets of transformational leadership, as principals who serve in these roles place instructional leadership first, are fueled by a keen awareness and consideration of the prevailing system and possess the ability to recognize and leverage data to produce optimal outcomes (Mendels, 2012).

Burns (1978) introduced the original concept of transformational leadership after analyzing the behaviors of political leaders, thereby expanding the work of Kohlberg's stages of moral development (1977) and Max Weber's theory of leadership and authority (1974). According to Burns (1978) transformational leadership is driven by the needs of followers, involving far more than compliance, it is a relationship that reciprocally inspires leaders and followers alike, where subordinates emerge as leaders, and leaders, in turn, as moral agents (Kuhnert \& Lewis, 1987). Transformational leadership fuels innovation at both the individual and at the broader, organizational level (Herold, Fedore, Caldwell, \& Liu, 2008). The shared accomplishment realized by the application of transformational leadership legitimizes those who actively partake in the process, enabling individuals to revive their organizational commitment and align their actions to achieve the universal goal at hand (Leithwood, 1992).

Burns (1978) also introduced the concept of transactional leadership. Transactional leadership involves an exchange of some type, where a subordinate receives a reward if he or she acts in the desired manner; if the opposite transpires, then a punishment ensues (McCleskey, 2014). Therefore, leaders who ascribe to the tenets associated with transactional leadership involve their respective subordinates in an affiliation of reciprocal necessity, as the inputs of both sides are recompensed (Kuhnert \& 
Lewis, 1987). When transactional leadership is present, the influence of the leader is paramount, as subordinates will do exactly as the leader desires, considering it is in their best interest (Kuhnert \& Lewis, 1987). While transactional leadership is linked to the reward and punishment system, it is considered as the basis of effective supervision, while transformational leadership is understood as enriching that foundation for improved leader efficacy (Waldman, 1990).

Bernard M. Bass further developed the work of Burns by amplifying the psychological underpinnings of transformational and transactional leadership (Bass, 1997). Not only did Bass (1985) expound upon the original ideas of transformational leadership by posing how it could be measured, but he also described how it would affect the motivation and performance of subordinates (Nielson, Randall, Yarker, \& Brenner, 2008). According to Bass (1985), the degree a leader is transformational is initially gauged in terms of how the leader influences supporters (Bass \& Steidlmeier, 1999). Through a transformational manner, supervisors stimulate subordinates in creating an identity tied to the general organizational mission (Bass, 1990). Bass, as opposed to Burns, posed that effective leadership may perhaps concurrently exhibit both transactional and transformational tenets (Smith, Matkin, \& Fritz, 2004).

Bernard Bass, accompanied by Bruce Avolio (1985), supplemented the research on transformational leadership through the introduction of the Full-Range of Leadership (FRL) model. The model infers that leaders exemplify behaviors aligned with transformational, transactional, and laissez-faire factors, but individually, they display more of one and less of the other two (Bass, 1998). The FRL also includes laissez-faire leadership, where the leader relinquishes responsibility and evades decision-making 
(Chaudhry \& Javed, 2012). Essentially, the FRL suggests that successful leaders are those who influence and motivate followers by elevating their sense of higher purpose to produce optimal performance results while delicately implementing inclusive, transactional and delegative management approaches (Gill, 2006).

School climate is another factor linked to leadership influencing student achievement. Marzano, Eaters, and McNulty (2005) affirm that school leadership and climate are inextricably associated with the productive operations of any multifaceted organization. School climate is experienced by stakeholders, and thereby influences their mindset regarding the organization (Hoy, Smith, \& Sweetland, 2003). The concept of school climate stands out as one of the most vital elements of any educational program (Hoyle \& Steffy, 1985). A school that enjoys a positive climate usually houses a cadre of motivated teachers. Teachers who are motivated are those who not only experience work-related fulfillment, but also endeavor towards excellence thereby developing their own capacity (Association, 2016). A positive climate where effective teaching and learning can flourish leads to heightened achievement (Lehr \& Christenson, 2002). As such, effective teaching serves as the most important factor impacting student learning (Dufour, 2011). When teachers perceive ill-treatment, their motivation lessens, and student outcomes are negatively affected (Hardman, 2011).

Staff longevity, accompanied by principal leadership and school climate, also play a role in student achievement. As staff members accrue more experience, they become more effective at their craft (Clark, Martorell, \& Rockoff, 2009) The research indicates that school principals require roughly five years to develop a climate that will produce heightened student learning outcomes (Gabarro, 1987). As well, the longer teachers 
serve, not only is their impact amplified through several cohort of students spanning several generations, but they better develop professionally, thereby embracing an inner awareness of determination and achievement (Ridgley, 2018). Professional longevity is accompanied by a subset of beneficial abilities that can only be amassed through years of service such as trustworthiness, resolution, and resilience (Ridgley, 2018).

\section{Background of the Problem}

Miami-Dade County Public Schools (MDCPS) is confronted yearly with the daunting task of raising the achievement levels of its students, many who oftentimes hail from less than privileged families. Essentially, MDCPS struggles annually as it attempts to close the achievement gap (Impact, 2018). There are some low-socioeconomic schools who have had success, however other schools in the same category have not. The case is especially true when middle schools (schools who offer education for students in grades

six through eight) are considered, as students at this level experience a substantial decline in standardized achievement test scores (Rockoff \& Lockwood, 2010). Nevertheless, a considerable body of research is lacking concerning middle school principals' influence on the academic attainment of lower socioeconomic students, especially when staff longevity and school climate are taken into effect.

Middle school students, according to recent Florida Standards Assessment (FSA) scores, did not fare well, as roughly $70 \%$ scored in the lowest quartile in both reading and mathematics (Rodriguez, 2016). In 2017, Title I public middle schools (schools with a high percentage of students who come from impoverished households) part of MDCPS, as per the Florida Department of Education grading system, produced the least percentage of "A" and "B" rated schools, as compared to elementary (kindergarten 
through fifth grade) and combination kindergarten through eighth grade (K-8) schools (United States Department of EducationTitle I, Part A, 2018). Thirty-two percent of Title I middle schools were rated as A or B, whereas $40 \%$ of Title I elementary and $33 \%$ of Title I K-8 combination schools earned such high ratings (Education F. D., 2017).

The academic situation described warrants school principals who can transform middle schools housing low-socioeconomic students and truly impact student achievement. Taking this concern into account, Title I middle schools were identified for this investigation.

\section{Setting of the Study}

The study was conducted with 30 Title I middle schools located in a large urban public school district in southeast Florida. In the 2017, schools were classified as Title I, when $68 \%$ or more of its students qualified for free or reduced-priced lunch (Miami-Dade County Public Schools, Title I Office, 2016) . There were 240 total Title I public schools out of 326 in Miami Dade County, spanning the 2017-2018 school year, and a total of 39 Title I middle schools (Florida Department of Education., Free/Reduced Lunches by District, 2017). Of these 39 schools, their free and reduced lunch percentages ranged from $78 \%$ to $97 \%$. As far as performance is concerned, using the 5-letter grade designation assigned in Florida (A-F) to Title I middle schools in 2017, 10.5\% scored an A, $10.5 \%$ scored a B, $65.8 \%$ scored a C, $10.5 \%$ scored a D, and two-and-a-half percent were not assigned a score (I) (Florida Department of Education, 2016-2017 School Grades, 2017). 


\section{Purpose and Significance of the Study}

While there is a substantial amount of research that directly ties classroom instruction to student achievement, a body of literature that addresses the direct impact of leadership considering moderating factors such as staff longevity and school climate is lacking (Robinson V., 2011; Thapa, Cohen, Gugffey, \& Higgins-D'Alessandro, 2013; Clark, Martorell, \& Rockoff, 2009). Specifically, when principal leadership is considered, the widespread idea is that principals who effect a transformational leadership style fulfill the various necessities of a school, which in turn lead to heightened achievement (Sergiovanni, 2007). Bass and Avolio (1994) found that organizational goals are optimally achieved when leaders make use of a full-range of leadership styles including transformational, transactional, and laissez-faire behaviors. Research concludes that both transactional and transformational leadership are complementary and indeed vital to organizations (Avolio, Bass, \& Jung, 1999). Before emerging as transformational, leaders must first master the management behaviors closely aligned to transactional approaches, for effective school leadership is achieved by executing both styles (Bass \& Avolio, 1994; Bass, 1997). Effective leadership creates the type of school climate conducive to teacher retention, and in turn leads to increased student achievement (Cohen, McCabe, Michelli, \& Pickeral, 2009).

Considering that principal leadership is linked to student achievement, identifying the correct balance of leadership characteristics, and its corresponding interaction with school culture and staff longevity is a topic to be further explored through research before the practical applicability is determined. As such, the purpose of the study was to examine the relationships between the leadership style of principals assigned to Title I 
middle schools, staff longevity, school climate, and overall school achievement. To carry out the study, various data sources were utilized. Principals' leadership style was gauged by their respective teachers' perception on the Multifactor Leadership Questionnaire, rater form (MLQ Form 5x-Short). The existing organizational culture was assessed by utilizing the results of the School Climate Survey, Feedback from Staff form, which was created by the school district. Principals and teachers completed a short survey developed by the researcher which allowed the researcher to quantify the length of time each participant had served in the same capacity at the current school. School achievement was measured by the school grade assigned by the Florida Department of Education grading system as determined by assessment scores, thereby categorizing " $\mathrm{D}$ " and "F" schools as low-achieving, and schools that earned grades ranging from "A" to "B" as high-achieving. School achievement was also measured by eight of the academic factors that result in the school grade (e.g., reading proficiency changes, reading learning gains changes, reading learning gains changes of the lowest quartile, math proficiency changes, math learning gains changes, math learning gains changes of the lowest quartile, science proficiency changes, and social studies proficiency changes).

Existing research fails to fully investigate the relationship between leadership, staff longevity, climate, and their related effects on student achievement, particularly involving middle schools. Middle schools often carry the culpability of student academic drops, especially for those students who enter middle school with existing low levels of academic achievement (Rockoff \& Lockwood, 2010). In turn, most of the existing research focuses on the various factors that are associated with student achievement but fails to directly explore the effects of principal leadership on student achievement (Sun \& 
Leithwood, 2015). As such, the study augments the existing research related to leadership theory. As well, there are some practical applications that can be used by the school district to train principals so that heightened achievement will result as new principals are trained and developed to lead the neediest schools.

\section{Theoretical Framework}

The investigation conducted followed the leadership continuum, the full-range model, as developed by Bass and Avolio. Bass and Avolio's research is applied in a wide range of organizations, ranging from healthcare to education. The two authors identified strategies contained within their continuum, varying from laissez-faire leadership behaviors, to transactional, and transformational leadership (Bass, 1985). Therefore, the theoretical foundation renders a leadership framework to evaluate which management style is most prevalent among principals, as perceived by teachers in Title I public middle schools, its correlation to student achievement, and how the implementation of successful practices may benefit comparable schools. Further, the Multifactor Leadership Questionnaire (MLQ-5X), comprised of 45 questions, also developed by Bass and Avolio, was administered to teachers (rater form) serving under the direction of Title I middle school principals, to assess the leadership characteristics of principals. The MLQ is the most often-utilized survey to gauge the factors within the full-range model (Antonakis, Avolio, \& Sivasubramaniam, 2003). School climate was measured by utilizing the School District's Climate Survey results readily available on the district's web page. Longevity was assessed via a demographic survey that quantified how many years the participant had served in the same capacity at the same school site. 


\section{Assumptions and Delimitations}

There are numerous assumptions associated with the investigation. First, the researcher assumed that the surveys were completed with sincerity, thereby providing a clear explanation of the participant's experience. It was also assumed that the school climate results presented an adequate picture of the existing school climate. The sample chosen for this study included middle school principals and teachers serving in 30 Title I middle schools. Second, the investigator presumed that participants read and replied to each question contained devoid of bias. Third, the researcher assumed that the school grade assigned, as well as the nine academic factors gauged by the Florida Department of Education, provided an accurate representation of students' academic achievement.

The study was limited to the insights reported by the participants and did not encompass the opinions of all stakeholders associated with the school community. For example, the opinions of students, parents, and community members, in gauging leadership style, and school achievement were not included. The leadership influence of principals is dependent upon the relationships cultivated with their corresponding subordinates, even though the perspective of respective stakeholder communities outside of those of teachers surveyed may provide some additional insight (Fullan, 2002). Further, academic achievement of students was limited to the school grades and academic factors as determined by the Florida Department of Education grading system, not considering other factors such as report card grades. 


\section{Definitions and Operational Terms}

\section{Achievement Gap}

The phrase "achievement gap" denotes disparities in achievement, more specific, standardized test scores, between White and students or other races, predominantly Black and other minorities (Landson-Billings, 2006).

\section{Active Management by Exception}

Active management by exception is defined as the act the transactional leader engages in when he or she constantly evaluates the subordinates' work and accordingly alters the tasks assigned based on progress (Odumeru, 2013).

\section{Climate}

School climate represents what is perceived by stakeholders, and thereby influences their mindset regarding the organization (Hoy, Smith, \& Sweetland, 2003). Climate is more of a short-term subset corresponding to the overarching "culture" of the organization. The idea of "culture" signifies the long-term, deeply-held impressions based on collective experiences and established traditions (Wagner \& Masden-Copas, 2002).

\section{Contingent Reward}

Contingent reward is frequently associated with the tenet of transactional leadership and is defined as those remitted for completing a task thoroughly, in accord with the established expectations (Houlfort, 2002). 


\section{Florida Standards Assessment (FSA)}

The FSA is a series of grade-level assessments in the state of Florida, tied to the state's Common Core-based standards that measure educational gains and overall academic progress of students (Florida Department of Education, K-12 Student Assessment, 2016).

\section{Full-Range Leadership Model}

The full-range leadership model was developed by Bass and Avolio and is a method of leadership that engages transformational, and transactional tenets to inspire followers' sense of overall purpose to produce optimal results (Pantaleon, 2015).

\section{Idealized Influence}

Idealized influence is detected in leaders whose actions are framed by collective vision and can proficiently convey that "vision" by forging an emotional connection with respective followers, thereby endeavoring acquisition of trust-- said leaders are regarded as possessing influence, which is essentially ideal (Barling, Slater, \& Kelloway, 2000). Leaders who possess idealized influence emerge as role models, since they are venerated, depended upon, and cherished (Bass \& Riggio, 2006).

\section{Individual Consideration}

Individualized consideration pertains to leaders serving as mentors, role models, and coaches for subordinates and stimulating personal development and growth along the way (Bass \& Avolio, 1994).

\section{Inspirational Motivation}

Inspirational motivation pertains to leaders who not only stimulate, but inherently inspire subordinates, and coherently and clearly communicate the goals of the 
organization and what tenets should be focused upon as vital (Stone, Russell, \&

Patterson, 2004).

\section{Intellectual Stimulation}

Intellectual stimulation is the aspect of transformational leadership that encourages followers to contemplate and visualize problems through different lenses and thereby contest the established way problems have traditionally been resolved in the organization (Stone, Russell, \& Patterson, 2004).

\section{Laissez-Faire Leadership}

The concept of laissez-faire leadership describes a leader who avoids or renounces making decisions (Chauldhry, 2012).

\section{Longevity}

"Longevity" may be used to refer to the length of service a person has served in a particular organization (Bobeck, 2002). For the purposes of this study, "longevity" relates to the amount of time the individual has served in the same capacity at the same school site.

\section{Low-Income}

According to the U.S. Department of Health and Human Services, a family of four is considered low income if its annual income falls at or below $\$ 24,250$ a year (Evaluation, 2016).

\section{Management by Exception}

Management by Exception is a regulatory method, founded on the exception principle. Subordinates should focus on routine situations daily and only escalate nonroutine problems to the leader (Whitehead, Boschee, \& Decker, 2013). 


\section{Multifactor Leadership Questionnaire (MLQ)}

The Multifactor Leadership Questionnaire was developed by Bass and Avolio and serves as the standard instrument for gauging three diverse leadership styles:

transformational, transactional, and laissez-faire (Antonakis, Avolio, \& Sivasubramaniam, 2003).

\section{Passive Management by Exception}

Passive management by exception is the act of delaying any corrective action until a problem arises (Odumeru, 2013).

\section{Proficiency}

Proficiency is defined as a passing score on the FSA, which is a score of a level three through level five (Florida Department of Education, Understanding Florida Standards Assessments Reports, 2016).

\section{Title I Schools}

Schools comprised of a high percentage of students who hail from low-income homes and receive financial assistance from the federal government through the Title I, Part A (Title I) of the Elementary and Secondary Act to assist in safeguarding student achievement are considered Title I (United States Department of EducationTitle I, Part A, 2016).

\section{Transactional Leadership}

Transactional leadership is a term used to describe leaders who lead predominantly by utilizing social exchanges for transaction or work products (Chauldhry, 2012). Essentially, subordinates who are led by transactional leaders receive rewards if they act in the desired manner. 


\section{Transformational Leadership}

Transformational leadership is viewed as contributing to the success of any organization, including schools (Eagley, Johannesen-Schmidt, \& Van Engen, 2003). Transformational leadership is comprised of four defined aspects: idealized influence, inspirational motivation, intellectual stimulation, and individualized consideration (Givens, 2008). Operationally, the concept of transformational leadership is defined as the measures gained on each of the transformational leadership dimensions contained on the Multifactor Leadership Questionnaire (MLQ 5X) as teachers provide their individual responses pertaining to each of their respective principals (Avolio \& Bass, 2004).

\section{Summary}

The purpose of this chapter was to introduce the key concepts related to the study. In this chapter, the notion of principal leadership in Title I middle schools and its relation to student achievement, as well as the prevalent achievement gap that seems to intensify at this academic level are introduced. The setting, purpose and significance of the investigation, along with the theoretical framework are also touched upon. Additionally, assumptions and limitations accompanied by significant definitions and operational terms are similarly reviewed.

The next chapter consists of a review of the literature encompassing the major concepts associated with this study. Chapter III will expound upon the methodologies and instruments utilized to explore the research questions. Chapter IV will discuss the findings related to the questions explored, and Chapter V will present conclusions and implications of the study. 


\section{CHAPTER II}

\section{REVIEW OF THE LITERATURE}

\section{INTRODUCTION}

Classifying leadership styles amongst school principals is not only complicated, but a multifaceted process. The principal is charged with making split-second decisions, along with juggling a plethora of other tasks. Principal leadership depicts a fundamental function in the overall management of an educational institution (Cardno, 2012).

The relationships between the leadership styles of Title I middle school principals, staff longevity, school climate, and overall school achievement was explored in the present study. A review of the literature, including an expansion on the theoretical framework supporting the proposed study, as well as a conceptualization supporting the need for the study because of the dearth of investigations exploring the relationships between each of the constructs are included. Additionally, the varied viewpoints, as well as the contemporary thoughts exposed through the literature are offered in the subsequent segments.

\section{Achievement Gap in the United States}

Daily, as principals enter their respective schools, they are faced with student scheduling, teacher observations, parent conferences, student discipline, and school cleanliness; additionally, they must guide their schools to improved student achievement, in their role as the primary instructional leader (Yisrael, 2012). The chore is further complicated when low-achieving schools, especially middle schools, are considered. 
Research has found that student achievement substantially declines in middle school, and thereby widening the achievement gap (Rockoff \& Lockwood, 2010).

Achievement gaps are of noteworthy concern since educational attainment in grades K-12 functions as the foundation to post-secondary schooling entrance, and to accomplishment in the labor market (Reardon, 2013). In the 1950s and 1960s, a middleclass job could easily be attained without a college degree, yet today the middle-class job market almost always requires a college degree (Carnevale, 2010). As such, the emphasis on closing the achievement gap has dominated the national discourse on education for years. The phrase "achievement gap" denotes disparities in achievement, more specific, standardized test scores between White and students of other races, predominantly Black and other minorities (Landson-Billings, 2006).

A great deal of attention has centered upon the Black-White achievement gap predominantly because of the United States' extensive history of slavery coupled with the 1960s civil rights movement (Reardon \& Galindo, 2006). The Black-White achievement gap dates back to the 1600 s in the nation's history, where $90 \%$ of the Black population was illiterate during the times of slavery (Smith, 1984). Black literacy was illegal until the end of the Civil War in 1865, and it was not until the enactment of the $14^{\text {th }}$ Amendment in 1868 that U.S. citizenship was provided to Blacks through the Reconstruction Period (Rierson, 1994). Even when Blacks could receive an education, the schools they attended were segregated, especially in the South, where a dual education system consisting of "White" and "Colored" schools was formed (Anderson, 1988). These "separate" public schools not only served Black students, but Asian, Latino, and Native American students as well (Street, 2005). Essentially, as the research 
suggests, the schools where the nation's minority students attended were substandard (Darling-Hammond, 2004).

Financial support was also relegated to a two-class system, as "White" schools were awarded two to three times more funding per student in comparison to "Black" schools (Wilson, 2009). The two-class system of segregation was governmentally supported, however the introduction of the Separate but Equal Doctrine provided some hope for non-White students (Orfield, 2009). According to this policy implemented in 1868, racial segregation was not in violation of the Constitution of the United States, if the facilities were equal (Belknap, 2004). In 1896, the Supreme Court decision in Plessy v. Ferguson further supported the Separate but Equal Doctrine (Orfield and Frankenberg, 2014). Minority students were forced to attend inferior schools for nearly a century (Orfield, 2009).

In 1954, the Supreme Court of the United States took steps to formally overturn Plessy v. Ferguson in the landmark case Brown v. Board of Education. The court unanimously (9-0) declared that it was unconstitutional for states to establish separate public schools for Black and White students (Mills, 2017). After the 1954 decision, schools allegedly were equal. Considering the decision contained no direction on how to realize school desegregation, many southern cities executed a considerable degree of deferment in the process (Brooks, 1996).

It was not until the Little Rock Nine (nine Black students) were denied entrance into the Arkansas district's high school in 1957, that the tables started to turn, as President Eisenhower directed national troops to forcibly escort the students into the school (Gooden, 2004). Even after equal schools were established for "colored" students, 
Black students still lagged White counterparts academically, consistently exposed to a less than standard, watered-down curriculum, oftentimes forced to complete meaningless low-level tasks (Delpit, 2006). Today, over sixty years later, many Black students still attend schools in culturally and economically remote areas (Rothstein, 2013). Thirty-nine percent of Black students come from families whose combined income stands below the poverty line, whereas only $12 \%$ of White students live the same financial reality (Rothstein, 2017).

Black students, however, are not the only minority group who have been affected by the achievement gap phenomenon. Another educational disparity that educational reforms have targeted is the Hispanic-White achievement gap. The Hispanic population in the United States, according to U.S. Census Bureau figures grew by $43 \%$, increasing from 35.3 million in 2000 to 50.5 million in 2010 , to represent $16 \%$ of the total population (Humes, 2011). Compared to White and Black students, Hispanic students enter Kindergarten with a lower level of overall school readiness (Duncan \& Magnuson, 2005; Fryer \& Levitt, 2004; Reardon, 2003; Rumberger \& Arellano, 2004; Reardon \& Galindo, 2006). Notwithstanding the overall increase of achievement assesment scores between 2005 and 2015, just 21\% of Hispanic fourth grade students realized proficient reading levels, compared to $46 \%$ of White students (Camera, 2018).

Overall immigration trends, not just pertaining to Hispanics, have greatly affected the academic disparities, as it is expected that minorities will account for $47.9 \%$ of the total population by $2020,56.9 \%$ by 2030, and $65.1 \%$ by the year 2040 (Colby \& Ortman, 2015). In fact, it is projected that in the year 2044, the U.S. will experience a census phenomenon and emerge as a "majority-minority" nation, as then the non-Hispanic, 
White population will comprise under $50 \%$ of the total population, with Blacks then encompassing 14\% and Hispanics 29\% (Colby \& Ortman, 2015).

Considering the projected numbers, the achievement gap should be steadily narrowing. However, according to researchers, the achievement gap has hardly tapered off during the last half-century, regardless of alleged improved race relations and augmented attention dedicated to narrowing academic incongruities amongst groupings of students (National Center for Education Statistics,2015). The National Assessment of Educational Progress (NAEP), considered the nation's academic report card, has been gauging the reading and mathematics skills attainment of American fourth, eighth, and tenth-grade students for over 40 years (Analysis, 2017). The achievement disparity between White-Black and White-Hispanic students, according to 2012 figures, is approximately $35 \%$ lesser than the statistics reported 40 years ago, yet these inequalities are still regarded as significant, as they range between 0.5 to 0.9 standard deviations below the mean (National Center for Education Statistics, 2013). Further, the average nine-year-old student today is performing at or about the same level as the average 13year-old performed in 1978; and the typical 13-year-old student today is at or about the same level as a typical 17-year-old student of 1978 (National Center for Education Statistics, 2013). On average, according to overall academic proficiency scores as gauged by data gathered from several standardized tests, Black students are performing approximately two grade levels below their White counterparts, and Hispanic students lag about one-and-a-half grade levels behind (Rabinovitz, 2016).

While scores have somewhat increased for Black and Hispanic students in reading and mathematics, the staunch academic disparity has nonetheless persisted. According to 
the long-term trend of the average 13-year-old middle school student reported by the National Center for Education Statistics, in 2012 Blacks and Hispanics trailed behind their White counterparts by 23 and 21 average scale score points respectively in reading, and by 29 and 22 points in mathematics (National Center for Education Statistics, 2018). 
Table 1

Average Scale Scores for Long Term Reading

\begin{tabular}{|c|c|c|c|c|c|c|c|c|}
\hline \multirow[b]{2}{*}{ Year } & \multicolumn{2}{|c|}{ White (not Hispanic) } & \multicolumn{2}{|c|}{ Black (not Hispanic) } & \multicolumn{2}{|c|}{ Hispanic } & \multicolumn{2}{|c|}{$\begin{array}{c}\text { Asian American or Pacific } \\
\text { Islander }\end{array}$} \\
\hline & $\begin{array}{l}\text { Average Scale } \\
\text { Score }\end{array}$ & Standard Error & $\begin{array}{l}\text { Average Scale } \\
\text { Score }\end{array}$ & Standard Error & $\begin{array}{l}\text { Average Scale } \\
\text { Score }\end{array}$ & $\begin{array}{l}\text { Standard } \\
\text { Error }\end{array}$ & $\begin{array}{l}\text { Average Scale } \\
\text { Score }\end{array}$ & Standard Error \\
\hline 2012 & 270 & 1.3 & 247 & 1.6 & 249 & 1.3 & 284 & 4.9 \\
\hline 2008 & 268 & 1.0 & 247 & 1.6 & 242 & 1.5 & 278 & 2.5 \\
\hline 2004 & 265 & 1.0 & 239 & 1.9 & 241 & 2.1 & 269 & 2.6 \\
\hline 1999 & 267 & 1.2 & 238 & 2.4 & 244 & 2.9 & 258 & 5.9 \\
\hline 1996 & 266 & 1.0 & 234 & 2.6 & 238 & 2.9 & 254 & 3.9 \\
\hline 1994 & 265 & 1.1 & 234 & 2.4 & 235 & 1.9 & 258 & 5.1 \\
\hline 1992 & 266 & 1.2 & 238 & 2.3 & 239 & 3.5 & 270 & 3.8 \\
\hline 1990 & 262 & 0.9 & 241 & 2.2 & 238 & 2.3 & 254 & 5.7 \\
\hline 1988 & 261 & 1.1 & 243 & 2.4 & 240 & 3.5 & 273 & 5.0 \\
\hline 1984 & 263 & 0.6 & 236 & 1.2 & 240 & 2.0 & 265 & 3.1 \\
\hline 1980 & 264 & 0.7 & 233 & 1.5 & 237 & 2.0 & 269 & 3.7 \\
\hline
\end{tabular}

Note. From National Average Scale Scores in Reading by Ethnicity from 1980-2012. From Statistics, N. C. (2018, January 1). NAEP Data Explorer. Retrieved from National Center for Education Statistics:

https://nces.ed.gov/nationsreportcard/lttdata/report.aspx 
Table 2

Average Scale Scores for Long Term Mathematics

\begin{tabular}{|c|c|c|c|c|c|c|c|c|}
\hline \multirow[b]{2}{*}{ Year } & \multicolumn{2}{|c|}{ White } & \multicolumn{2}{|c|}{ Black } & \multicolumn{2}{|c|}{ Hispanic } & \multicolumn{2}{|c|}{ Other } \\
\hline & $\begin{array}{l}\text { Average Scale } \\
\text { Score }\end{array}$ & Standard Error & $\begin{array}{l}\text { Average Scale } \\
\text { Score }\end{array}$ & Standard Error & $\begin{array}{l}\text { Average Scale } \\
\text { Score }\end{array}$ & Standard Error & $\begin{array}{l}\text { Average Scale } \\
\text { Score }\end{array}$ & Standard Error \\
\hline 2012 & 293 & 1.1 & 264 & 1.9 & 271 & 1.4 & 305 & 4.2 \\
\hline 2008 & 290 & 1.2 & 262 & 1.2 & 268 & 1.2 & 296 & 3.2 \\
\hline 2004 & 287 & 0.9 & 257 & 1.8 & 264 & 1.5 & 290 & 2.9 \\
\hline 1999 & 283 & 0.8 & 251 & 2.6 & 259 & 1.7 & 283 & 3.0 \\
\hline 1996 & 281 & 0.9 & 252 & 1.3 & 256 & 1.6 & 280 & 3.9 \\
\hline 1994 & 281 & 0.9 & 252 & 3.5 & 256 & 1.9 & 284 & 3.0 \\
\hline 1992 & 279 & 0.9 & 250 & 1.9 & 259 & 1.8 & 282 & 2.3 \\
\hline 1990 & 276 & 1.1 & 249 & 2.3 & 255 & 1.8 & 274 & 7.2 \\
\hline 1986 & 274 & 1.3 & 249 & 2.3 & 254 & 2.9 & 283 & 3.4 \\
\hline 1982 & 274 & 1.0 & 240 & 1.6 & 252 & 1.7 & 275 & 4.1 \\
\hline 1978 & 272 & 0.8 & 230 & 1.9 & 238 & 2.0 & 273 & 3.5 \\
\hline
\end{tabular}

Note. From National Average Scale Scores in Mathematics by Ethnicity from 1980-2012. From Statistics, N. C. (2018, January 1). NAEP Data Explorer. Retrieved from National Center for Education Statistics:

https://nces.ed.gov/nationsreportcard/lttdata/report.aspx 
Achievement gaps are not only attributed to race, because socioeconomic factors are also related to achievement (Becker \& Luthar, 2002). A family's socioeconomic standing is a strong predictor of educational achievement, as students considered in the lowest $20 \%$ economically often score over one standard deviation below counterparts from the top $20 \%$ (Reardon, 2011). When students from low socio-economic situations enter kindergarten, the discrepancy does not appear to taper as they progress from elementary to middle, and onward through high school (Reardon, 2011). Research indicates that household income is positively correlated to achievement levels, along with the prospect that a student will obtain a high school diploma, as well as take advantage of post-secondary educational opportunities (Hanover Research, 2014). When data captured from the census bureau in 2009 are analyzed, considering all students under the age of 18, 15.5 million students subsist in impoverished conditions, where the income generated in their respective homes is less than \$21, 947 a year (Ansell, 2017).

In the fall of 2017, approximately 50.7 million students walked through the doors of America's public schools (National Center for Education Statistics, 2018). Of those students enrolled, approximately $20 \%$, or 1 million, were considered low-income, accompanied by families who qualify for free and reduced-priced lunch (National Center for Education Statistics, 2017). Further research reveals that in the United States, the average family needs approximately $\$ 50,000$ of combined yearly income to adequately subsist (Darling-Hammond, 2010). Historically, socioeconomic factors serve as critical predictors of student achievement, and research indicates that the academic performance of students from disadvantaged backgrounds lag their more fortunate counterparts (Caro, 2012). 
The achievement gap, as it relates to students who come from affluent and impoverished families, appears to have increased in the past couple of decades. Income disparity has grown substantially since the 1970s, as policies developed in the 1980s mainly related to housing, income support, and additional safety nets for low-income families have worsened the overall financial situation for low-income households (Raerdon, 2013). Unfortunately, studies specify that the achievement gap is mounting, as the disparity amongst students from affluent and impoverished families stands at approximately 30 to $40 \%$ higher among children born after 2001 than between those who were born 25 years prior (Hanover Research, 2014).

Students who come from low socio-economic backgrounds usually encounter difficulties when it comes to academic progress in school (Jensen, 2017). These students are not read to aloud as frequently as students from families who are not economically stressed, and often lack exposure to the broad vocabularies that accompanies complex language (Rothstein, 2013). Studies have found that impoverished students, because of their lack of initial acquaintance with robust language skills, enter school at a disadvantage, and are twice as likely to suffer from grade retention, and one-third less likely to move on to college after high school (National School Boards Association, 2000)

Another factor linked to the achievement gap is language background. Average Scholastic Aptitude Test (SAT) scores have concluded that there is also a large disparity between students whose native language is English and those who are classified as English Language Learners (ELLs) in reading and writing (Fry, 2008). In the state of Florida, only $45 \%$ of ELL third graders attain proficient levels in standardized 
mathematics assessments, compared to $78 \%$ of White, monolingual peers, generating a 34-point disparity (Fry, 2008). Yet, as the Pew Hispanic Center found, when ELL students attend higher instead of lower-performing schools, then the gap is significantly constricted (Fry, 2008).

\section{Middle Schools and the Achievement Gap}

Middle Schools were created in America to provide students with an effective transitional place between elementary and high school, where students' needs would be paramount, thereby gaining exposure to rigorous coursework, and exploratory opportunities (Dickinson, 2001). Specifically, the middle school movement can be traced back to the 1960s, as an adjustment of the long-established junior high school (Yecke, 2005). In 1963, William M. Alexander proposed an undertaking to replace the traditional junior high, that was nothing more than a smaller replica of a senior high school, with a more educationally intimate setting designed for adolescents (Alexander, 1987). Alexander envisioned the middle school concept as a place where curriculum was designed to address the specific needs of teenagers through collaborative teaching, and interdisciplinary planning (Edwards \& Kemp, 2014).

The movement gained momentum throughout the next 20 years. The 1970s is regarded as a developing stage for the middle school concept, pronounced by endeavors to label, classify, and delineate what was purported by the idea of the "middle school" (Schaefer, 2016). By the late 1970s, there were over 4,000 fully operational middle schools in the United States (Schaefer \& Malu, 2016). The middle school movement expanded further through the $80 \mathrm{~s}$, as practices were developed unique to the middle 
school setting including pedagogically-centered curriculum, team-teaching, counseling, block scheduling, and an interdisciplinary approach (Schaefer \& Malu, 2016).

As the years have passed, the tide has turned, however. In 1997, editors on the Phi Delta Kappa brought to light the fact that in 1994, merely $28 \%$ of the nation's eighth grade students earned reading standardized assessment scores in the proficient and above range; the realization that middle schools were failing at exposing students to rigorous academic standards became apparent (Meyer, 2011). National Assessment for Progress (NAEP) mathematics scores prove that America's fourth-grade students increased their scores, between 1978 and 2008, by 24 points, whereas eighth-grade students, in the same time frame, only improved by 17 points (Meyer, 2011). Unfortunately, the middle school level not only presents a case for a decline in achievement, but it is where the achievement gap seems to widen as students progress through the educational continuum. Mathematics achievement, for example, declines by .12 standard deviations for $6^{\text {th }}$ graders after entering middle school; whereas reading achievement declines by .09 standard deviations (Rockoff \& Lockwood, 2010).

No matter the efforts to create a level of education where students achieve, grow, and establish a robust basis for high school, students continue to fall behind during their middle school years. American educational institutions, overall, are not adequately supporting the social, emotional, and academic necessities of its middle school students, as the developmental period has often been linked to a deteriorating sense of self and academic confidence (Jackson \& Davis, 2000). In fact, middle school students have often been found to lack the essential level of academic engagement necessary for future all-around accomplishment, including college, and career success (Carnegie Council on Adolescent Development, 1990). 
In Miami-Dade County Public Schools (MDCPS), the state of Florida's largest school district, and the nation's fourth largest, reading and mathematics achievement scores continue to decline throughout students' middle school years. After three years at the middle school level, students perform .14 and .23 standard deviations respectively below their K-8 counterparts (Schwerdt \& West, 2017). In Miami-Dade County, 237 of its 324 (73\%) total public schools are considered Title I, as they are comprised of over $73 \%$ of economically disadvantaged students receiving free or reduced-price lunch (Florida Department of Education, Florida School Accountability Reports, 2017).

State-issued school grades for MDCPS showed that middle school students scored below every other school grade configuration in 2017. Title I middle schools had the highest percentage of schools scoring lower than a "C" as established by the state of Florida school grading system. Four percent of senior high schools, five percent of elementary schools, seven percent of K-8 Centers, and 13\% of middle schools that fall into the Title I designation, scored below a letter grade of "C" (Florida Department of Education, 2017). The Miami-Dade County Public Schools' Superintendent Alberto M. Carvalho recently referred to middle schools as the Achilles Heel of the K-12 education spectrum (Carvalho, 2017). During these intermediate academic years, students are least engaged, and parents are minimally content with the middle school academic experience (Travis, 2017). In recent times, many of the nation's school districts are engaging in a middle school redesign process to address this pronounced gap (Rockoff \& Lockwood, 2017). 


\section{Title I Programs}

The Economic Opportunity Act (EOA) of 1964, which established the Elementary and Secondary Education Act (ESEA) of 1965, including the Title I federal grant, was a specific attempt to address the achievement gap through the provision of financial resources to the schools that educated the neediest and most academically susceptible students. Upon signing the bill, President Lyndon Johnson professed a national goal of equal educational opportunity for all students (Lowndes, Novkov, \& Warren, 2008). The ESEA represents the most significant source of national expenditure on elementary and secondary education (Thomas \& Brady, 2005). Specifically, the Title I grant was formulated to address the achievement gap that was partially in existence due to socioeconomic disparity factors (McCall, 2016). The implementation of the Title I program signified a momentous and decisive moment for the federal government's role in educational endeavors (McCall, 2016).

Traditionally, states and local governmental entities maintained control relevant to schooling, and the federal government involved itself exclusively once matters of fundamental national interest were at risk (Theobald, 2000). As such, considering the elimination of poverty a national concern, Title I legislation paved the road for an ongoing federal part in schooling by presenting educational impartiality as a crucial matter. The federal government's role in American education has developed into an ever-increasing educational staple. The federal government has broadened its involvement from administering fiscal assistance and holding local education agencies (LEAs) and state education agencies (SEAs) responsible because Title I funds were expended. The federal government now also prompts states to develop research-based 
academic systems and structures, assessments, and methods by which schools and their respective districts would be held accountable for student achievement (Giroux, 2016).

By the 1968-69 school year, Title I funding was assisting nearly nine million children across America's public schools (McClure \& Martin, 1969). In recent years, the policy's scope has expanded to serve more than 21 million children and provide funds to more than 56,000 public schools housing economically disadvantaged students (United States Department of Education, 2014). Since 1980, Title I funding to schools has grown from $\$ 3$ billion to nearly $\$ 15.4$ billion in 2017 (United States Department of Education, Total U.S. Expenditures for Elementary and Secondary Education, 2008; United States Department of Education, Fiscal Year, 2017).

In 2017, the Title I grant awarded Florida school districts 857 million dollars (United States Department of Education, 2017). The program affords LEAs revenues to assist students in achieving a quality education accompanied with the competence to reach levels of proficiency on the Florida Standards. The new Florida Standards surpassed the former Next Generation Sunshine Standards in challenging students by exposing them to more critical thinking, problem-solving and communication competencies, and were formally adopted on February 18, 2014 (Florida Department of Education, 2017). The school district of Miami-Dade County, in 2017, received a total award of 150 million dollars (United States Department of Education2017). The criteria stipulate that in order to receive Title I funding, $60 \%$ or above of a school's students must qualify for free or reduced-price lunch (Miami-Dade County Public Schools, Title I Administration 2017-2018 Participating Schools, 2017). Of the 325 public schools that 
comprise the school district, in 2017, 240 schools received assistance, and 39 of these were middle schools (Miami-Dade County Public Schools, Title I Administration 20172018 Participating Schools, 2017).

The process involving the distribution of Title I funds changed drastically in Florida with the enactment of House Bill (HB) 7069 during the 2017 Florida Legislative Session. HB 7069 required that the funding be first distributed to schools that educate students who fall above the $75 \%$ poverty threshold, then the remaining funds be directly disbursed to all remaining qualified Title I schools (regardless of the school's level of achievement), thereby restricting district control (Senate, 2017). In years past, school districts retained the power to allocate monies for valuable academic initiatives by shifting funds from more academically proficient Title I schools to more vulnerable ones. Some of Miami-Dade County's lowest achieving public Title I schools have, as result of Law 7069 , lost anywhere from $\$ 200,000$ to an upwards of $\$ 700,000$ in this funding shift (Schools, Legislative Updates, 2018). Many school districts across the state of Florida consider the law to undermine the intent of ESEA by restricting how Title I funds are allocated to schools and have filed a lawsuit against the state of Florida (Bakeman, 2018). The school district of Miami-Dade County Public Schools, while the most impacted by the new law, recently decided to allow diplomacy to take its course, and pass on joining the lawsuit (Bakeman, 2018).

According to Senate (2017) some change brought about as a result of the law, beyond the distribution of Title I-related funds are: (a) the requirement for public school districts to share their revenues with eligible charter schools; (b) the enactment of mandatory recess for elementary school students; the elimination of the Algebra 2 end-of- 
course exam requirement in high school; (c) the creation of a new bonus system for educators who meet the established parameters; and (d) increased accountability measures for low-achieving schools (Florida Senate, 2017). Across the state, public school districts are especially feeling the financial pinch further when it comes to construction, as each district is losing capital funding to improve charter school buildings, buildings that in the end, are not publicly-owned (Gurney \& Clark, 2017). The estimated five-year financial impact to Miami-Dade County Public School’s Capital Plan, earmarked for public school building maintenance and improvements, is $\$ 182,000,000$ (Miami-Dade County Public Schools, Legislative Updates, 2018).

\section{Educational Reforms}

Challenging academic standards have framed the impetus fueling the Title I grant under the ESEA since its inception. The federal government has authorized the law eight times after its initial enactment in 1965 (Jennings, 2016). Throughout the ESEA history, there have been some noteworthy authorizations, and associated policy implementations that have reached deeply into educational governance, mainly No Child Left Behind (NCLB), Race to the Top (RTTT), and Every Student Succeeds Act (ESSA).

Not even 20 years after the original authorization of ESEA, in 1983, President Ronald Reagan unveiled the findings of his blue-ribbon commission through the report $A$ Nation at Risk, thereby stimulating a more direct role of the federal government in K-12 public education (The National Commission on Excellence in Education, 1983). According to the findings captured in A Nation at Risk, the nation's schools were being battered by a rising tide of mediocrity, and further declared that "if an unfriendly foreign power had attempted to impose on America the mediocre educational performance that 
"existed, then it would have been viewed as an act of war" (The National Commission on Excellence in Education, 1983, p. 33). Due to the blue-ribbons panel's report, the nation's schools came under even more intense scrutiny. States were prompted to develop demanding standards increasing rigor in the classrooms, coupled with the development and implementation of more demanding teacher training programs (Ravitch, 1995).

In 2002, still fueled by the blue-ribbon panel's report, the much-acclaimed No Child Left Behind (NCLB) clause was born, as George W. Bush took the ESEA a step forward in educational oversight alongside another reauthorization. NCLB was the federal government's answer to the K-12 public education predicament. NCLB intended to ensure school districts and states were held accountable for improving the educational quality for students and transforming identified low-performing schools (Hewitt, 2011). With NCLB, the federal government mandated heightened accountability from the nation's schools, as annual standardized assessments were implemented to gauge the progress of schools with an acute focus on narrowing the achievement gap and intensifying teacher qualifications (United States Department of Education, 2002). NCLB obliged states to produce basic skills assessments, therefore proving Annual Yearly Progress (AYP) at specific grade levels as a prerequisite for receiving federal funds (Harris, 2007). As a result, states were required to administer standards-aligned yearly assessments in both reading and mathematics to students in $3^{\text {rd }}$ through $8^{\text {th }}$ grade (Michelman, 2016). According to the law, a timeline was identified where the nation's public-school student body would achieve or surpass each state's designated level of proficiency on state assessments by 2014 (United States Congress, 2017). Schools that repetitively failed to meet the established standards could face stringent injunctions, such 
as the redirection of federal monies to fund vouchers for students to attend private schools or receive tutoring (Bernhardt, 2003).

With the lack of financial backing to implement many of NCLB's mandates, the federal government offered, without any threat of penalty, a voluntary grants program, Race to the Top (RTTT), under the American Recovery and Reinvestment Act enacted by the Obama administration in 2009. The act assigned 4.35 billion dollars to the RTTT Fund, providing financial backing to NCLB mandates. RTTT offered substantial incentives to states that were willing to turn the heat up on systemic reform. States that applied for the grant were given points for implementing several policies. RTTT committed $\$ 4$ billion to 19 states that designed programs addressing more rigorous standards and thorough assessments. The participating states also developed improved data systems, provided direct support to school site personnel in their quest to transform into more effective educators, instituted policies that allowed the expansion of quality charter schools, and provided an in-depth focus on the services the lowest performing schools needed to turn them around (McGuinn, 2012).

Additionally, states that applied were evaluated on other aspects, including Science, Technology, Engineering, and Math (STEM) education prioritization, and Early Learning opportunities (McGuinn, 2012). Because of the RTTT initiative, the United States Department of Education produced an Annual Performance Report (APR) classifying each grantee's academic development (McGuinn, 2016). Conceivably the most noteworthy policy alteration prompted by NCLB and RTTT was the implementation of Common Core Standards-aligned assessments, thereby establishing a 
measure for the knowledge students should master at every grade level from K-12 (McGuinn, 2016).

Soon after the implementation of RTTT, President Obama signed the Every Student Succeeds Act (ESSA), thereby reauthorizing the ESEA of 1965 in 2015, and officially replacing the No Child Left Behind Act (Mathis \& Trujillo, 2016). Some researchers have posed that the new act significantly curbed the federal government's overreach in educational policy (Saultz, Fusarelli, \& McEachin, 2017). The law however, preserves the yearly assessment and reporting requirements initially outlined in NCLB. The law mandates for all states to continue testing $95 \%$ of all students in reading and mathematics yearly, once a year in high school, and once a year from grades three through eight (McGuinn, 2016). States were also required to assess students in science at three distinct points during a student's K-12 academic career (McGuinn, 2016).

Additionally, ESSA upheld the prerequisite of publicly disclosing assessment scores for each school and different subgroup populations of students including impoverished, minority, ELLs, and special education students (United States Department of Education, 2017). While the ESSA specifies that the standards adopted by each state must be challenging and tied to college readiness, it prohibits the federal government from forcing states to implement any specific collection of standards (i.e., Common Core) (McGuinn, 2016). Under the ESSA, states are allowed more discretion when it comes to selecting assessments, as well as the opportunity of replacing a state high school assessment with an SAT or ACT concordant score (Darling-Hammond, et al., 2016).

While states are required to present accountability plans to the U.S. Department of Education, there is lessened federal oversight, as they are now allowed to identify their 
own academic objectives accompanied with an explicit prospect of improvement and school appraisal concerning established goals (McGuinn, 2016). Moreover, the act also requires the development of plans to address consistently underperforming schools (Darling-Hammond, et al., 2016). The ESSA essentially curbs the control of the federal government in educational matters and returns oversight to the state.

\section{Principal Leadership and Student Achievement}

Schools today face a plethora of challenges when it comes to improving student achievement, yet research has identified one constant that stands at the forefront of overall school success, the school principal (Leithwood \& Wahlstrom, 2004). If one were to walk through the doors of a flourishing school, a highly effective principal will be found at its helm; the opposite also holds true (Leithwood \& Riehl, 2003). Principals fuel the motivation and capacity of the school's stakeholder community including students, teachers, parents and community members (Leithwood \& Hopkins, 2006). The position of the school principal is regarded as the most potent assignment within the educational ranks, serving as the anchor for an organization's success, carrying the primordial accountability of instructional quality and student development (Leithwood \& Riehl, 2003). In fact, the Mid-Continent Research Laboratory for Education and Learning (McRel) found a positive connection among school leadership and student attainment when it examined over 70 studies conducted in nearly 3,000 schools, housing 14,000 instructors and over one million students (Waters, Marzano, \& McNulty, 2003). Successful principals leverage their unique grasp of the technical attributes related to the educational process, framed by their ability to identify the precise moment which would 
prompt leadership style adjustments and thereby lead to enhanced performance (Mendels, 2012).

Studies have investigated the specific behaviors effected by principals that lead to academic success. One specific behavior is the degree the school principal is cognizant of the particulars surrounding the existing culture, and how he or she leverages this insight to address existing and prospective challenges (Waters, Marzano, \& McNulty, 2003). Another principal behavior identified is the emphasis on strengthening the culture of professional learning, which leads to the use of the best classroom practices (Wahlstrom, Louis, Leithwood, \& Anderson, 2010). The Wallace Foundation, one of the nation's most recognized authorities on educational improvement, has pinpointed several crucial practices of effective principals. Developing a rigorous academic plan, while fostering a culture of collaboration among stakeholders, along with mentoring teachers are some of the practices identified (Wallace Foundation, 2013).

Investigations into leadership have revealed additional principal practices, which are tied to achievement. One such practice is a "can-do" attitude which is keenly centered on fostering an environment where every student can and will learn (Principals \& Principals, 2013). Another example is developing and maintaining a high-quality teaching workforce (Principals \& Principals, 2013). In fact, the research determines that leadership is the single most significant factor influencing educators' inclinations to remain at the same school (Fernet, Trepanier, Austin, \& Levesque-Cote, 2016). Still another behavior directly linked to student outcomes is time. Effective principals recognize their influence on student learning and therefore spend more time on the aspects of the organization that will lead to the established goal, thus making the choices 
that will produce heightened outcomes in the end (Leithwood, Louis, Anderson, \& Wahlstrom, 2004).

\section{Transformational Leadership Style}

The concept of transformational leadership has been perceived through a variety of lenses. Bennis (1959) proffered the interpretation that transformative leadership was comprised of an individual's ability to advance another's awareness, construct meaning, and above all, stimulate individual commitment. While the term "transformational leadership" was presented by the sociologist James Downtown in the early 1970s, it was not until 1978, when political scientist and historian James MacGregor Burns proffered the notion of transformational leadership as a process based on the power of synergy between leaders and subordinates collaborating toward reciprocal benefit, that the study of transformational leadership commenced (Rada, 1999). According to Burns (1978) transformational leadership is a symbiotic, reciprocal progression where both the leader and the follower simultaneously assist one another in developing a heightened level of self-esteem and inspiration. The crucial aspect of leadership is the revelation of a common purpose accompanied by the interaction between purpose and ideals (Burns, 1978).

Transformational leadership is viewed as contributing to the success of any organization, including schools (Eagley, Johannesen-Schmidt, \& Van Engen, 2003). Principals serve as an academic institution's chief instructional leader, and according to Sergiovanni (2007) transformational leadership is the appropriate management approach that accordingly fulfills the various necessities of a school's stakeholder community as it promotes shared leadership in determining instructional practices coupled with curricular 
enhancements. Transformational leadership practices inspire unselfish commitment to organizational vision (Shields, 2006). The transferable currency or personified capital of transformational leadership exemplifies the way leaders in the educational field step outside the norm, and transcend the circumscribed structural framework, thereby radiating into the broader common framework that defines schools (Shields, 2006).

In the 1980s, Bernard M. Bass further developed the work of Burns by analyzing the psychological mechanism fueling transformational and transactional leadership (Bass, 1997). Prior to Bass's expansion, the term readily utilized was "transforming," as opposed to "transformational" (Leithwood \& Jantzi, 2009). For years, transformational leaders have been viewed as organizational heroes; they have been regarded as the ones who could ultimately motivate subordinates to a heightened level of achievement (Bass, 1990). Leaders who ascribe to the principals associated with transformational leadership are those who not only motivate, and intellectually stimulate, but also pay close attention to detail, especially when it comes to individual differences among peers and subordinates (Yammarino \& Dubinsky, 1994). According to Bass and Riggio (2008) the concept of transformational leadership stands as thoughtful, cerebral stimulus that fundamentally stimulates the transfer and delivery of content for teaching and learning; as transformational leaders fuel followers' passion for innovation. Along those lines, Leithwood and Jantzi (2006) describe transformational leadership as a progression, ultimately leading to heightened stages of organizational allegiance, as the desired outcomes are accomplished. School management necessitates principals to not only focus on accomplishing tasks, but on taking people into account as well. School principals today are faced with the colossal challenge of balancing managerial requirements with 
transformational initiatives, curricular implementation, and building capacity, while producing heightened academic outcomes (Fullan, 2001). Leaders who are transformational strive to comprehend and appreciate associates' individuality and recognize his or her place as an essential part of the whole and encourage each of them to cultivate his or her maximum capacity (Avolio \& Bass, 2004). Each member of the stakeholder population comes to the table with desires and expectations; the transformational leader recognizes this aspect and leverages it to further a more profound commitment to the vision and mission of the organization (Marquardt, 2011).

Transformational leadership poses a fruitful outlook on contemporary matters to address what is common knowledge and the undertakings that students must accomplish (Marzano, Waters, \& McNulty, 2005). Transformational leadership is vital when it comes to turning schools around and increasing achievement (Cisneros, 2010). Respectively, there are four dimensions related to transformational leadership: (a) idealized influence; (b) inspirational motivation; (c) intellectual stimulation; (d) and individual consideration (Bass, 2006). A meta-analysis of 39 studies discovered a positive correlation between a leader's effectiveness and all tenets of transformational leadership (Lowe, 1996).

Idealized influence is detected in leaders whose actions are framed by a collective vision and can proficiently convey that "vision" by forging an emotional connection with respective followers, thereby endeavoring acquisition of trust, said leaders are regarded as possessing influence, which in turn is "ideal" (Bass, 2010). Leaders who possess idealized influence emerge as role models since they are venerated, depended upon, and cherished (Bass \& Riggio, 2014). These leaders are recognized in such a manner because they are considered as holding prominent leadership skills accompanied by a robust sense 
of resolve powered by the tenacity to achieve all tasks and overcome challenges (Bass, 1990). Nonetheless, leaders who act with a sense of idealized influence use their authority to back the interests associated with his or her followers, as opposed to selfinterests (Bass, 2010). As such, they are capable of motivating subordinates to achieve at optimal levels, by serving in a manner that is viewed as genuinely attentive to the growth of their subordinates (Bass, 2010).

Inspirational motivation, and it pertains to leaders who not only stimulate, but inherently inspire subordinates, and coherently and clearly communicate the goals of the organization, accompanied by the specific tenets that should serve as the focus (Bass \& Avolio, 1994). Not only do transformational leaders communicate the most important goals that accompany the mission and vision of the organization, but they also provide a game plan on how to achieve said goals, with fervor and passion (Bass \& Riggio, 2014). Along those lines, the leader transfers his or her message with accuracy, confidence, and expertise. As well, the visionary leader leads with positivity and executes his or her duties with unrelenting enthusiasm (Kouzes \& Posner, 2002).

Another component that is associated with the tenet of inspirational motivation is intellectual stimulation (Eyal \& Roth, 2011). Leaders who are transformational in nature can motivate their respective followers to contemplate and visualize problems through different lenses, thereby evoking questioning of the established methods and the way problems have traditionally been resolved. As such, subordinates are encouraged, as opposed to discouraged from posing thought-provoking questions that many times challenge the established culture (Cashman, 2017). When intellectual stimulation is involved, subordinates are inspired to deeply reflect to resolve dilemmas at hand (Bass, 
1990). Those who are encouraged to engage in the process of intellectual stimulation develop a level of comfort, engaging in the ebb of flow of the practice either individually or cooperatively (Bass, 1985). As a direct result of intellectual stimulation, different methods, possibly never considered before, may be endeavored, consequently leading to a more innovative path to organizational achievement (Avolio \& Bass, 2004).

Another aspect of transformational leadership is individualized consideration. Individualized consideration pertains to leaders serving as mentors and role models for subordinates, thereby stimulating personal development and growth along the way (Bass \& Avolio, 1994). Leaders who are transformational accordingly act in an attentive manner to the distinct needs of his or her followers when it comes to individual accomplishment and development (Bass \& Riggio, 2014). Transformational leaders encourage employee feedback and dedicate efforts to coaching, allowing employees to feel as significant individual members vital to the organization's success, as opposed to immaterial followers (Bass \& Riggio, 2014).

\section{Transactional Leadership Style}

According to Burns (1978), when transformational leadership is compared to transactional leadership, opposites emerge, as he considers these two styles of management markedly unalike. Burns (1978) initially proposed that leaders who are transactional in nature approach subordinate relationships with a somewhat discriminate nature focused on bartering, and the success of the transactional leader hinges upon the

covenant forged as to the desired task outcomes between superior and underling. The idea was further expanded by Bass (1985) who described the practice of transactional leadership as a cost-benefit exercise where leader-subordinate dealings are concentrated 
on a succession of interactions or implicit agreements. Research poses that some of the tenets directly associated with transactional leadership are indeed necessary to lead schools (Marzano, Waters, \& McNulty, 2005).

Principals who are transactional are more commonplace and concentrate on rewarding followers in exchange for delivering the desired results (Judge, 2004). Transactional principals define objectives, communicate explicit agreements involving expectations, and provide reflective feedback at specific points of the designated project to ensure everyone is achieving in the expected manner (Vera \& Crossa, 2004). Transactional leadership involves the interactive value of effects with no common search of advanced order drive (Nguni, Sleegers, \& Denessen, 2006). Transactional leaders realize collaboration is accomplished through the interchange of incentives, and thereby stimulate subordinates to achieve as expected (Mahdinezhad, Saudi, Silong, \& Omar, 2013). When a leader engages in the act of conveying specific criterions of compliance and scrutinizing for nonconformity and incentivizes acquiescence, a transactional leadership style is being realized (Bass, Avolio, Jung, \& Berson, 2003). Transactional leadership is usually an acceptable course of action for the maintenance of existing conditions but may not be the appropriate course when profound change is needed in an organization (Nguni, Sleegers, \& Denessen, 2006).

Transactional leadership presents a deliberate, mutual-concession approach (Leithwood \& Duke, 1998). Transactional leadership entails leaders explicitly explaining the proposed goals, and conveying the arrangement for task accomplishment (Bass, 1990). Leaders whose management likeness is of a transactional disposition accomplish projects successfully when employees consent to hierarchical differences and the capacity 
to progress through this manner of interchange (Bass \& Bass, 2008). Three primary manifestations of transactional leadership are: (a) contingent reward, (b) passive, and (c) active-management-by- exception, and laissez-faire (Bass, Avolio, Jung, \& Berson, 2003).

Contingent reward embodies a leadership style that is preemptive and clearly defines the association amongst employee compensation by way of negotiation (Robinson \& Boies, 2016). Within the process of contingent reward, employers communicate the tasks at hand, along with the specifics related to the rewards to be gained if success is achieved (Avolio, Bass, \& Jung, 1999). The employer motivates subordinates by employing contingent rewards, promises, admiration, and sometimes retribution to realize anticipated levels of execution (Yukl, 2012). Simply stated, the notion infers that punishment and reward are contingent on the expected level of achievement and defines the work-for-pay contract in the employment affiliation. The superior elucidates anticipations, exchanges pledges and assets for patronage, organizes shared fulfilling contracts, arranges resources, barters support in exchange for performance, and supplies incentives for accomplishment (Bass \& Bass, 2008).

Another concept associated with transactional leadership, active and passive management-by-exception, captures the process of a leader's reaction to subordinate failure (Barling, 2014). A corrective exchange where supervisors emphasize the errors that subordinates should evade is thereby employed when leaders practice this management style. In active management-by-exception, leaders judiciously scrutinize the work of subordinates for mistakes and respond almost instantly in an oftendemeaning manner, repeatedly reminding subordinates about their job responsibilities to 
provoke them to achieve in the desired manner (Thoroughgood, Tate, Sawyer, \& Jacobs, 2012). Passive management-by-exception, in turn, describes leaders who circumvent any action and do not monitor the work of employees closely, until urgent situations present themselves, often at the expense of critical lapses (Avolio \& Bass, 2004). Passive management-by-exception is many times likened to a more traditional style of government centered upon rigidity such as was practiced by the European monarchies of old (Bass, 2000). Not only is passive management-by-exception depicted by decisionmaking avoidance, but by provisional penalties and other punitive measures aimed at correcting any nonconformity from the expected standard of performance (Yukl, 2012). The distinction between both concepts pertains to the timing associated with the leader's reaction to errors in active management-by-exception, the leader energetically anticipates subordinate error, whereas, in passive management-by-exception, the leader waits for mistakes before acting (Den Hartog, Van Muijen, \& Koopman, 1997).

A third dimension associated with transactional leadership is laissez-faire, where leaders work according to the conditions defined by workers, and subordinates are allowed autonomy accompanied by a degree of freedom for task completion (Bass, 2000). Laissez-faire leaders are often regarded as lacking the capacity to produce deepseeded change (Bass, 1998). According to Bass and Avolio (1995) laissez-faire leadership is associated with inactive behaviors, considered the absence of leadership, and many times is accompanied by the evasion of decision-making. As such, leaders who act in a laissez-faire manner fail to forge transactions or agreements with subordinates, and quite often postpone making decisions and do not invest time or energy in moving followers to act (Skogstad, Einarsen, Torsheim, Schanke, \& Hetland, 2007). 
When laissez-faire leadership is compared to transformational and transactional leadership, research has discovered that when employee satisfaction is considered, laissez-faire leaders frequently manage organizations comprised of employees who are not as gratified by their current situation (Avolio, 2011). As well, organizations that are led with this approach, often suffer in overall employee output and cohesiveness (Bass \& Bass, 2008). Nonetheless, the laissez-faire style is best suited for systems whose overall subordinate grouping is highly adept and benefits from a robust sense of selfdetermination (Antonakis, 2001).

\section{Full-Range-of-Leadership Model and Principal Leadership}

Particularly, the question of whether transactional or transformational leadership is more closely related to school achievement is of interest. When the theories were first explored, transformational and transactional leadership stood distinctly at odds, on two different ends of the organizational spectrum (Burns, 1978). As the theory evolved, leaders were found to be transactional, transformational, both, or neither (Vera \& Crossa, 2004). In fact, some researchers have uncovered that prosperous principals also possess transactional skills, and that while they may be mostly transformational, transactional skills must be mastered first (Van Wart, 2003). Bass and Avolio concluded that both transactional and transformational leadership were complementary and indeed vital to the success of organizations (Avolio, Bass, \& Jung, 1999).

Bass expounded upon the work both he and Avolio effected on transformational and transactional leadership by framing the concept of transformational leadership with a broader arrangement of dimensions; the updated representation is regarded as the fullrange-of-leadership model (Bass, 1998). The model is divided into three dimensions: (a) 
highly active forms of leadership, including tenets of transformational and contingent reward leadership; (b) relatively active modes of leadership such as active managementby-exception; and (c) passive leadership exemplars functioning as passive managementby-exception and laissez-faire leadership (Avolio \& Bass, 2002).

Organizational goals are optimally achieved when leaders make use of a full range of leadership styles including transformational, transactional, and laissez-faire behaviors (Bass \& Avolio, 1994). In line with his exploration, Bass developed the Multifactor Leadership Questionnaire that was later perfected with the help of Bruce Avolio in 1994. The MLQ is recognized as the fundamental method to quantify the practice of transformational leadership along with its corresponding dimensions, and it has been widely studied and validated (Kirkbride, 2006). Specifically, as documented through the MLQ manual, by way of factor analyses effecting a six-factor model for the instrument, construct validity is elucidated (Avolio \& Bass, 2004). When reliability is considered, the scores tallied for the MLQ subscales ranked anywhere from moderate to good, considering the instrument's 45 elements on the 5X-Short version via a five-point behavioral scale (Avolio, Bass, \& Jung, 1999). Immediately following, please find the specific components comprising the Full Range Leadership Model. 
Table 3

Components of the Full-Range-of-Leadership Model

\begin{tabular}{|c|c|}
\hline \multicolumn{2}{|c|}{ Transformational Leadership } \\
\hline Components & Characteristics \\
\hline $\begin{array}{l}\text { Idealized Influence } \\
\text { Attributes (IA) }\end{array}$ & $\begin{array}{l}\text { Leaders are considered as self-assured, commanding, and concentrate on } \\
\text { higher-order principles and beliefs. These leaders serve as role models that } \\
\text { associates aspire to emulate. Associates feel esteem, devotion, and } \\
\text { admiration towards the leader. }\end{array}$ \\
\hline $\begin{array}{l}\text { Idealized Influence } \\
\text { Behaviors (IB) }\end{array}$ & $\begin{array}{l}\text { Leader exploit their charismatic activities that are grounded upon values, } \\
\text { beliefs, and purpose. IB represents the leader's capacity to act in a manner } \\
\text { that fuels associates' confidence and conviction. }\end{array}$ \\
\hline $\begin{array}{l}\text { Inspirational Motivation } \\
\text { (IM) }\end{array}$ & $\begin{array}{l}\text { Leaders propel associates by communicating a captivating vision of the } \\
\text { future and acting in a manner that motivates and inspires by offering } \\
\text { significance and challenge to the work. They also speak passionately about } \\
\text { the tasks at hand and convey confidence that the aims will be realized. }\end{array}$ \\
\hline $\begin{array}{l}\text { Intellectual Stimulation } \\
\text { (IS) }\end{array}$ & $\begin{array}{l}\text { Leaders excite associate's efforts to act in novel and creative ways, thereby } \\
\text { challenging the status-quo. }\end{array}$ \\
\hline $\begin{array}{l}\text { Individual Consideration } \\
\text { (IC) }\end{array}$ & $\begin{array}{l}\text { Leaders consider associates as entities as opposed to a group by focusing on } \\
\text { the individual needs, capacities, and ambitions and behaving as a mentor. }\end{array}$ \\
\hline \multicolumn{2}{|c|}{ Transactional Leadership } \\
\hline Contingent Reward (CR) & $\begin{array}{l}\text { Leaders recognize the needs of associates and enable the accomplishment of } \\
\text { established objectives by connecting expectation with reward. }\end{array}$ \\
\hline $\begin{array}{l}\text { Management-By- } \\
\text { Exception Active } \\
\text { (MBEA) }\end{array}$ & $\begin{array}{l}\text { Leaders consistently supervise associate performance, expecting } \\
\text { nonconformity, and taking corrective action. }\end{array}$ \\
\hline \multicolumn{2}{|c|}{ Passive/Avoidant Leadership } \\
\hline $\begin{array}{l}\text { Management-By- } \\
\text { Exception Passive } \\
\text { (MBEP) }\end{array}$ & $\begin{array}{l}\text { Leaders supervise associate performance, waiting for deviations to be } \\
\text { brought to his or her attention prior to taking corrective action. }\end{array}$ \\
\hline $\begin{array}{l}\text { Laissez-Faire Leadership } \\
\text { (LF) }\end{array}$ & $\begin{array}{l}\text { Leaders who are inattentive and absent when needed and avoid making } \\
\text { decisions. }\end{array}$ \\
\hline
\end{tabular}

Note. From Antonakis et al., (2003; Avolio and Bass (2004); Bass and Riggio (2006); Nawaz and Bodla (2010); and Michel et al., (2011). 


\section{School Climate, Leadership, and Student Achievement}

An additional factor within the educational continuum that influences student achievement is school climate (Day, Gu, \& Sammons, 2016). School climate represents what is felt by stakeholders and impacts their mindset regarding the organization (Hoy, Smith, \& Sweetland, 2003). However, climate is a subset corresponding to the overarching "culture" of the organization. The idea of culture signifies the long-term, deeply-held impressions based on collective experiences and established traditions (Wagner \& Masden-Copas, 2002). The interconnectedness of climate to culture has been described in terms of an iceberg in the ocean, where culture signifies the foundation of the iceberg submerged below the surface of the water and not quickly visible; climate represents the portion of the same iceberg that can be effortlessly perceived by the naked eye (Bulach, Lunenburg, \& Potter, 2011).

Several studies have found a significant correlation between school climate and student learning outcomes (MacNeil, Prater, \& Busch, 2009; Waters, Marzano, \& McNulty, 2003; Witzers, Bosker, \& Kruger, 2003). Schein (2010) upholds that leadership forms and molds a school's culture, but he also poses that culture influences and even defines leadership. The concept of school climate, as some researchers claim, stands out as one of the most vital elements of any educational program (Hoyle \& Steffy, 1985). Sumner (2018) conducted a study of 40 middle schools and found a substantial relationship between climate and achievement in literacy $(r=.44, p<.05)$, social studies $(r=.37, p<.05)$, and science $(r=.33, p<.05)$. Along those same lines, schools that sustain a disciplined setting accompanied by high expectations for every student experience greater attainment of learning outcomes, especially on standardized assessments (Goddard, Hoy, 
\& Hoy, 2000). As explored by Christenson and Lehr (2002) a positive climate where effective teaching and learning can flourish leads to heightened achievement.

Marzano, Eaters, and McNulty (2005) affirm that school leadership and climate are inextricably associated with the productive operations of any multifaceted organization. Further, a considerable amount of literature references the significance of the relationship between principals' leadership and its influence on the overall environment of the institution (Bulach, Malone, \& Castleman, 1995). Norton (2002) assesses that principal leadership directly affects school climate, and therefore, student achievement.

Effective school leaders nurture an environment fueled by a welcoming, kind, and supportive spirit anchored upon the premise of the welfare and academic prosperity of every student and staff member (National Policy Board for Educational Administration, 2015). Further, the symbiotic nature that exists within schools is dependent upon the constructive dealings amongst its stakeholders, founded upon trust. Trust serves as the vital connection in the leader-subordinate relationship (DiPaola \& Hoy, 2012). A high degree of trust results in schools where principals interact with teachers in a respectful and considerate manner while communicating clear expectations (Tschannen-Moran, 2013). By establishing a positive tone in the building, school leaders build teacher morale, fortify parental relationships, strengthen professional collaboration, and ensure students are exposed to high-quality instruction (Hoy, Smith, \& Sweetland, 2003).

To strengthen an organization's climate, consistent nurturing and supervision is required (Hoy \& Hoy, 2003). Principals oversee the building's climate and accordingly regulate related systems and procedures to ensure an educationally conducive atmosphere 
exists (Stronge, Richard, \& Catano, 2008). Because successful school leaders are vested in the high morale of the organization and accordingly consider stakeholder cooperation a strength rather than a weakness, they are moved to build and uphold a constructive climate (Mitchell \& Castle, 2005). The literature indicates that principals have a positive influence over school climate when they adequately respond to the distinct needs of his or her staff by facilitating professional development within the intricate community of educators (Kelley, Thornton, \& Daugherty, 2005).

Some research has been conducted indirectly analyzing the possible moderating effects of school climate upon principal leadership and student achievement, yet there is no prevailing substantial body in existence. Robinson (2011) explored 26 studies between 1978 and 2006 that discuss the effects of school culture in the relationship between principal leadership and student outcomes. Robinson (2011) specifically found that establishing goals and expectations, promoting and participating in teacher learning and development, and ensuring an orderly and supporting environment affect the trajectory from leadership to student achievement. Establishing goals and expectations produced an effect size of 0.35 ; promoting and participating in teacher learning and development yielded a 0.84 average effect size; and ensuring an orderly and supportive environment produced an average effect size of 0.27 (Robinson, 2011). Along those same lines, Leithwood and Montgomery (1982) found that effective school leadership affects both school climate and student learning outcomes (Leithwood \& Montgomery, 1982). 


\section{Staff Longevity, Leadership, and Student Achievement}

When analyzing all variables that affect student achievement, it is essential to also recognize the longevity of the present staff members, including the principal and teachers. Consequently, much of the research has centered upon the factors associated with turnover, as opposed to longevity and retention.

As staff members accrue more experience, they become more effective at their craft (Clark, Martorell, \& Rockoff, 2009) The research indicates that school principals require roughly five years to develop a climate that will produce heightened student learning outcomes (Gabarro, 1987). Moreover, according to Seashore, Louis, Leithwood, Wahlstrom, and Anderson (2010), even if a principal were deemed effective at a previous school, once he or she enters a new building, the same time frame of five years applies, as it takes this amount of time to execute the guidelines and practices associated with school performance. Time is also needed to stabilize and take the appropriate measures to enhance the quality of the educational program (Seashore-Louis, Leithwood, Wahlstrom, \& Anderson, 2010). On the other hand, principal change is often aligned to decreased adherence to initiatives and is accompanied, more times than not, by the absence of collective stakeholder vision (Wallace Foundation, 2013). Acquiring traction in one building is imperative for school success, as a high level of turnover has been cited as the catalyst for negative effects on student achievement (Walker, 2009).

Consecutively, teacher longevity also has an impact on student achievement. According to recently published research, $17 \%$ of teachers leave the profession within the first five years (Gray, Taie, \& O'Rear, 2015). Teachers who lead students to improved 
achievement are more likely to remain at their current school site (Boyd, Lankford, Loeb, \& Wyckoff, 2011). Teacher turnover is highest in schools that serve low-income students (Allensworth, Ponisciak, \& Mazzeo, 2009). Teacher turnover often leaves classrooms to the instruction of interim teachers who are often inexperienced, and many times less than prepared for the task of teaching, as they themselves are gaining knowledge on how to become a teacher at the expense of the classroom students (Sellers, 2018). Additionally, the longer teachers serve, the better impact they have over several cohorts of students spanning several generations; the teachers develop professionally, and they embrace an inner awareness of determination and achievement (Ridgley, 2018). Professional longevity is accompanied by a subset of beneficial abilities that can only be amassed through years of service such as trustworthiness, resolution, and resilience (Ridgley, 2018). Some research has been conducted that indirectly points to the moderating effects of staff longevity on the relationship between principal leadership and student achievement, yet no substantial body of research is in existence. Hallinger and Heck (2010) reviewed the conclusions derived from a series of quantitative studies focusing upon the relationship between the contributions of leadership to school capacity for improvement and student outcomes and found that collective school leadership can positively affect achievement.

\section{Summary}

This chapter provided a review of pertinent literature related to the key concepts guiding the study. The chapter began with a discussion of the prevalent achievement gap in the United States, and then goes on to expound upon the pronounced presence of this achievement gap at the middle school level, especially where low socioeconomic schools 
(regarded as Title I schools) are concerned. Next, significant educational reforms seeking to remedy this academic problem are discussed. The chapter then expounds upon the importance of principal leadership, and different types of leadership styles, when it comes to student achievement related to minimizing the achievement gap. Next, two moderating factors, school climate and staff longevity, are expounded upon and their potential effects on the association between principal leadership and student achievement. 


\section{CHAPTER III}

\section{METHODOLOGY}

As noted by Sergiovanni (1995), the school principal is often considered to possess the utmost position of authority in enhancing the overall quality of a school, including student achievement. Considering the number of tasks principals are faced with daily, it is imperative that principals respond accordingly given such daunting demands (Daresh, Ganter, K., \& Hvizdak, 2000). Because of the demands associated with the position, principals often find themselves frustrated (Lashway, 2018). It is crucial that a well-defined awareness is shared, specifically involving the impact principal leadership has on overall school achievement. Consequently, the purpose of the present investigation was to examine the relationship between the leadership style of principals assigned to Title I middle schools, staff longevity, school culture and overall school achievement.

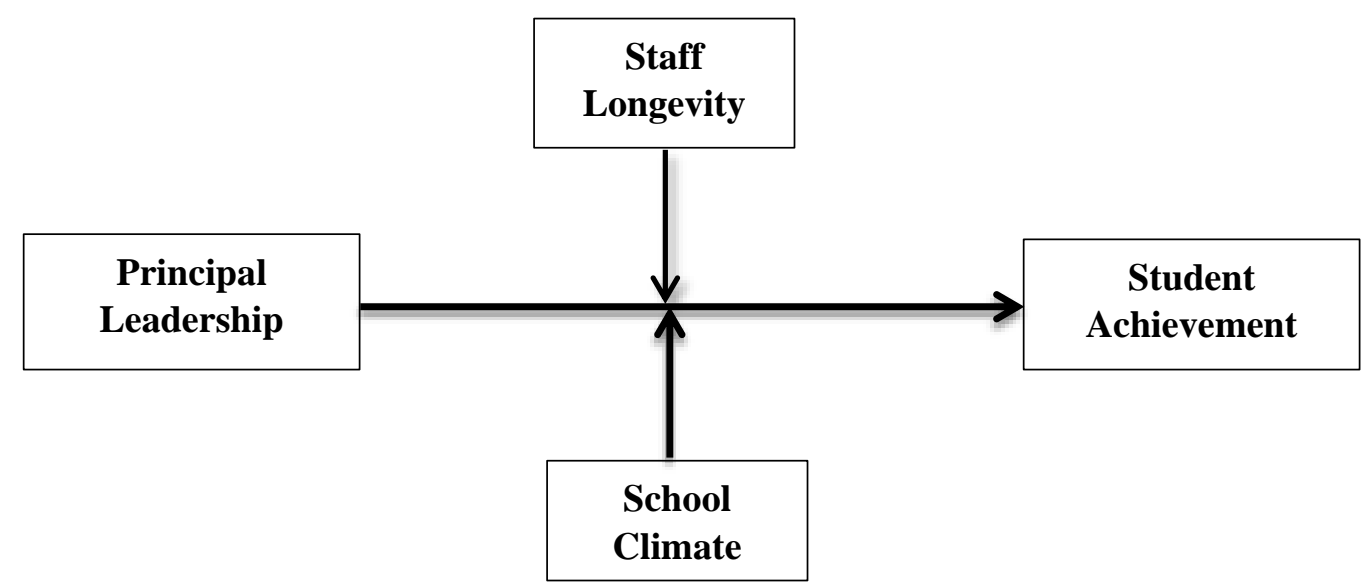

Figure 1. Conceptual model of the relationships between principal leadership, student achievement, school climate, and staff longevity. 


\section{Research Questions}

By effecting the study associated with this dissertation, the investigator focused on the following principal question: What is the relationship between the leadership styles of principal assigned to Title I middle schools, staff longevity, school climate, and school achievement? The subsequent sub-questions and hypotheses further directed the investigation:

Research Question 1: Does principal leadership that is more transformational than the norm predict a school's academic achievement level as determined by the Florida Department of Education grading system?

H01a: Principal leadership as determined by the results of the MLQ-5X survey that is transformational will positively predict achievement based on school grade.

H01b: Principal leadership as determined by the results of the MLQ-5X survey that is transformational will positively predict achievement based on reading proficiency changes.

Ho1c: Principal leadership as determined by the results of the MLQ-5X survey that is transformational will positively predict achievement based on reading learning gains changes.

H01d: Principal leadership as determined by the results of the MLQ-5X survey that is transformational will positively predict achievement based on reading learning gains changes of the lowest quartile. 
H01e: Principal leadership as determined by the results of the MLQ-5X survey that is transformational will positively predict achievement based on math proficiency changes.

H01f: Principal leadership as determined by the results of the MLQ-5X survey that is transformational will positively predict achievement based on math learning gains changes.

H01g: Principal leadership as determined by the results of the MLQ-5X survey that is transformational will positively predict achievement based on math learning gains of the lowest quartile.

H01h: Principal leadership as determined by the results of the MLQ-5X survey that is transformational will positively predict achievement based on science proficiency changes.

H01i: Principal leadership as determined by the results of the MLQ-5X survey that is transformational will positively predict achievement based on social studies proficiency changes.

Research Question 2: Does principal leadership that is more transactional than the norm predict a school's academic achievement level as determined by the Florida Department of Education grading system?

H02a: Principal leadership as determined by the results of the MLQ-5X survey that is transactional will negatively predict achievement based on overall school grade. 
$\mathrm{H}_{02 \mathrm{~b}}$ Principal leadership as determined by the results of the MLQ-5X survey that is transactional will negatively predict achievement based on reading proficiency changes.

$\mathrm{H}_{02 c}$ : Principal leadership as determined by the results of the MLQ-5X survey that is transactional will negatively predict achievement based on reading learning gains changes.

H02d: Principal leadership as determined by the results of the MLQ-5X survey that is transactional will negatively predict achievement based on reading learning gains changes of the lowest quartile.

H02e: Principal leadership as determined by the results of the MLQ-5X survey that is transactional will negatively predict achievement based on math proficiency changes.

H02f: Principal leadership as determined by the results of the MLQ-5X survey that is transactional will negatively predict achievement based on math learning gains changes.

H02g: Principal leadership as determined by the results of the MLQ-5X survey that is transactional will negatively predict achievement based on math learning gains of the lowest quartile.

$\mathrm{H}_{02 \mathrm{~h}}$ Principal leadership as determined by the results of the MLQ-5X survey that is transactional will negatively predict achievement based on science proficiency changes. 
$\mathrm{H}_{02 \mathrm{i}}$ : Principal leadership as determined by the results of the MLQ-5X survey that is transactional will negatively predict achievement based on social studies proficiency changes.

Research Question 3 Is there a relationship between the leadership style scores of the middle school principals surveyed, and school climate in predicting overall school achievement?

$\mathrm{H}_{3 \mathrm{a}}$ : Staff longevity will positively predict overall school achievement based on overall school grade.

$\mathrm{H}_{3 \mathrm{~b}}$ : Staff longevity will positively predict reading proficiency changes.

$\mathrm{H}_{3 c}$ : Staff longevity will positively predict reading learning gains changes.

$\mathrm{H}_{3 \mathrm{~d}}$ : Staff longevity will positively predict reading learning gains changes of the lowest quartile.

$\mathrm{H}_{3 \mathrm{e}}$ : Staff longevity will positively predict math proficiency changes.

$\mathrm{H}_{3 f}$ : Staff longevity will positively predict math learning gains changes.

$\mathrm{H}_{3 \mathrm{~g}}$ : Staff longevity will positively predict math learning gains changes of the lowest quartile.

$\mathrm{H}_{3 \mathrm{~h}}$ : Staff longevity will positively predict science proficiency changes.

$\mathrm{H}_{3 i}: \quad$ Staff longevity will positively predict social studies proficiency changes.

Research Question 4: Is there a relationship between the leadership style scores of the middle school principals surveyed, and school climate in predicting overall school achievement? 
$\mathrm{H}_{4 a}$ : Positive school climate will positively predict overall school achievement based on overall school grade.

$\mathrm{H}_{4 b}$ : Positive school climate as identified by staff members will positively predict reading proficiency changes.

$\mathrm{H}_{4 c}$ : Positive school climate as identified by staff members will positively predict reading learning gains changes.

$\mathrm{H}_{4 \mathrm{~d}}$ : Positive school climate as identified by staff members will positively predict reading learning gains changes of the lowest quartile.

$\mathrm{H}_{4 \mathrm{e}}$ : Positive school climate as identified by staff members will positively predict math proficiency changes.

$\mathrm{H}_{4 \mathrm{f}}$ : Positive school climate as identified by staff members will positively predict math learning gains changes.

$\mathrm{H}_{4 \mathrm{~g}}$ : Positive school climate as identified by staff members will positively predict math learning gains changes of the lowest quartile.

H4h: Positive school climate as identified by staff members will positively predict science proficiency changes.

$\mathrm{H}_{4 i}$ : Positive school climate as identified by staff members will positively predict social studies proficiency changes. 


\section{Research Design}

Considering the goal of the study was to explore the relationship between principal leadership styles, staff longevity, school climate, and school achievement, the investigator effected a non-experimental, ex-post facto research design. Ex-post facto was the most suitable design to explore the research questions posed since it is grounded upon variables that cannot be controlled by the investigator, as they have already transpired (Newman, Newman, Brown, \& McNeely, 2005). The noted research design explores situations as they have naturally and fluidly occurred (Johnson \& Christensen, 2017). As well, the design was quantitative in nature, thereby depicting data in abridged terms using statistical analysis (Sprinthall, 2012).

Moreover, considering efficiency and cost-effectiveness, data were collected by way of online surveys. The online survey method provides a high level of general ability in representing a large population, as it has the potential to reach more individuals, and yields a higher response rate when compared to other methods (Lefever, Dal, \& Matthiasdottir, 2007). As well, surveys offer a convenient, cost-effective and timeefficient method of collecting data, and can be administered to participants through a wide-range of methods, including e-mail, fax, or directly via the Internet (Church \& Waclawski, 2017). The method is highly reliable for research as it offers all participants a standardized stimulus devout of the researcher's own biases (Granello \& Wheaton, 2004). There are also some weaknesses associated with the online survey method of gathering data. Surveys are not ideal when it comes to capturing data related to controversial issues, as the reality behind the controversy may be better captured through focus groups or in-person interviews (Groves, et al., 2009). 
The Multifactor Leadership Questionnaire ( $5 \mathrm{X}$ short form), rater form, was used to gather data for the study which required approximately 15-20 minutes to complete (Bass \& Avolio, 1996). Additionally, the MDCPS School Climate survey was utilized to gauge a school's climate rating, derived from collective staff responses. Staff longevity was quantified using an accompanying demographic survey which will allowed participants to identify the length of service at the school site in the current position.

Two independent variables encompassing three leadership factors guided the study: transformational, and transactional leadership. Transformational leadership legitimizes those who actively partake in the process, as it enables individuals to revive their organizational commitment and align their actions accordingly to achieve the universal goal at hand (Leithwood, 1992). Transactional leadership involves an exchange of some type, where a subordinate receives a reward if he or she acts in the desired manner; if the follower does not adhere to the desires of his or her respective leader, then a punishment ensues (McCleskey, 2014). Laissez-faire leadership describes a leader who essentially avoids or renounces making decisions (Chauldhry, 2012).

The dependent variable was student achievement, specifically related to Title I middle schools. School achievement was determined depending on the school grade assigned to each school and the assessments imposed by the Florida Department of Education. A grade of "A" or "B" is considered as high-achieving, whereas a grade of a "D" or an "F" is regarded as low-achieving. Grades in middle schools are calculated on the basis of nine factors: English Language Arts (ELA) proficiency percentage; ELA learning gains percentage; ELA lowest quartile learning gains percentage; mathematics proficiency percentage; math learning gains percentage; math lowest quartile learning 
gains percentage; eighth grade science proficiency percentage; seventh grade social studies (Civics) proficiency percentage; and acceleration percentage (Florida Department of Education, 2017 School Grades Overview, 2017). Each of the nine components are each valued at 100 points each (Florida Department of Education, 2017 School Grades Overview, 2017). The average of the total amount derived from each of the nine categories then determines the school grade assigned.

\section{Table 4}

Florida School Grading Scale

\begin{tabular}{|l|l|}
\hline School & Percentage \\
\hline A & $62 \%$ or above \\
\hline B & $54 \%-61 \%$ \\
\hline C & $41 \%-53 \%$ \\
\hline D & $32 \%-40 \%$ \\
\hline F & $31 \%$ or less \\
\hline
\end{tabular}

Note. From Florida School Grades. Retrieved from fldoe.org http://schoolgrades.fldoe.org/

Considering staff longevity and school climate are factors that exist between principal leadership and student achievement, and both are identified as moderating variables. The study therefore also sought to identify the influence of these two additional variables on the predictive ability of principal leadership when it comes to student achievement in the types of schools identified (Creswell, 2009).

\section{Population and Sample}

The study was actualized inside a sizeable urban school district in southeast Florida and explored the relationships between the leadership styles of principals assigned to Title I middle schools, staff longevity, school climate and overall school achievement. The school district in question houses 41 total middle schools; 39 of those 
schools fall under the Title I umbrella. There are 15 Title I middle school situated in the North, 13 in the Central, and 11 in the South Region. Of the 39 schools in question, 34 of them are led by principals who have served for at least one year. As such, 34 of the principals were invited to participate in the study. Thirty of the 34 schools agreed to participate via their principal, which in turn yielded an $85 \%$ confidence level, with a five percent confidence interval (n.a., 2018).

The second sample population involved surveying the teachers who have served in the same school for at least one year, serving under the leadership of the 30 principals described above. The 30 middle schools in question house approximately 1240 teachers who have served at least one year. The number of teachers assigned to the 30 schools in question ranged between 21 and 100, based on student enrollment (Miami-Dade County Public Schools, Middle Schools, 2018). After inviting the 1240 teachers who had served at their current school site for at least one year, 290 teachers successfully consented and participating in the study, thereby yielding a 95\% confidence level with a five percent confidence interval (n.a., 2018).

\section{Instrumentation}

\section{The Multifactor Leadership Questionnaire (MLQ Form 5X)}

The Multifactor Leadership Questionnaire (MLQ-5X), short form, was employed to evaluate the transformational, transactional, and laissez-faire leadership nature of the principals who partook in the investigation. The rater form, comprised of 45 items, was taken by the teachers who agreed to participate to evaluate their respective principal's leadership style. The survey employs a five-point Likert scale ranging from (0) not at all to (4) frequently, if not always. 
The first part of the survey contains 36 questions and outlines the three general leadership styles, and is further subdivided into nine associated subscales, comprised of four elements each. The consequences or outcomes of leadership will be captured in the other nine questions. Sample questions are included in Table 5 and 6.

There are five dimensions correlated with transformational leadership: idealized influence-attributed (IA), idealized influence behavior (IB), inspirational motivation (IM), intellectual stimulation (IS), and individualized consideration (IC). Idealized influence-attributed captures the capacity of leaders to inculcate pride in respective subordinates (Heinitz, Liepmann, \& Felfe, 2005). Behavioral idealized influence represents the level which leaders institute trust amid the follower population (Heinitz, Liepmann, \& Felfe, 2005). Inspirational motivation denotes the leader's capacity to communicate and create a shared vision and commitment amongst his or her followers (Gillespie \& Mann, 2004). The concept of intellectual stimulation exists when leaders encourage followers to contemplate and visualize problems through different lenses, thereby challenging the established ways problems have traditionally been resolved in the organization (Stone, Russell, \& Patterson, 2004). Individualized consideration pertains to leaders serving as mentors, role models, and coaches for subordinates and stimulating personal development and growth along the way (Bass \& Avolio, 1994).

There are three dimensions related to transactional leadership: contingent reward (CR), management-by-exception-active (MBEA), and management-by-exception-passive (MCEP). The concept of contingent reward is depicted when subordinates are rewarded for completing a task thoroughly, according to the established expectations (Houlfort, 2002). Active management by exception is realized when leaders continually evaluate 
subordinate work and accordingly alter the assigned tasks based on progress (Odumeru, 2013). Passive management by exception is the act of delaying any corrective action until a problem arises (Odumeru, 2013).

Lastly, laissez-faire leadership is deemed as the non-leadership component of the full-range model and thereby denotes the absence of leadership. Leaders whose leadership style is described as laissez-faire in nature typically evade all facets related to their respective position, avoid decision-making, are inattentive and often cannot be located when a need arises requiring his or her presence (Bass \& Avolio, 1993). The laissez-faire leadership factor does not have any supplementary dimensions; however, it is comparable to passive management-by-exception leadership (Bass \& Avolio, 2000).

To understand the overall effectiveness of the organization in relation to leadership behaviors, the MLQ 5X-short form also includes three additional dimensions, regarded as outcome criteria: extra effort (EEF), effectiveness (EEF), and satisfaction (SAT). The behaviors associated with the concept of extra effort are when one is driven for achievement and therefore goes the extra mile by undertaking more than what is generally expected. Effectiveness denotes the capacity to adequately command a group to attain the anticipated outcomes while also taking into account the needs of subordinates (Di Schiena, Letens, Van Aken, \& Farris, 2013). The third outcome, satisfaction, specifies that the work being commanded by the leader is regarded as fulfilling by subordinates (Di Schiena, Letens, Van Aken, \& Farris, 2013). 
Table 5

Transformational Leadership Constructs and Item Statements

\begin{tabular}{|c|c|}
\hline \multicolumn{2}{|r|}{ Transformational Leadership } \\
\hline Construct & Item Statement \\
\hline \multirow{4}{*}{$\begin{array}{l}\text { Idealized Influence } \\
\text { Behavior }\end{array}$} & Talks about his/her most important values and beliefs. \\
\hline & Specifies the importance of having a strong sense of purpose. \\
\hline & Considers the moral and ethical consequences of decisions. \\
\hline & Emphasizes the importance of having a collective sense of mission. \\
\hline \multirow{4}{*}{$\begin{array}{l}\text { Idealized Influence } \\
\text { Attributed }\end{array}$} & Instills pride in others for being associated with him/her. \\
\hline & Goes beyond self-interest for the good of the group. \\
\hline & Acts in ways that build respect. \\
\hline & Displays a sense of power and confidences of decisions. \\
\hline \multirow[t]{4}{*}{ Inspirational Motivation } & Talks optimistically about the future. \\
\hline & Talks enthusiastically about what needs to be accomplished. \\
\hline & Articulates a compelling vision of the future. \\
\hline & Expresses confidence that goals will be achieved. \\
\hline \multirow[t]{4}{*}{ Intellectual Stimulation } & Re-examines critical assumptions to question whether they are \\
\hline & Seeks differing perspectives. \\
\hline & Gets subordinates to analyze problems from different perspectives. \\
\hline & Suggests new ways of looking at how to complete assignments. \\
\hline \multirow[t]{4}{*}{ Individual Consideration } & Spends time teaching and coaching. \\
\hline & Treats subordinates as individuals. \\
\hline & Considers subordinates as having individual needs, abilities, and \\
\hline & Helps to develop strengths in subordinates. \\
\hline
\end{tabular}

Note. From Avolio, B. J., \& Bass, B. (2004). Multifactor leadership questionnaire: manual and sampler set (3rd ed.). 
Table 6

Transactional Leadership Construct and Item Statements

\begin{tabular}{|c|c|}
\hline \multicolumn{2}{|r|}{ Transactional Leadership } \\
\hline Construct & Item Statement \\
\hline \multirow[t]{4}{*}{ Contingent Reward } & Provides subordinates with assistance in exchange for efforts. \\
\hline & Discusses in specific terms who is responsible for achieving performance \\
\hline & $\begin{array}{l}\text { Makes clear what one can expect to receive when performance goals are } \\
\text { achieved. }\end{array}$ \\
\hline & Expresses satisfaction when expectations are met. \\
\hline \multirow{4}{*}{$\begin{array}{l}\text { Management-by-Exception- } \\
\text { Active }\end{array}$} & Focuses attention on irregularities, mistakes, exceptions and deviations. \\
\hline & Concentrates his/her full attention on dealing with mistakes, complaints, and \\
\hline & Keeps track of all mistakes. \\
\hline & Directs attention to failures. \\
\hline \multirow{4}{*}{$\begin{array}{l}\text { Management-by-Exception- } \\
\text { Passive }\end{array}$} & Fails to interfere until problems become serious. \\
\hline & Waits for things to go wrong before taking action \\
\hline & Shows that he/she is a firm believer in "If it isn't broke don't fix it." \\
\hline & Demonstrates that problems must become chronic before taking action. \\
\hline \multirow[t]{4}{*}{ Laissez-faire } & Avoids getting involved when important issues arise. \\
\hline & Is absent when needed. \\
\hline & Avoids making decisions. \\
\hline & Delays responding to urgent questions. \\
\hline
\end{tabular}

Note. From Avolio, B. J., \& Bass, B. (2004). Multifactor leadership questionnaire: manual and sampler set ( $3^{\text {rd }}$ ed.). Menlo Park: Mind Garden.

The MLQ-5X has been utilized in over 500 research studies and is regarded as a sound forecast for leadership behavior across an extensive array of organizations including public, private, governmental, and military (Muenjon \& Armstrong, 2008). Reliability has been established by the Cronbach's alpha value which ranged from .67 to .94 (Hair \& Black, 2010). Reliability coefficients values of .70 are adequate, although when performing fundamental research, values of .80 and above are preferred (Nunnally \& Bernstein, 1994). The MLQ-5X is a validated measure as well and is considered the best instrument to capture the full range of leadership styles (Ozaralli, 2003). The scales contained within the instrument have established sound to outstanding internal 
consistency with alpha coefficients beyond the .80 stage for all MLQ scales (Bass \& Riggio, 2006). The established reliability coefficients are captured in the following table. Table 7

MLQ-5X Reliability Coefficients

\begin{tabular}{|c|c|}
\hline Subscales & Reliabilities Coefficients \\
\hline \multicolumn{2}{|c|}{ Transformational Leadership } \\
\hline Idealized Attributes (IA) & .86 \\
\hline Idealized Behavior (IB) & .87 \\
\hline Inspirational Motivation (IM) & .91 \\
\hline Intellectual Stimulation (IS) & .90 \\
\hline Individualized Consideration (IC) & .90 \\
\hline \multicolumn{2}{|c|}{ Transactional Leadership } \\
\hline Contingent Reward (CR) & .87 \\
\hline Active Management-by- Exception (MBEA) & .74 \\
\hline Passive Management-by-Exception (MBEP) & .82 \\
\hline \multicolumn{2}{|c|}{ Laissez-Faire Leadership } \\
\hline Laissez-Faire Leadership & .83 \\
\hline \multicolumn{2}{|l|}{ Leadership Outcomes } \\
\hline Extra Effort (EE) & .91 \\
\hline Effectiveness (EFF) & .91 \\
\hline Satisfaction (SAT) & .94 \\
\hline
\end{tabular}

Note. From Bass, B. M., \& Avolio, B. J. (1995). MLQ Multifactor Leadership Questionnaire for Research: Permission set. Redwood City: Mindgarden.

\section{The Miami-Dade County Public Schools (MDCPS) School Climate Survey}

The MDCPS School Climate Survey was utilized to quantify school climate.

Considering the ease in retrieving individual school climate results from the school district's web site, due to its prior use in research, the instrument was selected (Horng, Klasik, \& Loeb, 2010). The instrument is comprised of three forms: student, staff and parent. The forms were distributed randomly to a representative sample of students and their parents, while all instructional staff are provided the opportunity to participate in the survey (Miami-Dade County Public Schools: Assessment, 2018). To analyze each 
school's pattern over time, the items contained in the surveys remain consistent from year to year (Miami-Dade County Public Schools, Annual Climate Survey, 2018). The staff and parent surveys are each comprised of 35 items, while the student survey contains 27 items. Responses are in a Likert scale format consisting of responses such as strongly agree, agree, not known/undecided, disagree or strongly disagree. For the purposes of this study, the staff form was the only portion utilized. Specifically, 12 out of the 35 questions were utilized in the study as those depict factors related to principal leadership and school climate. The 12 specific questions utilized are depicted in Table 12.

There is no definite score expressed, that serves as the standard when it comes to the climate survey, as the questions contain both positive and negative prompts such as "My principal is an effective administrator," and "My ability to do the best possible job at this school is limited by lack of concern/support from my principal" (Miami-Dade County Public Schools: Assessment, 2018). However, staff members do have an opportunity to assign the school an overall grade, ranging from A-F (Miami-Dade County Public Schools: Assessment, 2018). The internal consistency of the survey was determined by effecting Cronbach's Alpha. According to the measure, the staff forms yielded an alpha of 0.88 (Miami-Dade County Public Schools, School Climate Survey, 2018).

\section{Data Collection}

The process of data collection was based on the Tailored Design Method (TDM) as developed by Dillman (2014). Specifically, the process commenced after both the Institutional Review Board Research Compliance of Florida International University and the Miami-Dade County Public Schools Research Review Committee approved the study 
(IRB\# 2311). The investigator then communicated with each principal selected for participation through a telephone conversation to fully explain the purposes associated with the study. After each leader agreed to partake in the study, the investigator requested their assistance in ensuring the selected teachers would complete the surveys.

Along those lines, the MLQ-5X was transferred to an online version by the investigator utilizing the Google Survey Platform. The online surveying procedure contained two elements, the first containing items related to staff longevity, and the second, all the questions included on the MLQ-5X rater forms. An email comprised of a description of the study, online consent form, written assertion of anonymity, and a link leading to the survey (if consent was obtained) was distributed to the desired participants through the Miami Dade County Public Schools email outlook system. After three days, a reminder email was sent to the desired participants containing all the information as the original email. One week after the start of the study, another email was distributed to the desired participants. Two weeks after the start of the survey, a final reminder email was sent to the desired participants via email asking them to please partake in the study. Survey data was collected between October 3, 2018 and October 29, 2018.

School achievement was determined by the release of 2018 standardized assessment scores related to each school in question by the Florida Department of Education. The Florida Standards Assessments (FSA) measure educational gains and related progress in English Language Arts (ELA), Mathematics, and End-of-Course (EOC) subjects, such as Algebra and Geometry (Florida Department of Education, 2018). Specifically, school grades as determined by the Florida Department of Education were utilized in addition to specific academic factors. 
School climate data was determined by utilizing results related to the schools included in the study and were imported into SPSS for statistical analysis.

\section{Pilot Study}

A pilot study was carried out through utilization of a Google survey with five principals and ten volunteer teachers who do not serve as actual participants in the investigation to determine the clarity related to the directions and questions that were to be included in the surveys, as well as, the total amount of time required to complete the surveys. Based on the feedback provided, the researcher made two corrections related to the placement of commas but did not reword any question as the pilot study determined those clear and free of vagueness.

\section{Statistical Analysis}

Considering the goal of the study was to explore the relationships between principal leadership styles, staff longevity, school climate, and school achievement, the investigator carried out a non-experimental, ex-post facto research design. The MLQ-5X scores accompanied by demographic data was tested to determine their respective correlations in predicting overall school achievement. The type of research design selected was suitable for gathering data essential to explore the hypothesized correlations amongst principal leadership, and the dependent variable, overall school achievement, as well as the level which principal leadership predicted student achievement. Statistical analyses were performed for each leadership dimension captured by the MLQ-5X utilizing the Statistical Package for the Social Sciences (SPSS, version 25).

To establish whether there was an association between the predictor and criterion variable, the investigator effected the Pearson Product-Moment Correlation. The means 
for the independent and dependent variables was calculated next and evaluated to determine if a relationship existed between the variables. The Pearson correlation coefficient, $r$, registers a value ranging from +1 to -1 , where the stronger the association between the two variables, the closer the coefficient will be to +1 or -1 , contingent on whether the relationship is positive or negative (Newman, Newman, Brown, \& McNeely, 2005). The Pearson Product-Moment Correlation was carried out involving the independent variable and the dependent variable (i.e., leadership and student achievement). The significance of the results was then verified by the performance of a $t$ test to evaluate the strength of the resulting associations. A regression analysis was employed to establish the predictive strength of the correlation established by the regression analysis. The significance of the results was then tested using a $t$ test.

Moderation occurs when the association between two variables is contingent on a third variable (Hayes A. F., 2018). Considering that staff longevity and climate were identified as moderating variables and were hypothesized to affect the relationship between leadership and achievement, moderated regression analyses were conducted to determine each variable's predictability.

\section{Limitations}

While the data collected for the current study was analyzed through quantitative research methods, the limited sample size may prevent the results from being deemed as generalizable outside of the existing setting. The investigator endeavored to unearth the relationships between the leadership styles of middle school principals and overall school achievement. As such, supplementary research with a larger sample size, applying the 
findings of the present study, would reinforce the concepts expounded upon in Chapter V.

\section{Summary}

This chapter presented the research questions and associated hypotheses that will be tested in the investigation. As well, the chapter offered a detailed explanation of the research design, population and sample, instruments used, data collection methods, statistical analyses and related limitations. The results of the investigation will be discussed in the next chapter. 


\section{CHAPTER IV}

\section{RESULTS}

The purpose of the study was to examine the relationship between the leadership styles of principals assigned to Title I middle schools, staff longevity, school climate, and overall school achievement. The variables involved in the investigation were principal leadership styles, staff longevity, and school climate. To establish whether a relationship

among the noted variables could be corroborated as well as whether said variables would be determined as predicting school achievement as hypothesized, statistical analyses were conducted. The contents of the following chapter, therefore, address the outcomes of the statistical tests of the stated hypotheses and offer descriptive statistics involving the participants in the study and their respective schools.

\section{Demographics of the Sample}

\section{Staff}

The sample included 290 staff members (teachers) from 30 schools who have served at least one year at the same school — the teachers who participated completed the Multifactor Leadership Questionnaire-5X (short form) developed by Bass and Avolio (2005), consisting of 45 Likert-type items as well as a demographic set of questions comprised of eight items. The efforts involved in ensuring as many staff members at the schools selected to complete the survey proved to be challenging and required two follow-up emails throughout the survey period in October of 2018. Once the survey period was closed, the results with the accompanying constructs were transferred to an Excel file. Moreover, a frequency analysis of the 290 participants was extracted from the demographic piece of the survey which included the number of years at the current 
school site, number of total years in the field of education, highest degree obtained, gender, ethnicity, and age. As well, an analysis was conducted respective to each of the 30 schools involving total student enrollment, free and reduced lunch rate, English Language Learner (ELL) percentage, and disabled student percentage.

\section{Number of Years at the Same School Site}

A frequency analysis of the number of years at the same school site specified that the range fell between one and 39 years of service. The average number of years participants had served at each school site was $8.87(S D=7.21)$ years.

\section{Number of Years in the Education}

A frequency analysis of the number of years in the field of education revealed that the number of years staff members had served in the field of education ranged between one and 44 years. The average number of years participants had served in the field of education was $17.09(S D=9.02)$ years.

\section{Highest Degree Obtained}

A frequency analysis of the highest degree obtained revealed that $39.64 \%(n=$ $115)$ of the participants had earned a bachelor's degree, $40.71 \%(n=118)$ a master's degree, $13.57 \%(n=39)$ a specialist's degree, and 6.07\% $(n=18)$ a doctorate degree.

\section{Gender}

A frequency analysis of gender indicated that 209 (72\%) of the participants were female and $81(28 \%)$ were male. 


\section{Ethnicity}

A frequency analysis of ethnicity revealed that 64 (22.0\%) of the participants were African American or Black, two (0.73\%) were Asian, 145 (50.0\%) were Hispanic, eight $(2.6 \%)$ were Other, and $71(24.6 \%)$ were White.

Age

A frequency analysis of the age of the respondents revealed that the average age of each was $47.16(S D=10.19)$ years.

\section{Enrollment}

An analysis of the total number of students enrolled at each of the schools included in the investigation revealed that five (16.67\%) of the schools had an enrollment under 500 students, 17 schools (56.67\%) had an enrollment between 501 and 1000, six schools (20\%) had between 1001-1500 students enrolled, and two schools (7\%) had an enrollment between 1501-2000 students. Specifically, the enrollment of students ranged between 324 and 1793 total students for the 2017-2018 school year.

\section{Free and Reduced Lunch Rates}

An analysis of the free and reduced lunch rates reported for each of the schools in question revealed that seven $(23.33 \%)$ of the schools had a free and reduced lunch rate ranging from $80-85 \%$, two $(6.67 \%)$ of schools fell within the range of $86 \%$ to $90 \%, 10$ $(33.33 \%)$ of the schools had a rate that fell between $91 \%$ and $95 \%$, and $11(36.67 \%)$ of the schools percentage fell between $96 \%$ and $100 \%$. Specifically, the rates fell between $80 \%$ and $99 \%$. The average rate was $90.4 \%$. 


\section{English Language Learners (ELL)}

An analysis of the number of students categorized as English Language Learners (ELL) revealed that the total percentage at each school ranged from $9.3 \%$ to $57 \%$, with the large majority of schools $(n=19)$ having $9-20 \%$ of the total student population categorized as English Language Learners.

\section{Students With Disabilities}

An analysis of the number of students categorized as disabled at the schools in question revealed ranges between $5.1 \%$ and $32.4 \%$, with the large majority of the schools $(n=15)$ having $12-18 \%$ of the total student population categorized as having a disability of some sort. 
Table 8

Participating Schools Demographics

\begin{tabular}{|c|c|c|}
\hline Profile & $N$ & Percentage \\
\hline \multicolumn{3}{|c|}{ Student Enrollment } \\
\hline $1-500$ & 5 & 16.67 \\
\hline $501-1000$ & 17 & 56.67 \\
\hline $1001-1500$ & 6 & 20 \\
\hline $1501-2000$ & 2 & 7 \\
\hline \multicolumn{3}{|c|}{ Free and Reduced Lunch } \\
\hline $80-85 \%$ & 7 & 23.33 \\
\hline $86-90 \%$ & 2 & 6.67 \\
\hline $91-95 \%$ & 10 & 33.33 \\
\hline $96-99 \%$ & 11 & 37.67 \\
\hline \multicolumn{3}{|c|}{ English Language Learners } \\
\hline $9-20 \%$ & 19 & 63.33 \\
\hline $21-32 \%$ & 9 & 30 \\
\hline $33-44 \%$ & 1 & 3.33 \\
\hline $45-57 \%$ & 1 & 3.33 \\
\hline \multicolumn{3}{|l|}{ Disability } \\
\hline $5-11 \%$ & 9 & 30 \\
\hline $12-18 \%$ & 15 & 50 \\
\hline $19-25 \%$ & 5 & 16.67 \\
\hline $26-33 \%$ & 1 & 3.33 \\
\hline
\end{tabular}

\section{Descriptive Statistics}

\section{Multifactor Leadership Questionnaire}

Represented in Table 9 are the mean scores and standard deviations associated with the staff perceptions of principal leadership behaviors as gauged by the MLQ Form 5x, Rater Form (Bass, 2016). The mean scores captured for each principal included in the study were drawn from the respective faculty responses which ranged from six percent to $65 \%$, and are based on the replies provided for items gauging each leadership behavior applying a 5-point Likert scale spanning from 4 ("frequently, if not always") to 
0 ("not at all"). The mean score ranged from $3.58(S D=0.69)$ for Inspirational Motivation characterized as a tenet of Transformational Leadership to $0.63(S D=0.87)$ for Laissez-faire leadership characterized as Passive-Avoidant. On the transformational leadership spectrum, the scores ranged from $2.76(S D=1.05)$ for Individualized Consideration to $3.58(S D=0.69)$ for Inspirational Motivation. As far as transactional leadership is concerned, the highest score registered at $3.25(S D=0.85)$ for Contingent Reward.

When analyzing the mean scores derived for each leadership behavior, percentile rankings based on the norm population were determined using the MLQ Manual as a guide (Avolio \& Bass, 2004). Details about said percentile ranking can be found in Table 9, and show that all five behaviors associated with transformational leadership ranked at or above the $50^{\text {th }}$ percentile in comparison to the norm population (Avolio \& Bass, 2004). The means associated with the two behaviors aligned with transactional leadership, Contingent Reward, and Management-by-Exception-Active were both at the $70^{\text {th }}$ percentile. As far as Passive-Avoidant leadership behaviors are concerned, principals ranked in the $50^{\text {th }}$ percentile for Management-by Exception-Passive, and in the $60^{\text {th }}$ percentile for Laissez-Faire. 
Table 9

Summary of Scores on the MLQ Form $5 X(N=290)$

\begin{tabular}{lccc}
\hline Leadership Measure & $M$ & $S D$ & Percentile \\
\hline Transformational & & & \\
$\quad$ Idealized Influence-Attributes (IA) & 3.24 & 0.88 & 60 \\
$\quad$ Idealized Influence-Behaviors (IB) & 3.31 & 0.73 & 60 \\
$\quad$ Inspirational Motivation (IM) & 3.58 & 0.69 & 80 \\
$\quad$ Intellectual Stimulation (IS) & 2.95 & 0.99 & 60 \\
$\quad$ Individual Consideration (IC) & 2.76 & 1.05 & 50 \\
Transactional & & & \\
Contingent Reward (CR) & 3.25 & 0.85 & 70 \\
$\quad$ Management-by-Exception-Active (MBEA) & 2.01 & 1.02 & 70 \\
Passive-Avoidant & & & \\
$\quad$ Management-by-Exception-Passive (MBEP) & 0.93 & 0.85 & 50 \\
Laissez-Faire (LF) & 0.63 & 0.87 & 60 \\
\hline
\end{tabular}

\section{School Climate Survey}

To measure each school's climate, The Miami-Dade County Public School's School Climate survey results were utilized. The researcher used 12 of the 34 items on the Staff survey which closely aligned with principal leadership, and the summary of the mean percent of the "strongly agree" or "agree" responses to each of the 12 items corresponding to the 30 schools are captured in Table 9. Mean scores associated with these 12 items ranged from $90 \%(S D=8.32)$ for "treats me with respect" to $57 \%(S D=$ 21.06) for "staff morale is high at my school." 
Table 10

Summary of School Climate Staff Survey Results $(N=30)$

\begin{tabular}{lcc}
\hline & $\begin{array}{c}M \text { percentage of } \\
\text { Strongly Agree or } \\
\text { Agree Responses }\end{array}$ & $S D$ \\
\hline is an effective administrator & 83.65 & 12.86 \\
represents the school in a positive manner & 88.08 & 11.53 \\
demonstrates good interpersonal skills & 83.65 & 15.3 \\
deals with conflict constructively & 78.92 & 14.49 \\
responds in a reasonable time to my concerns & 85.45 & 10.87 \\
treats me with respect & 90.28 & 8.32 \\
is receptive to constructive criticism & 72.68 & 15.47 \\
is supportive of teachers & 82.78 & 14.44 \\
staff morale is high at my school & 56.57 & 21.06 \\
annual teacher evaluations are fair and reasonable & 59.42 & 13.71 \\
annual teacher evaluations are used to improve teacher & & 15.99 \\
performance & 60.18 & 19.79 \\
overall climate or atmosphere at my school is positive and helps & & \\
students learn & 78.87 & \\
\hline
\end{tabular}

\section{Staff Longevity}

Staff Longevity was determined by asking each participant to identify the number of years they had served in the same capacity at the current school site, as well as the total amount of years in the field of education. The average number of years participants have served at each school site was $8.87(S D=7.21)$ years, and the range was between one and 39 years. The average number of years participants have served in the field of education was $17.09(S D=9.02)$ years, ranging from one to 44 years in total.

\section{School Grade}

One of the factors utilized to determined school achievement was each school's grade as determined by the Florida Accountability System and is represented in Table 11. Out of the 30 schools studied, 13 schools or $43 \%$ of the total number were considered high-achieving, as they earned either an "A" or "B" in 2018 (Florida School 
Accountability Reports, 2018). Respectively, two or $6.7 \%$ of the schools in the study were considered as low-achieving, earning a grade of a "D" in 2018 (Florida School Accountability Reports, 2018).

Table 11

Summary of School Grades $2018(N=30)$

\begin{tabular}{lcc}
\hline School Grade & $N$ & Percent \\
\hline A & 5 & 16.7 \\
B & 8 & 27 \\
C & 15 & 50 \\
D & 2 & 6.7 \\
F & 0 & 0 \\
Total & 30 & 100.4 \\
\hline
\end{tabular}

Note. (Florida School Accountability Reports, 2018).

As discussed in Chapter three, there are nine factors, each weighted at 100 points each, used to determine a middle school's grade based on the Florida grading system. One of these nine factors is acceleration rate. Acceleration rate in middle school is determined by a rather complicated formula involving a denominator and numerator. The denominator involves the number of current-year students who have enrolled in a high school course that is gauged by an End of Course Exam (EOC), such as Algebra or Geometry, and the number of prior-year students who sat for a high school industry certification exam (2016-17 Guide to Calculating School and District Grades, 2018). The numerator is then determined by the number of students in the denominator who scored at a proficiency level or higher on the gauging exam (Florida Department of Education, 2017 School Grades Overview, 2017). Because the acceleration rate involves prior year scores, it was not used in this study. The additional eight features that were used involving current year scores were changes in reading and math proficiency, learning 
gains, and learning gains of the lowest quartile accompanied by science and social studies proficiency changes when 2018 scores are compared to those of 2017. The data is captured in Table 12.

\section{Overall Academic Changes}

The range in the change of overall academic scores from 2017 to 2018 spanned from a 90-point gain to a 53-point decreases (Florida School Accountability Reports, 2018). The average overall change in scores was $25.4(S D=36.44)$ points. Most of the schools $(n=20$ or $67 \%)$ achieved overall gains from 2017 to 2018 (Florida School Accountability Reports, 2018). Ten schools (33\%) achieved losses when 2017 scores are compared to those produced in 2018 (Florida School Accountability Reports, 2018).

\section{Reading Proficiency Changes}

Reading proficiency is established when students score a three or above on the FSA 5-point scale, signifying they are scoring at or above grade level (Florida Department of Education, 2017 School Grades Overview, 2017). The range in the change of overall reading proficiency scores from 2017 to 2018 spanned from a 14-point gain to a seven-point loss (Florida School Accountability Reports, 2018). The average overall change in reading proficiency scores was $1.87(S D=4.59)$ points (Florida School Accountability Reports, 2018). Most of the schools ( $n=19$ or 63\%) achieved overall gains from 2017 to 2018 (Florida School Accountability Reports, 2018). Eleven schools (3\%) achieved no gains or losses when 2017 scores are compared to those produced in 2018 (Florida School Accountability Reports, 2018). 


\section{Reading Learning Gains Changes}

Reading learning gains are established when a student makes an anticipated year's growth according to the score on the Reading FSA (2016-17 Guide to Calculating School and District Grades, 2018). The range in the change of overall reading learning gain scores spanned from an 11-point gain to an eight-point decrease (Florida School Accountability Reports, 2018). The average overall change in reading learning gains scores was $1.97(S D=5.54)$ points (Florida School Accountability Reports, 2018). Most of the schools (17 or 57\%) achieved overall gains from 2017 to 2018 (Florida School Accountability Reports, 2018). Thirteen schools (43\%) achieved no gain or losses when 2017 scores are compared to those produced in 2018 (Florida School Accountability Reports, 2018).

\section{Reading Learning Gains of the Lowest Quartile (L25) Changes}

Reading learning gains of the lowest quartile are determined when a student who scored in the lowest $25 \%$ of student scores the prior year makes an anticipated year's growth according to the score on the Reading FSA (2016-17 Guide to Calculating School and District Grades, 2018). The range in the change of overall reading learning gains of the lowest quartile scores spanned from a 28-point gain to a 10-point decrease (Florida School Accountability Reports, 2018). The average overall change in reading learning gains of the lowest quartile scores was $5.53(S D=8.65)$ points (Florida School Accountability Reports, 2018). Most of the schools ( $n=22$ or $73 \%$ ) achieved overall gains from 2017 to 2018, whereas eight schools (27\%) achieved no gain or losses when 2017 scores are compared to those produced in 2018 (Florida School Accountability Reports, 2018). 


\section{Math Proficiency Changes}

Mathematics proficiency is established when students score a three or above on the state assessments, signifying they are scoring at or above grade level (2016-17 Guide to Calculating School and District Grades, 2018). The range in the change of overall mathematics proficiency scores from 2017 to 2018 spanned from a 15-point gain to a nine-point decrease (Florida School Accountability Reports, 2018). The average overall change in mathematics proficiency scores was $2.97(S D=5.42)$ points (Florida School Accountability Reports, 2018). Most of the schools ( $n=21$ or $70 \%)$ achieved overall gains from 2017 to 2018. Nine schools (30\%) achieved no gain or losses when 2017 scores are compared to those produced in 2018 (Florida School Accountability Reports, 2018).

\section{Math Learning Gains Changes}

Mathematics learning gains are established when a student makes an anticipated year's growth according to the score on the Mathematics FSA (2016-17 Guide to Calculating School and District Grades, 2018). The range in the change of overall mathematics learning gain scores spanned from a 20-point gain to a 20-point loss (Florida School Accountability Reports, 2018). The average overall change in mathematics learning gains scores was $2.73(S D=8.49)$ points (Florida School Accountability Reports, 2018). Most of the schools ( $n=18$ or $60 \%$ ) achieved overall gains from 2017 to 2018 (Florida School Accountability Reports, 2018). Twelve schools (40\%) achieved no gain or losses when 2017 scores are compared to those produced in 2018 (Florida School Accountability Reports, 2018). 


\section{Math Learning Gains of the Lowest Quartile (L25) Changes}

Mathematics learning gains of the lowest quartile are determined when a student who scored in the lowest $25 \%$ of student scores the prior year makes an anticipated year's growth according to the score achieved on the state assessment in math (2016-17 Guide to Calculating School and District Grades, 2018). The range in the change of overall mathematics learning gains of the lowest quartile scores spanned from a 27-point gain to a 12-point decrease (Florida School Accountability Reports, 2018). The average overall change in mathematics learning gains of the lowest quartile scores was $6.13(S D=10.04)$ points (Florida School Accountability Reports, 2018). Most of the schools ( $n=20$ or 67\%) achieved overall gains from 2017 to 2018, whereas 10 schools (33\%) achieved no gain or losses when 2017 scores are compared to those produced in 2018 (Florida School Accountability Reports, 2018).

\section{Science Proficiency Changes}

Science proficiency is established when students score a three or above on the FSAA Science five-point scale signifying they are scoring at or above grade level (201617 Guide to Calculating School and District Grades, 2018). The Science proficiency test is only taken in eighth grade in middle school (2016-17 Guide to Calculating School and District Grades, 2018). The range in the change of overall science proficiency scores from 2017 to 2018 spanned from an 11-point gain to a seven-point loss (Florida School Accountability Reports, 2018). The average overall change in science proficiency scores was $1.97(S D=5.05)$ points (Florida School Accountability Reports, 2018). Seventeen (57\%) of the schools demonstrated increases in science proficiency, whereas $13(43 \%)$ of 
the school demonstrated no change or decreases (Florida School Accountability Reports, 2018).

\section{Social Studies Proficiency Changes}

Social studies proficiency is established when students score a three or above on the Civics EOC five-point scale signifying they are scoring at or above grade level (201617 Guide to Calculating School and District Grades, 2018). The assessment is only taken in seventh grade in middle school (2016-17 Guide to Calculating School and District Grades, 2018). The range in the change of overall social studies proficiency scores from 2017 to 2018 spanned from a 14-point gain to a 17-point loss (Florida School Accountability Reports, 2018). The average overall change in science proficiency scores was $2.23(S D=8.19)$ points (Florida School Accountability Reports, 2018). Seventeen $(57 \%)$ of the schools demonstrated increases in social studies proficiency, whereas 13 (43\%) of the school demonstrated decreases or no change (Florida School Accountability Reports, 2018). 
Table 12

Summary of Changes Involving Specific Academic Factors Evaluated $(N=30)$

\begin{tabular}{lcc}
\hline Ranges of Change & $N$ & \\
\hline Overall Academic Points & 20 & Percentage \\
\hline 1 and 90-point increase & 10 & 66.70 \\
1 and 53-point decrease & $N$ & 33.30 \\
\hline Reading Proficiency & 19 & Percentage \\
\hline 1 and 14-point increase & 2 & 63.33 \\
No Change $(0)$ & 9 & 6.67 \\
1 and 7-point decrease & $N$ & 30.00 \\
\hline Reading Learning Gains & 17 & Percentage \\
\hline 1 and 11-point increase & 2 & 56.70 \\
No Change $(0)$ & 11 & 6.67 \\
1 and 8-point decrease & $N$ & 36.67 \\
\hline Reading Learning Gains of L25 & 22 & Percentage \\
\hline 1 and 28-point increase & 1 & 73.33 \\
No Change $(0)$ & 7 & 3.33 \\
1 and 10-point decrease & $N$ & 23.33 \\
\hline Math Proficiency & 21 & Percentage \\
\hline 1 and 15-point increase & 2 & 70.00 \\
No Change $(0)$ & 7 & 6.70 \\
1 and 9-point decrease & $N$ & 23.33 \\
\hline Math Learning Gains & 18 & Percentage \\
\hline 1 and 20-point increase & 12 & 60.00 \\
1 and 20-point decrease & $N$ & 40.00 \\
\hline Math Learning Gains L25 & 20 & Percentage \\
\hline 1 and 27-point increase & 1 & 66.67 \\
No Change $(0)$ & 9 & 3.33 \\
1 and 12-point decrease & $N$ & 30.00 \\
\hline Science Proficiency & 17 & Percentage \\
\hline 1 and 11-point increase & 2 & 56.70 \\
No Change $(0)$ & $N$ & 36.67 \\
1 and 7-point decrease & 17 & 56.70 \\
\hline Social Studies Proficiency & 4 & 13.33 \\
\hline and 14-point increase & 9 & 30.00 \\
No Change $(0)$ & & \\
1 and 17-point decrease & $N$ & \\
\hline & 11 & \\
\hline
\end{tabular}




\section{Results of Testing the Research Hypotheses \\ Analysis of the Hypotheses}

A correlation analysis was conducted between the research variables to test the related hypotheses and to determine the extent of each variable's interrelationship. Subsequently, Table 13 depicts the outcomes of the analysis and captures the correlations among the variables. Correlations between predictor variables larger than .90 should be deleted or combined, as that would signify they are gauging the same construct (Green, 1991). No correlation between predictor variables was found to be above .90 . The strength and direction of relationships among the research variables were mostly as expected. Interestingly, however, school grade demonstrated a significant negative relationship with school climate $(r=-.27, p<.01)$ and longevity $(r=-.20, p<$ $.01)$. 
Table 13

Intercorrelations of MLQ-5X Leadership Factors, School Grade, Staff Climate, and Staff Longevity

\begin{tabular}{|c|c|c|c|c|c|c|c|c|c|c|c|c|}
\hline & & IA & IB & IM & IS & $\mathrm{IC}$ & $\mathrm{CR}$ & MBEA & MBEP & GR & $\mathrm{CL}$ & LONG \\
\hline \multirow[t]{2}{*}{ IA } & $\begin{array}{l}\text { Pears. Corr. } \\
\text { Sig. (1-tail.) }\end{array}$ & 1 & & & & & & & & & & \\
\hline & $N$ & 290 & & & & & & & & & & \\
\hline \multirow[t]{3}{*}{ IB } & Pears. Corr. & $.766^{* * *}$ & 1 & & & & & & & & & \\
\hline & Sig.(1-tail.) & 0.000 & & & & & & & & & & \\
\hline & $N$ & 290 & 290 & & & & & & & & & \\
\hline \multirow[t]{3}{*}{ IM } & Pears. Corr. & $.795^{* * *}$ & $.805^{* * *}$ & 1 & & & & & & & & \\
\hline & Sig.(1-tail.) & 0.000 & 0.000 & & & & & & & & & \\
\hline & $N$ & 290 & 290 & 290 & & & & & & & & \\
\hline \multirow[t]{3}{*}{ IS } & Pears. Corr. & $.799^{* * *}$ & $.707^{* * * *}$ & $.692^{* * *}$ & 1 & & & & & & & \\
\hline & Sig.(1-tail.) & 0.000 & 0.000 & 0.000 & & & & & & & & \\
\hline & $N$ & 290 & 290 & 290 & 290 & & & & & & & \\
\hline \multirow[t]{3}{*}{ IC } & Pears. Corr. & $.806^{* * *}$ & $.635^{* * *}$ & $.648^{* * *}$ & $.802^{* * *}$ & 1 & & & & & & \\
\hline & Sig.(1-tail.) & 0.000 & 0.000 & 0.000 & 0.000 & & & & & & & \\
\hline & $N$ & 290 & 290 & 290 & 290 & 290 & & & & & & \\
\hline \multirow[t]{3}{*}{$\mathrm{CR}$} & Pears. Corr. & $.818^{* * *}$ & $.737^{* * *}$ & $.790^{* * * *}$ & $.780^{* * *}$ & $.722^{* * *}$ & 1 & & & & & \\
\hline & Sig.(1-tail.) & 0.000 & 0.000 & 0.000 & 0.000 & 0.000 & & & & & & \\
\hline & $N$ & 290 & 290 & 290 & 290 & 290 & 290 & & & & & \\
\hline \multirow[t]{3}{*}{ MBEA } & Pears. Corr. & 0.059 & $.202^{* * * *}$ & 0.088 & $.178^{* *}$ & 0.060 & $.133^{*}$ & 1 & & & & \\
\hline & Sig.(1-tail.) & 0.156 & 0.000 & 0.066 & 0.001 & 0.155 & 0.012 & & & & & \\
\hline & $N$ & 290 & 290 & 290 & 290 & 290 & 290 & 290 & & & & \\
\hline \multirow[t]{3}{*}{ MBEP } & Pears. Corr. & $-.206^{* * * *}$ & $-.143^{* *}$ & $-.167^{* *}$ & $-.225^{* * *}$ & $-.244^{* * *}$ & $-.168^{* *}$ & 0.070 & 1 & & & \\
\hline & Sig.(1-tail.) & 0.000 & 0.007 & 0.002 & 0.000 & 0.000 & 0.002 & 0.116 & & & & \\
\hline & $N$ & 290 & 290 & 290 & 290 & 290 & 290 & 290 & 290 & & & \\
\hline \multirow[t]{3}{*}{ GR } & Pears. Corr. & -0.036 & 0.010 & -0.037 & -0.089 & -0.046 & 0.000 & -0.085 & -0.014 & 1 & & \\
\hline & Sig.(1-tail.) & 0.272 & 0.435 & 0.267 & 0.066 & 0.217 & 0.499 & 0.075 & 0.405 & & & \\
\hline & $N$ & 290 & 290 & 290 & 290 & 290 & 290 & 290 & 290 & 290 & & \\
\hline \multirow[t]{3}{*}{$\mathrm{CL}$} & Pears. Corr. & $.220^{* * *}$ & $.181^{* *}$ & 0.082 & $.250^{* * *}$ & $.183^{* *}$ & $.178^{* *}$ & 0.063 & -0.040 & $-.266^{* * *}$ & 1 & \\
\hline & Sig.(1-tail.) & 0.000 & 0.001 & 0.081 & 0.000 & 0.001 & 0.001 & 0.144 & 0.249 & 0.000 & & \\
\hline & $N$ & 290 & 290 & 290 & 290 & 290 & 290 & 290 & 290 & 290 & 292 & \\
\hline \multirow[t]{3}{*}{ LONG } & Pears. Corr. & 0.072 & 0.041 & 0.069 & $.137^{* *}$ & 0.068 & 0.083 & 0.061 & 0.021 & $-.201^{* * *}$ & 0.089 & 1 \\
\hline & Sig.(1-tail.) & 0.110 & 0.243 & 0.121 & 0.010 & 0.122 & 0.080 & 0.151 & 0.360 & 0.000 & 0.064 & \\
\hline & $N$ & 290 & 290 & 290 & 290 & 290 & 290 & 290 & 290 & 290 & 290 & 290 \\
\hline
\end{tabular}


Table 13 (continued)

Note. $*$ Correlational is significant at the 0.05 level (1-tailed); **Correlational is significant at the 0.01 level (1-tailed) $* * *$ Correlational is significant at the .001 level (1-tailed); IA=Idealized InfluenceAttributes; IB=Idealized Influence-Behaviors; IM=Inspirational Motivation; IS= Intellectual Stimulation; $\mathrm{IC}=$ Individualized Consideration; $\mathrm{CR}=$ Contingent Reward; MBEA=Management-by-Exception-Active; MBEP=Management-by-Exception-Passive; $\mathrm{GR}=$ School Grade; $\mathrm{CL}=$ Staff Climate; LONG=Staff Longevity

\section{Research Hypothesis 1a}

The results of the hierarchical regression analyses where $\mathrm{H}_{1}$ a was tested, demonstrated that there was no significant relationship between the transformational variables measured and school grade when controlling for enrollment, English Language Learner percentage, disability percentage, and free and reduced lunch percentage (see Table 14). The results of the analyses in the first step, which involved the control variables, were $F(4,285)=8.252, p=.000$. The results of the analyses in the second step where the transformational leadership variables were included were $F(5,280)=3.876, p$ $=.539$, and accounted for $1.1 \%$ of the additional variance. Consequently, Research Hypothesis 1a was not supported. 
Table 14

Summary of Hierarchical Multiple Regression Analysis for Transformational Leadership Variables Predicting School Grade $(N=290)$

\begin{tabular}{|c|c|c|c|c|}
\hline Variables & $\beta$ & $R^{2}$ & Significance & Sig. $F$ Change \\
\hline \multicolumn{5}{|l|}{ Step 1} \\
\hline Enrollment & .126 & & .040 & \\
\hline English Language Learners \% & .030 & & .629 & \\
\hline Disability \% & .470 & & .000 & \\
\hline \multirow[t]{2}{*}{ Free and Reduced Lunch \% } & .040 & & .545 & \\
\hline & & $.202 * * *$ & & \\
\hline \multicolumn{5}{|l|}{ Step 2} \\
\hline Idealized Influence-Attributes & -.033 & & .785 & \\
\hline Idealized Influence-Behaviors & .148 & & .134 & \\
\hline Inspirational Motivation & -.111 & & .278 & \\
\hline Intellectual Stimulation & -.095 & & .359 & \\
\hline \multirow[t]{2}{*}{ Individualized Consideration } & .033 & & .742 & \\
\hline & & .011 & & .539 \\
\hline Total $R^{2}$ & & $.213 * * *$ & & \\
\hline
\end{tabular}

\section{Research Hypothesis $1 \mathrm{~b}$}

Reading proficiency, as a whole, accounts for 100 out of a possible 900 total points when determining a school's grade. The results of the hierarchical regression analysis where $\mathrm{H}_{1 \mathrm{~b}}$ was tested demonstrated that there was no significant relationship between the transformational variables measured and reading proficiency changes when controlling for enrollment, English Language Learner percentage, disability percentage, and free and reduced lunch percentage (see Table 15). The results of the analysis in the first step, which involved the control variables, were $F(4,285)=385.669, p=.000$. The results of the analyses in the second step where the transformational leadership variables were included were $F(5,280)=173.555, p=.932$, and accounted for $.03 \%$ of the additional variance. Consequently, Research Hypothesis $1 \mathrm{~b}$ was not supported. 
Table 15

Summary of Hierarchical Regression Analysis for Transformational Leadership Variables Predicting Reading Proficiency $(N=290)$

\begin{tabular}{|c|c|c|c|c|}
\hline Variables & $\beta$ & $R^{2}$ & Significance & Signif. $F$ Change \\
\hline \multicolumn{5}{|l|}{ Step 1} \\
\hline Enrollment & .199 & & .001 & \\
\hline English Language Learners \% & -.053 & & .368 & \\
\hline Disability $\%$ & .322 & & .000 & \\
\hline \multirow[t]{2}{*}{ Free and Reduced Lunch \% } & .422 & & .000 & \\
\hline & & $.273 * * *$ & & \\
\hline \multicolumn{5}{|l|}{ Step 2} \\
\hline Idealized Influence Attributes & -.081 & & .485 & \\
\hline Idealized Influence Behaviors & -.022 & & .818 & \\
\hline Inspirational Motivation & .080 & & .413 & \\
\hline Intellectual Stimulation & -.048 & & .629 & \\
\hline \multirow[t]{2}{*}{ Individualized Consideration } & .055 & & .569 & \\
\hline & & .003 & & .932 \\
\hline Total $R^{2}$ & & $.253^{* * * *}$ & & \\
\hline
\end{tabular}

\section{Research Hypothesis 1c}

Reading learning gains, as a whole, accounts for 100 out of a possible 900 points.

As such, this piece was analyzed. The results of the hierarchical regression analysis

where $\mathrm{H}_{1 \mathrm{c}}$ was tested demonstrated that there was no significant relationship between the transformational variables measured and reading learning gains, when controlling for enrollment, English Language Learner percentage, disability percentage, and free and reduced lunch percentage (see Table 16). The results of the analysis in the first step, which involved the control variables, were $F(4,285)=341.767, p=.000$. The results of the analyses in the second step where the transformational leadership variables were included were $F(5,280)=166.336, p=.411$, and accounted for $1.5 \%$ of the additional variance. Consequently, Research Hypothesis 1c was not supported. 
Table 16

Summary of Hierarchical Regression Analysis for Transformational Leadership Variables Predicting Reading Learning Gains $(N=290)$

\begin{tabular}{|c|c|c|c|c|}
\hline Variables & $\beta$ & $R^{2}$ & Significance & Signif. $F$ Change \\
\hline \multicolumn{5}{|l|}{ Step 1} \\
\hline Enrollment & .081 & & 194 & \\
\hline English Language Learners \% & -.082 & & .196 & \\
\hline Disability \% & .042 & & .488 & \\
\hline Free and Reduced Lunch \% & .442 & & .000 & \\
\hline \multicolumn{5}{|l|}{ Step 2} \\
\hline Idealized Influence-Attributes & -.129 & & .298 & \\
\hline Idealized Influence-Behaviors & -.005 & & .957 & \\
\hline Inspirational Motivation & .200 & & .058 & \\
\hline Intellectual Stimulation & -.100 & & .344 & \\
\hline \multirow[t]{2}{*}{ Individualized Consideration } & .062 & & .546 & \\
\hline & & .015 & & .411 \\
\hline Total $R^{2}$ & & $.172^{* * *}$ & & \\
\hline
\end{tabular}

\section{Research Hypothesis 1d}

Reading learning gains of the lowest quartile, as a whole, accounts for 100 out of a possible 900 points. As such, this piece was analyzed. The results of the hierarchical regression analysis where $\mathrm{H}_{1 \mathrm{~d}}$ was tested demonstrated a significant positive relationship between the transformational variables measured and reading learning gains of the lowest quartile, when controlling for enrollment, English Language Learner percentage, disability percentage, and free and reduced lunch percentage are depicted in Table 17. The results of the analysis in the first step, which involved the control variables, were $F(4,285)=1132.837, p=.000$. The results of the analyses in the second step where the transformational leadership variables were included were $F(5,280)=616.515, p=.008$, and accounted for $4.3 \%$ of the additional variance. Further, a significant positive association was found between Inspirational Motivation and reading learning gains of the lowest quartile $(\beta=.31 . p<.01)$. In addition, a significant negative association was 
found between Idealized Influence-Attributes and reading learning gains of the lowest quartile $(\beta=-.237 . p<.05)$. Overall, Research Hypothesis $1_{\mathrm{d}}$ was accepted.

Table 17

Summary of Hierarchical Regression Analysis for Transformational Leadership Variables Predicting Reading Learning Gains of Lowest Quartile $(N=290)$

\begin{tabular}{|c|c|c|c|c|}
\hline Variables & $\beta$ & $R^{2}$ & Significance & $\begin{array}{c}\text { Signif. } F \\
\text { Change }\end{array}$ \\
\hline \multicolumn{5}{|l|}{ Step 1} \\
\hline Enrollment & .049 & & .423 & \\
\hline English Language Learners \% & -.286 & & .000 & \\
\hline Disability \% & -.070 & & .242 & \\
\hline \multirow[t]{2}{*}{ Free and Reduced Lunch \% } & .540 & & .000 & \\
\hline & & $.193 * * *$ & & \\
\hline \multicolumn{5}{|l|}{ Step 2} \\
\hline Idealized Influence-Attributes & -.237 & & $.046^{*}$ & \\
\hline Idealized Influence-Behaviors & -.076 & & .432 & \\
\hline Inspirational Motivation & .314 & & $.002 * *$ & \\
\hline Intellectual Stimulation & -.198 & & .052 & \\
\hline \multirow[t]{2}{*}{ Individualized Consideration } & .161 & & .106 & \\
\hline & & .043 & & .008 \\
\hline Total $R^{2}$ & & $.236^{* * *}$ & & \\
\hline
\end{tabular}

\section{Research Hypothesis 1e}

Math proficiency, as a whole, accounts for 100 out of a possible 900 points when determining school grade. The results of the hierarchical regression analysis where $\mathrm{H}_{1 \mathrm{e}}$ was tested demonstrated that while there was a significant relationship between the transformational variables measured and math proficiency, when controlling for enrollment, English Language Learner percentage, disability percentage, and free and reduced lunch percentage, none of the separate leadership measures were significant predictors on their own. (see Table 18). The results of the analysis in the first step, which involved the control variables, were $F(4,285)=210.759, p=.000$. The results of the analyses in the second step where the transformational leadership variables were included 
were $F(5,280)=127.229, p<.05$, and explained $4.1 \%$ of the additional variance.

Research Hypotheses 1e was accepted.

Table 18

Summary of Hierarchical Regression Analysis for Transformational Leadership Variables Predicting Math Proficiency $(N=290)$

\begin{tabular}{|c|c|c|c|c|}
\hline Variables & $\beta$ & $R^{2}$ & Significance & Signif. $F$ Change \\
\hline \multicolumn{5}{|l|}{ Step 1} \\
\hline Enrollment & .151 & & .019 & \\
\hline English Language Learners \% & -.264 & & .000 & \\
\hline Disability \% & -.098 & & .118 & \\
\hline \multirow[t]{2}{*}{ Free and Reduced Lunch \% } & .059 & & .398 & \\
\hline & & $.114^{* * *}$ & & \\
\hline \multicolumn{5}{|l|}{ Step 2} \\
\hline Idealized Influence-Attributes & .080 & & .520 & \\
\hline Idealized Influence-Behaviors & .085 & & .405 & \\
\hline Inspirational Motivation & -.058 & & .584 & \\
\hline Intellectual Stimulation & .060 & & .576 & \\
\hline \multirow[t]{2}{*}{ Individualized Consideration } & .049 & & .638 & \\
\hline & & .041 & & .021 \\
\hline Total $R^{2}$ & & $.155^{* * *}$ & & \\
\hline
\end{tabular}

\section{Research Hypothesis if}

Math learning gains, as a whole, accounts for 100 out of a possible 900 points when determining school grade. The results of the hierarchical regression analysis where $\mathrm{H}_{1 \mathrm{e}}$ was tested demonstrated that there was no significant relationship between the transformational variables measured and math learning gains, when controlling for enrollment, English Language Learner percentage, disability percentage, and free and reduced lunch (see Table 19). The results of the analysis in the first step, which involved the control variables, were $F(4,285)=1063.834, p=.000$. The results of the analyses in the second step where the transformational leadership variables were included were $F(5$, $280)=526.033, p=.074$, and accounted for $2.7 \%$ of the additional variance. Therefore, Hypothesis $1_{\mathrm{f}}$ was not supported. 
Table 19

Summary of Hierarchical Regression Analysis for Transformational Leadership Variables Predicting Math Learning Gains $(N=290)$

\begin{tabular}{|c|c|c|c|c|}
\hline Variables & $\beta$ & $R^{2}$ & Significance & Signif. $F$ Change \\
\hline \multicolumn{5}{|l|}{ Step 1} \\
\hline Enrollment & .019 & & .745 & \\
\hline English Language Learners \% & -.424 & & .000 & \\
\hline Disability $\%$ & -.069 & & .234 & \\
\hline \multirow[t]{2}{*}{ Free and Reduced Lunch \% } & -.073 & & .264 & \\
\hline & & $.237^{* * *}$ & & \\
\hline \multicolumn{5}{|l|}{ Step 2} \\
\hline Idealized Influence-Attributes & .117 & & .313 & \\
\hline Idealized Influence-Behaviors & .108 & & .260 & \\
\hline Inspirational Motivation & -.065 & & .511 & \\
\hline Intellectual Stimulation & .042 & & .677 & \\
\hline \multirow[t]{2}{*}{ Individualized Consideration } & -.040 & & .681 & \\
\hline & & .027 & & .074 \\
\hline Total $R^{2}$ & & $.241 * * *$ & & \\
\hline
\end{tabular}

\section{Research Hypothesis 1g}

Math learning gains of the lowest quartile, as a whole, accounts for 100 out of a possible 900 points when determining school grade The results of the hierarchical regression analysis where $\mathrm{H}_{1 \mathrm{~g}}$ was tested demonstrated that there was no significant relationship between the transformational variables measured and math learning gains of the lowest quartile, when controlling for enrollment, English Language Learner percentage, disability percentage, and free and reduced lunch (see Table 20). The results of the analysis in the first step, which involved the control variables, were $F(4,285)=$ $552.764, p=.000$. The results of the analyses in the second step where the transformational leadership variables were included were $F(5,280)=266.609, p=.670$, and explained $1.0 \%$ of the additional variance. Therefore, Hypothesis $1 \mathrm{~g}$ was not supported. 
Table 20

Summary of Hierarchical Regression Analysis for Transformational Leadership Variables Predicting Math Learning Gains of Lowest Quartile $(N=290)$

\begin{tabular}{|c|c|c|c|c|}
\hline Variables & $\beta$ & $R^{2}$ & Significance & Signif. $F$ Change \\
\hline \multicolumn{5}{|l|}{ Step 1} \\
\hline Enrollment & .033 & & .609 & \\
\hline English Language Learners \% & -.337 & & .000 & \\
\hline Disability $\%$ & .160 & & .011 & \\
\hline \multirow[t]{2}{*}{ Free and Reduced Lunch \% } & .049 & & .488 & \\
\hline & & $.117 * * *$ & & \\
\hline \multicolumn{5}{|l|}{ Step 2} \\
\hline Idealized Influence-Attributes & .012 & & .924 & \\
\hline Idealized Influence-Behaviors & .112 & & .282 & \\
\hline Inspirational Motivation & -.014 & & .899 & \\
\hline Intellectual Stimulation & .049 & & .655 & \\
\hline \multirow[t]{2}{*}{ Individualized Consideration } & -.119 & & .261 & \\
\hline & & .010 & & .670 \\
\hline Total $R^{2}$ & & $.127 * * *$ & & \\
\hline
\end{tabular}

\section{Research Hypothesis 1h}

Science proficiency, as a whole, accounts for 100 out of a possible 900 points when determining school grade. The results of the hierarchical regression analysis where $\mathrm{H}_{1 \mathrm{~h}}$ was tested demonstrated that there was no significant relationship between the transformational variables measured and science proficiency, when controlling for enrollment, English Language Learner percentage, disability percentage, and free and reduced lunch (see Table 21). The results of the analysis in the first step, which involved the control variables, were $F(4,285)=559.952, p=.000$. The results of the analysis in the second step where the transformational leadership variables were included were $F(5$, $280)=256.952, p=.465$, and accounted for $1.1 \%$ of the additional variance. Therefore, Hypothesis $1 \mathrm{~h}$ was not supported. 
Table 21

Summary of Hierarchical Regression Analysis for Transformational Leadership Variables Predicting Science Proficiency $(N=290)$

\begin{tabular}{|c|c|c|c|c|}
\hline Variables & $\beta$ & $R^{2}$ & Significance & Signif. $F$ Change \\
\hline \multicolumn{5}{|l|}{ Step 1} \\
\hline Enrollment & .416 & & .000 & \\
\hline English Language Learners \% & -.021 & & .715 & \\
\hline Disability $\%$ & -.017 & & .757 & \\
\hline \multirow[t]{2}{*}{ Free and Reduced Lunch \% } & .603 & & .000 & \\
\hline & & $.333 * * *$ & & \\
\hline \multicolumn{5}{|l|}{ Step 2} \\
\hline Idealized Influence-Attributes & .093 & & .400 & \\
\hline Idealized Influence-Behaviors & .028 & & .753 & \\
\hline Inspirational Motivation & -.116 & & .214 & \\
\hline Intellectual Stimulation & -.136 & & .150 & \\
\hline \multirow[t]{2}{*}{ Individualized Consideration } & .098 & & .287 & \\
\hline & & .011 & & .465 \\
\hline Total $R^{2}$ & & $.344 * * *$ & & \\
\hline
\end{tabular}

\section{Research Hypothesis 1i}

Social studies proficiency, as a whole, accounts for 100 out of a possible 900

points when determining school grade. The results of the hierarchical regression analysis where $\mathrm{H}_{1 \mathrm{i}}$ was tested demonstrated that while there was a significant relationship between the transformational variables measured and social studies proficiency when controlling for enrollment, English Language Learner percentage, disability percentage, and free and reduced lunch percentage, none of the separate leadership measures were significant predictors (see Table 22). The results of the analysis in the first step, which involved the control variables, were $F(4,282)=268.959, p=.001$. The results of the analysis in the second step where the transformational leadership variables were included were $(5,280)$ $=188.058, p<.05$, and accounted for 3.9\% of the additional variance. Research Hypothesis $1_{\mathrm{i}}$ was therefore accepted. 
Table 22

Summary of Hierarchical Regression Analysis for Transformational Leadership Variables Predicting Social Studies Proficiency $(N=290)$

\begin{tabular}{|c|c|c|c|c|}
\hline Variables & $\beta$ & $R^{2}$ & Significance & Signif. $F$ Change \\
\hline \multicolumn{5}{|l|}{ Step 1} \\
\hline Enrollment & -.142 & & .032 & \\
\hline English Language Learners \% & .131 & & .050 & \\
\hline Disability $\%$ & .124 & & .055 & \\
\hline \multirow[t]{2}{*}{ Free and Reduced Lunch \% } & -.039 & & .585 & \\
\hline & & $.067 * *$ & & \\
\hline \multicolumn{5}{|l|}{ Step 2} \\
\hline Idealized Influence-Attributes & -.073 & & .568 & \\
\hline Idealized Influence-Behaviors & .158 & & .133 & \\
\hline Inspirational Motivation & .183 & & .095 & \\
\hline Intellectual Stimulation & -.183 & & .096 & \\
\hline \multirow{2}{*}{ Individualized Consideration } & .014 & & .897 & \\
\hline & & $.039 *$ & & .036 \\
\hline Total $R^{2}$ & & $.106^{* * *}$ & & \\
\hline
\end{tabular}

\section{Research Hypothesis 2a}

The results of the hierarchical regression analysis where $\mathrm{H}_{2 \mathrm{a}}$ was tested demonstrated that there was no significant relationship between the transactional variables measured and school grade when controlling for enrollment, English Language Learner percentage, disability percentage, and free and reduced lunch percentage (see Table 23). The results of the analysis in the first step, which involved the control variables, were $F(4,285)=8.252, p=.000$. The results of the analysis in the second step where the transactional leadership variables were included were $F(3,282)=4.801, p$ $=.730$, and accounted for $0.4 \%$ of the additional variance. Consequently, Research Hypothesis 2 a was not supported. 
Table 23

Summary of Hierarchical Regression Analysis for Transactional Leadership Variables Predicting School Grade $(N=290)$

\begin{tabular}{|c|c|c|c|c|}
\hline Variables & $\beta$ & $R^{2}$ & Significance & Signif. $F$ Change \\
\hline \multicolumn{5}{|l|}{ Step 1} \\
\hline Enrollment & .126 & & .040 & \\
\hline English Language Learners \% & .030 & & .629 & \\
\hline Disability \% & .407 & & .000 & \\
\hline \multirow[t]{2}{*}{ Free and Reduced Lunch \% } & .040 & & .545 & \\
\hline & & $.202 * * *$ & & \\
\hline \multicolumn{5}{|l|}{ Step 2} \\
\hline Contingent Reward & -.011 & & .840 & \\
\hline Management-by-Exception-Active & -.058 & & .283 & \\
\hline \multirow[t]{2}{*}{ Management-by-Exception-Passive } & .001 & & .991 & \\
\hline & & .004 & & .730 \\
\hline Total $R^{2}$ & & .206 & & \\
\hline
\end{tabular}

\section{Research Hypothesis 2b}

The results of the hierarchical regression analysis where $\mathrm{H}_{2 b}$ was tested demonstrated that there was no significant relationship between the transactional variables measured and reading proficiency changes when controlling for enrollment, English Language Learner percentage, disability percentage, and free and reduced lunch percentage (see Table 24). The results of the analysis in the first step, which involved the control variables, were $F(4,282)=385.669, p=.000$. The results of the analysis in the second step where the transactional leadership variables were included were $F(3,282)=$ $223.765 ; p=.652$, and accounted for $0.4 \%$ of the additional variance. Consequently, Research Hypothesis 2b was not supported. 
Table 24

Summary of Hierarchical Regression Analysis for Transactional Leadership Variables Predicting Reading Proficiency $(N=290)$

\begin{tabular}{|c|c|c|c|c|}
\hline Variables & $\beta$ & $R^{2}$ & Significance & Signif. $F$ Change \\
\hline \multicolumn{5}{|l|}{ Step 1} \\
\hline Enrollment & .199 & & .001 & \\
\hline English Language Learners \% & -.053 & & .368 & \\
\hline Disability $\%$ & .322 & & .000 & \\
\hline \multirow[t]{2}{*}{ Free and Reduced Lunch \% } & .422 & & .000 & \\
\hline & & $.273 * * *$ & & \\
\hline \multicolumn{5}{|l|}{ Step 2} \\
\hline Contingent Reward & -.026 & & .623 & \\
\hline Management-by-Exception-Active & -.016 & & .757 & \\
\hline \multirow[t]{2}{*}{ Management-by-Exception-Passive } & -.06 & & .249 & \\
\hline & & .004 & & .652 \\
\hline Total $R^{2}$ & & $.277 * * *$ & & \\
\hline
\end{tabular}

\section{Research Hypothesis 2c}

The results of the hierarchical regression analysis where $\mathrm{H}_{2 \mathrm{c}}$ was tested demonstrated that there was no significant relationship between the transactional variables measured and reading learning gains, when controlling for enrollment, English Language Learner percentage, disability percentage, and free and reduced lunch percentage (see Table 25). The results of the analysis in the first step, which involved the control variables, were $F(4,285)=341.767, p=.000$. The results of the analysis in the second step where the transactional leadership variables were included were $F(3,282)=$ $203.465, p=.529$, and accounted for $0.7 \%$ of the additional variance. Consequently, Research Hypothesis 2c was not supported. 
Table 25

Summary of Hierarchical Regression Analysis for Transactional Leadership Variables Predicting Reading Learning Gains $(N=290)$

\begin{tabular}{|c|c|c|c|c|}
\hline Variables & $\beta$ & $R^{2}$ & Significance & Signif. $F$ Change \\
\hline \multicolumn{5}{|l|}{ Step 1} \\
\hline Enrollment & .081 & & .194 & \\
\hline English Language Learners \% & -.082 & & 196 & \\
\hline Disability $\%$ & .042 & & 488 & \\
\hline \multirow{2}{*}{ Free and Reduced Lunch \% } & 442 & & .000 & \\
\hline & & $.157 * * *$ & & \\
\hline \multicolumn{5}{|l|}{ Step 2} \\
\hline Contingent Reward & -.017 & & .767 & \\
\hline Management-by-Exception-Active & -.001 & & .984 & \\
\hline \multirow[t]{2}{*}{ Management-by-Exception-Passive } & -.082 & & .140 & \\
\hline & & .007 & & .529 \\
\hline Total $R^{2}$ & & $.164 * * *$ & & \\
\hline
\end{tabular}

\section{Research Hypothesis 2d}

The results of the hierarchical regression analysis where $\mathrm{H}_{2 \mathrm{~d}}$ was tested

demonstrated that there was no significant relationship between the transactional variables measured and reading learning gains of the lowest quartile, when controlling for enrollment, English Language Learner percentage, disability percentage, and free and reduced lunch percentage (see Table 26). The results of the analysis in the first step, which involved the control variables, were $F(4,285)=1132.837, p=.000$. The results of the analysis in the second step where the transactional leadership variables were included were $F(3,282)=679.837, p=.332$, and accounted for $1.0 \%$ of the additional variance. Consequently, Research Hypothesis $2 \mathrm{~d}$ was not supported. 
Table 26

Summary of Hierarchical Regression Analysis for Transactional Leadership Variables Predicting Reading Learning Gains of Lowest Quartile $(N=290)$

\begin{tabular}{|c|c|c|c|c|}
\hline Variables & $\beta$ & $R^{2}$ & Significance & Signif. $F$ Change \\
\hline \multicolumn{5}{|l|}{ Step 1} \\
\hline Enrollment & .049 & & .423 & \\
\hline English Language Learners \% & -.286 & & .000 & \\
\hline Disability $\%$ & -.010 & & .242 & \\
\hline \multirow[t]{2}{*}{ Free and Reduced Lunch \% } & .540 & & .000 & \\
\hline & & $.193 * * *$ & & \\
\hline \multicolumn{5}{|l|}{ Step 2} \\
\hline Contingent Reward & -.096 & & .082 & \\
\hline Management-by-Exception-Active & .024 & & .661 & \\
\hline \multirow{2}{*}{ Management-by-Exception-Passive } & .014 & & .800 & \\
\hline & & .010 & & .332 \\
\hline Total $R^{2}$ & & $.203^{* * *}$ & & \\
\hline
\end{tabular}

\section{Research Hypothesis 2e}

The results of the hierarchical regression analysis where $\mathrm{H}_{2 \mathrm{e}}$ was tested demonstrated that there was an overall significant positive relationship between the transactional variables measured and math proficiency changes $(p<.05)$ when controlling for enrollment, English Language Learner percentage, disability percentage, and free and reduced lunch percentage (see Table 27). Further analysis also revealed that one of the transactional leadership measures tested, Contingent Reward, serves as a significant predictor of math proficiency chains $(p<.05)$. The results of the analysis in the first step, which involved the control variables, were $F(4,282)=210.759, p=.000$. The results of the analysis in the second step where the transactional leadership variables were included were $F(3,282)=$ $147.338, p=.042$, and accounted for $2.5 \%$ of the additional variance. Research Hypothesis $2 \mathrm{e}$ was therefore rejected. 
Table 27

Summary of Hierarchical Regression Analysis for Transactional Leadership Variables Predicting Math Proficiency $(N=290)$

\begin{tabular}{|c|c|c|c|c|}
\hline Variables & $\beta$ & $R^{2}$ & Significance & Signif. $F$ Change \\
\hline \multicolumn{5}{|l|}{ Step 1} \\
\hline Enrollment & .151 & & .019 & \\
\hline English Language Learners \% & -.264 & & .000 & \\
\hline Disability $\%$ & -.098 & & .118 & \\
\hline \multirow[t]{2}{*}{ Free and Reduced Lunch \% } & .059 & & .398 & \\
\hline \multirow{2}{*}{\multicolumn{5}{|c|}{ Step 2}} \\
\hline & & & & \\
\hline Contingent Reward & .133 & & $.020 *$ & \\
\hline Management-by-Exception-Active & .064 & & .253 & \\
\hline \multirow{2}{*}{ Management-by-Exception-Passive } & -.025 & & .658 & \\
\hline & & .025 & & .042 \\
\hline Total $R^{2}$ & & $.139^{* * *}$ & & \\
\hline
\end{tabular}

\section{Research Hypothesis $2 f$}

The results of the hierarchical regression analysis where $\mathrm{H}_{2 \mathrm{f}}$ was tested demonstrated that there was an overall positive significant relationship between the transactional variables measured and math learning gains when controlling for enrollment, English Language Learner percentage, disability percentage, and free and reduced lunch percentage (see Table 28). Further analysis also revealed that one of the transactional leadership measures tested, Contingent Reward serves as a significant predictor of math learning gains $(p<.05)$. The results of the analysis in the first step, which involved the control variables, were $F(4,285)=1063.834, p=.000$. The results of the analysis in the second step where the transactional leadership variables were included were $F(3,282)=667.593, p=.032$, and accounted for $2.3 \%$ of the additional variance. Research Hypothesis $2 \mathrm{f}$ was rejected. 
Table 28

Summary of Hierarchical Regression Analysis for Transactional Leadership Variables Predicting Math Learning Gains $(N=290)$

\begin{tabular}{|c|c|c|c|c|}
\hline Variables & $\beta$ & $R^{2}$ & Significance & Signif. $F$ Change \\
\hline \multicolumn{5}{|l|}{ Step 1} \\
\hline Enrollment & .019 & & .745 & \\
\hline English Language Learners \% & -.424 & & .000 & \\
\hline Disability $\%$ & -.069 & & .234 & \\
\hline \multirow[t]{2}{*}{ Free and Reduced Lunch \% } & -.073 & & .264 & \\
\hline & & $237 * * *$ & & \\
\hline \multicolumn{5}{|l|}{ Step 2} \\
\hline Contingent Reward & .126 & & $.017 *$ & \\
\hline Management-by-Exception-Active & .060 & & .253 & \\
\hline \multirow{2}{*}{ Management-by-Exception-Passive } & -.030 & & .572 & \\
\hline & & $.023 *$ & & .032 \\
\hline Total $\mathrm{R}^{2}$ & & .261 & & \\
\hline
\end{tabular}

\section{Research Hypothesis 2g}

The results of the hierarchical regression analysis where $\mathrm{H}_{2 \mathrm{~g}}$ was tested demonstrated that there was no overall significant relationship between the transactional variables measured and math learning gains of the lowest quartile when controlling for enrollment, English Language Learner percentage, disability percentage, and free and reduced lunch percentage. However, Management by Exception Active was a significant predictor $(p<.05)$ (see Table 29). The results of the analysis in the first step, which involved the control variables, were $F(4,285)=552.764, p=.000$. The results of the analysis in the second step where the transactional leadership variables were included were $F(3,282)=354.516, p=.202$, and accounted for $1.4 \%$ of the additional variance. Overall, Research Hypothesis 2g was rejected. 
Table 29

Summary of Hierarchical Regression Analysis for Transactional Leadership Variables Predicting Math Learning Gains of Lowest Quartile $(N=290)$

\begin{tabular}{lcccc}
\hline \multicolumn{1}{c}{ Variables } & $\beta$ & $R^{2}$ & Significance & $\begin{array}{c}\text { Signif. } F \\
\text { Change }\end{array}$ \\
\hline Step 1 & & & & \\
$\quad$ Enrollment & .033 & & .609 & \\
English Language Learners \% & -.337 & & .000 & \\
Disability \% & .160 & & .011 & \\
$\quad$ Free and Reduced Lunch \% & .049 & & .488 & \\
Step 2 & & $0.117^{* * *}$ & & .892 \\
$\quad$ Contingent Reward & .008 & & $.037^{*}$ & \\
Management-by-Exception-Active & .118 & & .724 & \\
$\quad$ Management-by-Exception-Passive & -.020 & & \\
& & 0.014 & & \\
\hline Total $R^{2}$ & & $0.131^{* * *}$ & & \\
Note. ${ }^{*} p<.05, * * * p<.001$ & & & &
\end{tabular}

\section{Research Hypothesis $2 \mathrm{~h}$}

The results of the hierarchical regression analysis where $\mathrm{H}_{2 \mathrm{~h}}$ was tested demonstrated that there was no overall significant relationship between the transactional variables measured and science proficiency when controlling for enrollment, English Language Learner percentage, disability percentage, and free and reduced lunch percentage (see Table 30). The results of the analysis in the first step, which involved the control variables, were $F(4,285)=552.764, p=.000$. The results of the analysis in the second step where the transactional leadership variables were included were $F(3,282)=$ $321.751, \mathrm{p}=.853$, and accounted for $0.2 \%$ of the additional variance. Therefore, Research Hypothesis $2 \mathrm{~h}$ was not supported. 
Table 30

Summary of Hierarchical Regression Analysis for Transactional Leadership Variables Predicting Science Proficiency $(N=290)$

\begin{tabular}{|c|c|c|c|c|}
\hline Variables & $\beta$ & $R^{2}$ & Significance & Signif. $F$ Change \\
\hline \multicolumn{5}{|l|}{ Step 1} \\
\hline Enrollment & .416 & & .000 & \\
\hline English Language Learners \% & -.021 & & .715 & \\
\hline Disability \% & -.017 & & .757 & \\
\hline \multirow[t]{2}{*}{ Free and Reduced Lunch \% } & .603 & & .000 & \\
\hline & & $.333 * * *$ & & \\
\hline \multicolumn{5}{|l|}{ Step 2} \\
\hline Contingent Reward & -.005 & & 915 & \\
\hline Management-by-Exception-Active & -.036 & & .467 & \\
\hline \multirow[t]{2}{*}{ Management-by-Exception-Passive } & -.021 & & .676 & \\
\hline & & .002 & & .853 \\
\hline Total $R^{2}$ & & $.335^{* * * *}$ & & \\
\hline
\end{tabular}

\section{Research Hypothesis $2 \mathrm{i}$}

The results of the hierarchical regression analysis where $\mathrm{H}_{2 \mathrm{i}}$ was tested

demonstrated that there was no overall significant relationship between the transactional variables measured and social studies proficiency when controlling for enrollment, English Language Learner percentage, disability percentage, and free and reduced lunch percentage (see Table 31). The results of the analysis in the first step, which involved the control variables, were $F(4,285) 268.959, p=.001$. The results of the analysis in the second step where the transactional leadership variables were included were $F(3,282)=$ $173.462, p=.451$, and accounted for $0.9 \%$ of the additional variance. Therefore, Research Hypothesis 2i was not supported. 
Table 31

Summary of Hierarchical Regression Analysis for Transactional Leadership Variables Predicting Social Studies Proficiency $(N=290)$

\begin{tabular}{|c|c|c|c|c|}
\hline Variables & $\beta$ & $R^{2}$ & Significance & $\begin{array}{l}\text { Signif. } F \\
\text { Change }\end{array}$ \\
\hline \multicolumn{5}{|l|}{ Step 1} \\
\hline Enrollment & -.142 & & .032 & \\
\hline English Language Learners \% & .131 & & .050 & \\
\hline Disability \% & .124 & & .055 & \\
\hline Free and Reduced Lunch \% & -.039 & & .585 & \\
\hline \multicolumn{5}{|l|}{ Step 2} \\
\hline Contingent Reward & .017 & & .775 & \\
\hline Management-by-Exception-Active & .089 & & .127 & \\
\hline \multirow[t]{2}{*}{ Management-by-Exception-Passive } & .006 & & .917 & \\
\hline & & .009 & & .451 \\
\hline Total $R^{2}$ & & $.076^{* *}$ & & \\
\hline
\end{tabular}

\section{Research Hypothesis 3a}

The results of the hierarchical regression analysis where $\mathrm{H}_{3}$ was tested

demonstrated that there was a significant negative relationship between staff longevity and school grade

( $\beta=-.178, p<.01)$ when controlling for the leadership variables related to transformational and transactional leadership (see Table 32). The results of the analysis in the first step, which involved the control variables, were $F(8,281)=.795, p<.001$. The results of the analysis in the second step where staff longevity was included were $F(1,280)=1.265, p=.003$, and accounted for $3.1 \%$ of the additional variance. Consequently, Research Hypothesis $3 \mathrm{a}$ was rejected. 
Summary of Hierarchical Regression Analysis for Staff Longevity in Predicting School Grade $(N=290)$

\begin{tabular}{|c|c|c|c|c|}
\hline Variables & $\beta$ & $R^{2}$ & Significance & Signif. $F$ Change \\
\hline \multicolumn{5}{|l|}{ Step 1} \\
\hline Idealized Influence-Attributes & -.048 & & .727 & \\
\hline Idealized Influence-Behaviors & .204 & & .066 & \\
\hline Inspirational Motivation & .161 & & .173 & \\
\hline Intellectual Stimulation & -.245 & & .040 & \\
\hline Individualized Consideration & .014 & & .897 & \\
\hline Contingent Reward & .204 & & .086 & \\
\hline Management-by-Exception-Active & -.091 & & .144 & \\
\hline \multirow[t]{2}{*}{ Management-by-Exception-Passive } & -.033 & & .589 & \\
\hline & & .039 & & \\
\hline \multicolumn{5}{|l|}{ Step 2} \\
\hline \multirow[t]{2}{*}{ Staff Longevity } & -.178 & & .003 & \\
\hline & & .031 & & .003 \\
\hline
\end{tabular}

Note: $* p<.05, * * p .01$

\section{Research Hypothesis 3b}

The results of the hierarchical regression analysis where $\mathrm{H}_{3 \mathrm{~b}}$ was tested demonstrated that there was no significant relationship between staff longevity and reading proficiency changes, when controlling for the leadership variables related to transformational and transactional leadership (see Table 33). The results of the analysis in the first step, which involved the control variables, were $F(8,281)=16.086, p=.587$. The results of the analysis in the second step where staff longevity was included were $F(1,280)=15.382, p=.482$, and accounted for $0.2 \%$ of the additional variance.

Consequently, Research Hypothesis 3b was not supported. 
Table 33

Summary of Hierarchical Regression Analysis for Staff Longevity in Predicting Reading Proficiency $(N=$ 290)

\begin{tabular}{|c|c|c|c|c|}
\hline Variables & $\beta$ & $R^{2}$ & Significance & Signif. $F$ Change \\
\hline \multicolumn{5}{|l|}{ Step 1} \\
\hline Idealized Influence-Attributes & -.053 & & .700 & \\
\hline Idealized Influence-Behaviors & .094 & & .397 & \\
\hline Inspirational Motivation & -.009 & & .937 & \\
\hline Intellectual Stimulation & -.186 & & .121 & \\
\hline Individualized Consideration & .017 & & .880 & \\
\hline Contingent Reward & .133 & & .267 & \\
\hline Management-by-Exception-Active & -.048 & & .439 & \\
\hline \multirow[t]{2}{*}{ Management-by-Exception-Passive } & -.090 & & .144 & \\
\hline & & .023 & & \\
\hline \multicolumn{5}{|l|}{ Step 2} \\
\hline \multirow[t]{2}{*}{ Staff Longevity } & -.042 & & .482 & \\
\hline & & .002 & & .482 \\
\hline Total $R^{2}$ & & .025 & & \\
\hline
\end{tabular}

\section{Research Hypothesis 3c}

The results of the hierarchical regression analysis where $\mathrm{H}_{3 \mathrm{c}}$ was tested demonstrated that there was no significant relationship between the staff longevity and reading learning gains, when controlling for the leadership variables related to transformational and transactional leadership (see Table 34). The results of the analysis in the first step, which involved the control variables, were $F(8,281)=31.555, p=.398$. The results of the analysis in the second step where staff longevity was included were $F(1,280)=37.508, p=.092$, and accounted for $0.1 \%$ of the additional variance. Consequently, Research Hypothesis 3c was not supported. 
Table 34

Summary of Hierarchical Regression Analysis for Staff Longevity in Predicting Reading Learning Gains $(N=290)$

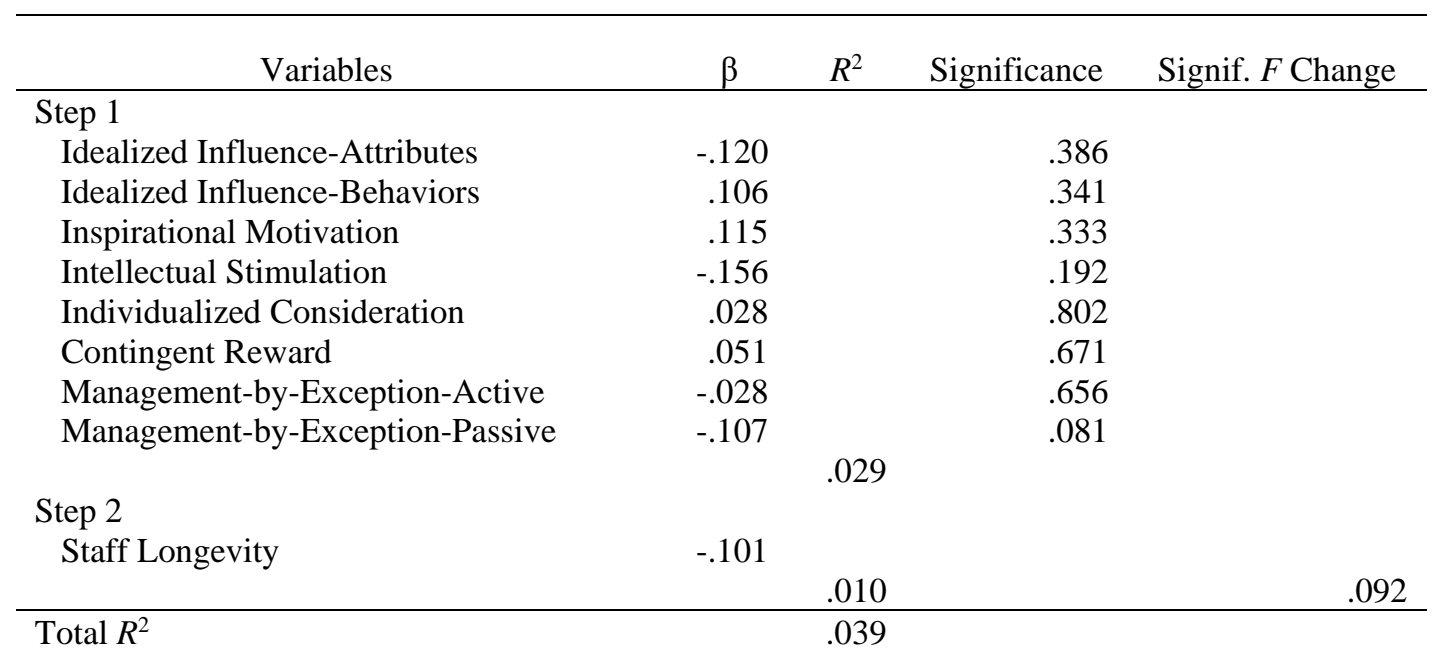

\section{Research Hypothesis 3d}

The results of the hierarchical regression analysis where $\mathrm{H}_{3 \mathrm{~d}}$ was tested demonstrated that there was no significant relationship between staff longevity and reading learning gains of the lowest quartile, when controlling for the leadership variables related to transformational and transactional leadership (see Table 35). The results of the analysis in the first step, which involved the control variables, were $F(8,281)=128.420, p=.123$. The results of the analysis in the second step where staff longevity was included were $F(1,280)=132.333, p=.153$, and accounted for $0.7 \%$ of the additional variance. Consequently, Research Hypothesis 3d was not supported. 
Table 35

Summary of Hierarchical Regression Analysis for Staff Longevity in Predicting Reading Learning of Lowest Quartile $(N=290)$

\begin{tabular}{lrrrr}
\hline \multicolumn{1}{c}{ Variables } & $\beta$ & $R^{2}$ & Significance & Signif. F Change \\
\hline Step 1 & & & & \\
Idealized Influence-Attributes & -.183 & .182 & .885 \\
Idealized Influence-Behaviors & .016 & .011 & .084 \\
Inspirational Motivation & .302 & .178 & .340 \\
Intellectual Stimulation & -.205 & & .777 & \\
Individualized Consideration & .150 & & .959 & \\
Contingent Reward & -.113 & & & \\
Management-by-Exception-Active & .018 & & .153 & \\
Management-by-Exception-Passive & -.003 & .044 & & \\
Step 2 & & & &
\end{tabular}

\section{Research Hypothesis 3e}

The results of the hierarchical regression analysis where $\mathrm{H}_{3 \mathrm{e}}$ was tested

demonstrated that there was no significant relationship between staff longevity and math proficiency changes when controlling for the leadership variables related to transformational and transactional leadership (see Table 36). The results of the analysis in the first step, which involved the control variables, were $F(8,281)=42.354, p=.102$. The results of the analysis in the second step where staff longevity was included were $F(1,280)=37.676, p=.920$, and accounted for no additional variance. Consequently, Research Hypothesis 3e was not supported. 
Table 36

Summary of Hierarchical Regression Analysis for Staff Longevity in Predicting Math Proficiency (N=290)

\begin{tabular}{|c|c|c|c|c|}
\hline Variables & $\beta$ & $R^{2}$ & Significance & Signif. $F$ Change \\
\hline \multicolumn{5}{|l|}{ Step 1} \\
\hline Idealized Influence-Attributes & .156 & & .254 & \\
\hline Idealized Influence-Behaviors & .005 & & .961 & \\
\hline Inspirational Motivation & .030 & & .797 & \\
\hline Intellectual Stimulation & 083 & & .483 & \\
\hline Individualized Consideration & .031 & & .783 & \\
\hline Contingent Reward & -.121 & & .308 & \\
\hline Management-by-Exception-Active & .088 & & .156 & \\
\hline \multirow[t]{2}{*}{ Management-by-Exception-Passive } & 010 & & .872 & \\
\hline & & .046 & & \\
\hline \multirow{3}{*}{$\begin{array}{l}\text { Step } 2 \\
\text { Staff Longevity }\end{array}$} & & & & \\
\hline & .006 & & .920 & \\
\hline & & .000 & & .920 \\
\hline
\end{tabular}

\section{Research Hypothesis 3f}

The results of the hierarchical regression analysis where $\mathrm{H}_{3 \mathrm{e}}$ was tested demonstrated that there was no significant relationship between staff longevity and math learning gains when controlling for the leadership variables related to transformational and transactional leadership (see Table 37). The results of the analysis in the first step, which involved the control variables, were $F(8,281)=61.608, p=.44$. The results of the analysis in the second step where staff longevity was included were $F(1,280)=67.738, p$ $=.170$, and accounted for $0.7 \%$ of the additional variance. Consequently, Research Hypothesis $3 \mathrm{f}$ was not supported. 
Table 37

Summary of Hierarchical Regression Analysis for Staff Longevity in Predicting Math Learning Gains $(N=$ 290)

\begin{tabular}{|c|c|c|c|c|}
\hline Variables & $\beta$ & $R^{2}$ & Significance & Signif. $F$ Change \\
\hline \multicolumn{5}{|l|}{ Step 1} \\
\hline Idealized Influence-Attributes & .144 & & .296 & \\
\hline Idealized Influence-Behaviors & -.005 & & .966 & \\
\hline Inspirational Motivation & .057 & & 632 & \\
\hline Intellectual Stimulation & .022 & & .852 & \\
\hline Individualized Consideration & -.052 & & .645 & \\
\hline Contingent Reward & -.046 & & .701 & \\
\hline Management-by-Exception-Active & .089 & & .152 & \\
\hline \multirow[t]{2}{*}{ Management-by-Exception-Passive } & -.014 & & .815 & \\
\hline & & .028 & & \\
\hline \multicolumn{5}{|l|}{ Step 2} \\
\hline \multirow[t]{2}{*}{ Staff Longevity } & -.082 & & .170 & \\
\hline & & .007 & & .170 \\
\hline
\end{tabular}

\section{Research Hypothesis 3g}

The results of the hierarchical regression analysis where $\mathrm{H}_{3 \mathrm{~g}}$ was tested

demonstrated that there was no significant relationship between the staff longevity and math learning gains of the lowest quartile when controlling for the leadership variables related to transformational and transactional leadership (see Table 38). The results of the analysis in the first step, which involved the control variables, were $F(8,281)=61.547, p$ $=.485$. The results of the analysis in the second step where staff longevity was included were $F(1,280)=70.860, p=.137$, and accounted for $0.8 \%$ of the additional variance. Consequently, Research Hypothesis $3 \mathrm{~g}$ was not supported. 
Table 38

Summary of Hierarchical Regression Analysis for Staff Longevity in Predicting Math Learning Gains of Lowest Quartile $(N=290)$

\begin{tabular}{|c|c|c|c|c|}
\hline Variables & $\beta$ & $R^{2}$ & Significance & Signif. $F$ Change \\
\hline \multicolumn{5}{|l|}{ Step 1} \\
\hline Idealized Influence-Attributes & .078 & & .571 & \\
\hline Idealized Influence-Behaviors & .053 & & .636 & \\
\hline Inspirational Motivation & .093 & & .435 & \\
\hline Intellectual Stimulation & -.048 & & 691 & \\
\hline Individualized Consideration & -.114 & & .312 & \\
\hline Contingent Reward & -.058 & & .629 & \\
\hline Management-by-Exception-Active & .116 & & .065 & \\
\hline \multirow[t]{2}{*}{ Management-by-Exception-Passive } & -.032 & & .601 & \\
\hline & & .026 & & \\
\hline \multicolumn{5}{|l|}{ Step 2} \\
\hline \multirow[t]{2}{*}{ Staff Longevity } & -.089 & & .137 & \\
\hline & & .008 & & 137 \\
\hline
\end{tabular}

\section{Research Hypothesis 3h}

The results of the hierarchical regression analysis where $\mathrm{H}_{3 \mathrm{~h}}$ was tested demonstrated that there was no significant relationship between the staff longevity and science proficiency when controlling for the leadership variables related to transformational and transactional leadership (see Table 39). The results of the analysis in the first step, which involved the control variables, were $F(8,281)=32.421, p=.192$. The results of the analysis in the second step where staff longevity was included were $F(1,280)=30.103, p=.479$, and accounted for $0.2 \%$ of the additional variance.

Consequently, Research Hypothesis $3 \mathrm{~h}$ was not supported. 
Table 39

Summary of Hierarchical Regression Analysis for Staff Longevity in Predicting Science Proficiency $(N=$ 290)

\begin{tabular}{|c|c|c|c|c|}
\hline Variables & $\beta$ & $R^{2}$ & Significance & Signif. $F$ Change \\
\hline \multicolumn{5}{|l|}{ Step 1} \\
\hline Idealized Influence-Attributes & .100 & & .465 & \\
\hline Idealized Influence-Behaviors & .114 & & .302 & \\
\hline Inspirational Motivation & -.306 & & .010 & \\
\hline Intellectual Stimulation & -.199 & & .094 & \\
\hline Individualized Consideration & .015 & & .891 & \\
\hline Contingent Reward & .262 & & .028 & \\
\hline Management-by-Exception-Active & -.040 & & .524 & \\
\hline \multirow[t]{2}{*}{ Management-by-Exception-Passive } & -.037 & & .547 & \\
\hline & \multicolumn{4}{|c|}{ Step 2} \\
\hline \multirow[t]{2}{*}{ Staff Longevity } & .042 & & .479 & \\
\hline & & .002 & & .479 \\
\hline
\end{tabular}

\section{Research Hypothesis $3 i$}

The results of the hierarchical regression analysis where $\mathrm{H}_{3 \mathrm{i}}$ was tested

demonstrated that there was no significant relationship between the staff longevity and social studies proficiency when controlling for the leadership variables related to transformational and transactional leadership (see Table 40). The results of the analysis in the first step, which involved the control variables, were $F(8,281)=109.278, p=.043$. The results of the analysis in the second step where staff longevity was included were $F(1,280)=104.138, p=.257$, and accounted for $0.4 \%$ of the additional variance. Consequently, Research Hypothesis $3_{\mathrm{i}}$ was not supported. 
Table 40

Summary of Hierarchical Regression Analysis for Staff Longevity in Predicting Social Studies Proficiency $(N=290)$

\begin{tabular}{|c|c|c|c|c|}
\hline Variables & $\beta$ & $R^{2}$ & Significance & Signif. $F$ Change \\
\hline \multicolumn{5}{|l|}{ Step 1} \\
\hline Idealized Influence-Attributes & -.028 & & .836 & \\
\hline Idealized Influence-Behaviors & .179 & & 103 & \\
\hline Inspirational Motivation & .225 & & .055 & \\
\hline Intellectual Stimulation & -.196 & & .097 & \\
\hline Individualized Consideration & .062 & & .579 & \\
\hline Contingent Reward & -.152 & & 198 & \\
\hline Management-by-Exception-Active & .068 & & .269 & \\
\hline \multirow[t]{2}{*}{ Management-by-Exception-Passive } & -.007 & & .912 & \\
\hline & & $.055^{*}$ & & \\
\hline \multicolumn{5}{|l|}{ Step 2} \\
\hline \multirow[t]{2}{*}{ Staff Longevity } & -.067 & & .257 & \\
\hline & & .004 & & .257 \\
\hline Total $R^{2}$ & & $.059^{*}$ & & \\
\hline
\end{tabular}

\section{Research Hypothesis 4a}

The results of the hierarchical regression analysis where $\mathrm{H}_{4 a}$ was tested demonstrated that there was a significant negative relationship between the school climate and school grade $(\beta=-.282, p<.001)$ when controlling for the leadership variables related to transformational and transactional leadership (see Table 41). The results of the analysis in the first step, which involved the control variables, were $F(8,281)=.795, p=.187$. The results of the analysis in the second step where school climate was included were $F(1,280)=1.997, p=.000$, and accounted for $7.1 \%$ of the additional variance.

Consequently, Research Hypothesis 4a was rejected. 
Table 41

Summary of Hierarchical Regression Analysis for School Climate in Predicting School Grade $(N=290)$

\begin{tabular}{|c|c|c|c|c|}
\hline Variables & $\beta$ & $R^{2}$ & Significance & Signif. $F$ Change \\
\hline \multicolumn{5}{|l|}{ Step 1} \\
\hline Idealized Influence-Attributes & -.048 & & .727 & \\
\hline Idealized Influence-Behaviors & .204 & & .066 & \\
\hline Inspirational Motivation & -.161 & & .173 & \\
\hline Intellectual Stimulation & -.245 & & .040 & \\
\hline Individualized Consideration & .014 & & .897 & \\
\hline Contingent Reward & .204 & & .086 & \\
\hline Management-by-Exception-Active & -.091 & & .144 & \\
\hline \multirow[t]{2}{*}{ Management-by-Exception-Passive } & -.033 & & .589 & \\
\hline & & .039 & & \\
\hline \multicolumn{5}{|l|}{ Step 2} \\
\hline \multirow[t]{2}{*}{ School Climate } & -.282 & & .000 & \\
\hline & & .071 & & .000 \\
\hline Total $R^{2}$ & & $.110^{* * *}$ & & \\
\hline
\end{tabular}

\section{Research Hypothesis $4 \mathrm{~b}$}

The results of the hierarchical regression analysis where $\mathrm{H}_{4 \mathrm{~b}}$ was tested

demonstrated that there was a significant negative relationship between the school climate and reading proficiency changes $(\beta=-.233, p<.01)$ when controlling for the leadership variables related to transformational and transactional leadership (see Table 42). The results of the analysis in the first step, which involved the control variables, were $F(8,281)=16.086, p=.587$. The results of the analysis in the second step where school climate was included were $F(1,280)=44.820$, $p=.000$ and accounted for $4.9 \%$ of the additional variance. Consequently, Research Hypothesis $4 \mathrm{~b}$ was rejected. 
Table 42

Summary of Hierarchical Regression Analysis for School Climate in Predicting Reading Proficiency $(N=$ 290)

\begin{tabular}{|c|c|c|c|c|}
\hline Variables & $\beta$ & $R^{2}$ & Significance & Signif. $F$ Change \\
\hline \multicolumn{5}{|l|}{ Step 1} \\
\hline Idealized Influence-Attributes & -.053 & & .700 & \\
\hline Idealized Influence-Behaviors & .094 & & .397 & \\
\hline Inspirational Motivation & -.009 & & .937 & \\
\hline Intellectual Stimulation & -.186 & & .121 & \\
\hline Individualized Consideration & .017 & & .880 & \\
\hline Contingent Reward & .133 & & .267 & \\
\hline Management-by-Exception-Active & -.048 & & .439 & \\
\hline \multirow[t]{2}{*}{ Management-by-Exception-Passive } & -.090 & & .144 & \\
\hline & & .023 & & \\
\hline \multicolumn{5}{|l|}{ Step 2} \\
\hline \multirow[t]{2}{*}{ School Climate } & -.233 & & .000 & \\
\hline & & $.049 * *$ & & .000 \\
\hline Total $R^{2}$ & & $.072^{* *}$ & & \\
\hline
\end{tabular}

\section{Research Hypothesis 4c}

The results of the hierarchical regression analysis where $\mathrm{H}_{4 \mathrm{c}}$ was tested

demonstrated that there was a significant negative relationship between the school

climate and reading learning gains $(\beta=-.280, p<.01)$ when controlling for the leadership variables related to transformational and transactional leadership (see Table 43). The results of the analysis in the first step, which involved the control variables, were $F(8$, $281)=31.555, p=.398$. The results of the analysis in the second step where school climate was included were $F(1,280)=95.744, p=.000$, and accounted for $7 \%$ of the additional variance. Consequently, Research Hypothesis $4_{c}$ was rejected. 
Table 43

Summary of Hierarchical Regression Analysis for School Climate in Predicting Reading Learning Gains $(N=290)$

\begin{tabular}{lcccc}
\hline \multicolumn{1}{c}{ Variables } & $\beta$ & $R^{2}$ & Significance & Signif. $F$ Change \\
\hline Step 1 & & & .386 & \\
$\quad$ Idealized Influence-Attributes & -.120 & & .341 & \\
Idealized Influence-Behaviors & .106 & .333 & \\
Inspirational Motivation & .115 & & .192 & \\
Intellectual Stimulation & -.156 & .802 & \\
Individualized Consideration & .028 & .671 & \\
Contingent Reward & .051 & & .656 \\
$\quad$ Management-by-Exception-Active & -.028 & & .081 \\
Management-by-Exception-Passive & -.107 & .029 & & .000 \\
Step 2 & & & & \\
School Climate & -.280 & & & \\
& & .070 & &
\end{tabular}

\section{Research Hypothesis 4d}

The results of the hierarchical regression analysis where $\mathrm{H}_{4 \mathrm{~d}}$ was tested demonstrated that there was a significant negative relationship between the school climate and reading learning gains of the lowest quartile $(\beta=-.281, p<.001)$ when controlling for the leadership variables related to transformational and transactional leadership (see Table 44). The results of the analysis in the first step, which involved the control variables, were $F(8,281)=128.420, p=.123$. The results of the analysis in the second step where school climate was included were $F(1,280)=299.046, p=.000$ and accounted for $7.1 \%$ of the additional variance. Consequently, Research Hypothesis $4 d$ was rejected. 
Table 44

Summary of Hierarchical Regression Analysis for School Climate in Predicting Reading Learning Gains of Lowest Quartile $(N=290)$

\begin{tabular}{lrccc}
\hline \multicolumn{1}{c}{ Variables } & $\beta$ & $R^{2}$ & Significance & $\begin{array}{c}\text { Signif. } F \\
\text { Change }\end{array}$ \\
\hline Step 1 & & & & \\
$\quad$ Idealized Influence-Attributes & -.183 & & .182 & \\
$\quad$ Idealized Influence-Behaviors & .016 & .885 & \\
$\quad$ Inspirational Motivation & .302 & .011 & \\
$\quad$ Intellectual Stimulation & -.205 & .084 & \\
Individualized Consideration & .150 & .178 & \\
$\quad$ Contingent Reward & -.113 & & .340 & \\
$\quad$ Management-by-Exception-Active & .018 & & .777 & $.0000^{* *}$ \\
$\quad$ Management-by-Exception-Passive & -.003 & .044 & & \\
Step 2 & & & & $.000^{* * *}$ \\
School Climate & -.281 & & & \\
& & .071 & & \\
\hline Total $R^{2}$ & & $.115^{* * * *}$ & & \\
Note. $* * p<.01, * * * p<.001$ & & & &
\end{tabular}

\section{Research Hypothesis 4e}

The results of the hierarchical regression analysis where $\mathrm{H}_{4}$ e was tested

demonstrated that there was a significant positive relationship between the school climate and math proficiency changes $(\beta=.348, p<.001)$ when controlling for the leadership variables related to transformational and transactional leadership (see Table 45). The results of the analysis in the first step, which involved the control variables, were $F(8$, $281)=42.354, p=.102$. The results of the analysis in the second step where school climate was included were $F(1,280)=126.769, p=.000$, and accounted for $10.8 \%$ of the additional variance. Consequently, Research Hypothesis 4e was supported. 
Table 45

Summary of Hierarchical Regression Analysis for School Climate in Predicting Math Proficiency $(N=290)$

\begin{tabular}{|c|c|c|c|c|}
\hline Variables & $\beta$ & $R^{2}$ & Significance & Signif. $F$ Change \\
\hline \multicolumn{5}{|l|}{ Step 1} \\
\hline Idealized Influence-Attributes & .156 & & .254 & \\
\hline Idealized Influence-Behaviors & .005 & & .961 & \\
\hline Inspirational Motivation & .030 & & .797 & \\
\hline Intellectual Stimulation & .083 & & .483 & \\
\hline Individualized Consideration & .031 & & .783 & \\
\hline Contingent Reward & -.121 & & .308 & \\
\hline Management-by-Exception-Active & .088 & & .156 & \\
\hline \multirow[t]{2}{*}{ Management-by-Exception-Passive } & .010 & & .872 & \\
\hline & & $.046^{* * *}$ & & \\
\hline \multicolumn{5}{|l|}{ Step 2} \\
\hline \multirow[t]{2}{*}{ School Climate } & .348 & & .000 & \\
\hline & & .108 & & .000 \\
\hline Total $R^{2}$ & & $.154 * * *$ & & \\
\hline
\end{tabular}

Note: $* * * p=<.001$

\section{Research Hypothesis $4 \mathrm{f}$}

The results of the hierarchical regression analysis where $\mathrm{H}_{4 \mathrm{f}}$ was tested

demonstrated that there was a significant positive relationship between the school climate and math learning gains ( $\beta=.153, p<.05$ ) when controlling for the leadership variables related to transformational and transactional leadership (see Table 46). The results of the analysis in the first step, which involved the control variables, were $F(8,281)=61.608, p$ $=.441$. The results of the analysis in the second step where school climate was included were $F(1,280)=96.609, p=.013$, and accounted for $2.1 \%$ of the additional variance. Consequently, Research Hypothesis $4_{\mathrm{f}}$ was supported. 
Table 46

Summary of Hierarchical Regression Analysis for School Climate in Predicting Math Learning Gains $(N=$ 290)

\begin{tabular}{|c|c|c|c|c|}
\hline Variables & $\beta$ & $R^{2}$ & Significance & Signif. $F$ Change \\
\hline \multicolumn{5}{|l|}{ Step 1} \\
\hline Idealized Influence-Attributes & .144 & & .296 & \\
\hline Idealized Influence-Behaviors & -.005 & & .966 & \\
\hline Inspirational Motivation & .057 & & .632 & \\
\hline Intellectual Stimulation & .022 & & .852 & \\
\hline Individualized Consideration & -.052 & & .645 & \\
\hline Contingent Reward & -.046 & & .701 & \\
\hline Management-by-Exception-Active & .089 & & .152 & \\
\hline \multirow[t]{2}{*}{ Management-by-Exception-Passive } & -.014 & & .815 & \\
\hline & & .028 & & \\
\hline \multicolumn{5}{|l|}{ Step 2} \\
\hline \multirow[t]{2}{*}{ School Climate } & .153 & & 013 & \\
\hline & & .021 & & 013 \\
\hline Total $R^{2}$ & & $.049 *$ & & \\
\hline
\end{tabular}

\section{Research Hypothesis 4g}

The results of the hierarchical regression analysis where $\mathrm{H}_{4 \mathrm{~g}}$ was tested demonstrated that there was no significant relationship between the school climate and math learning gains of the lowest quartiles when controlling for the leadership variables related to transformational and transactional leadership (see Table 47). The results of the analysis in the first step, which involved the control variables, were $F(8,281)=61.547, p$ $=.485$. The results of the analysis in the second step where school climate was included were $F(1,280)=55.816, p=.697$, and accounted for $0.1 \%$ of the additional variance. Consequently, Research Hypothesis 4g was not supported. 
Table 47

Summary of Hierarchical Regression Analysis for School Climate in Predicting Math Learning Gains of Lowest Quartile $(N=290)$

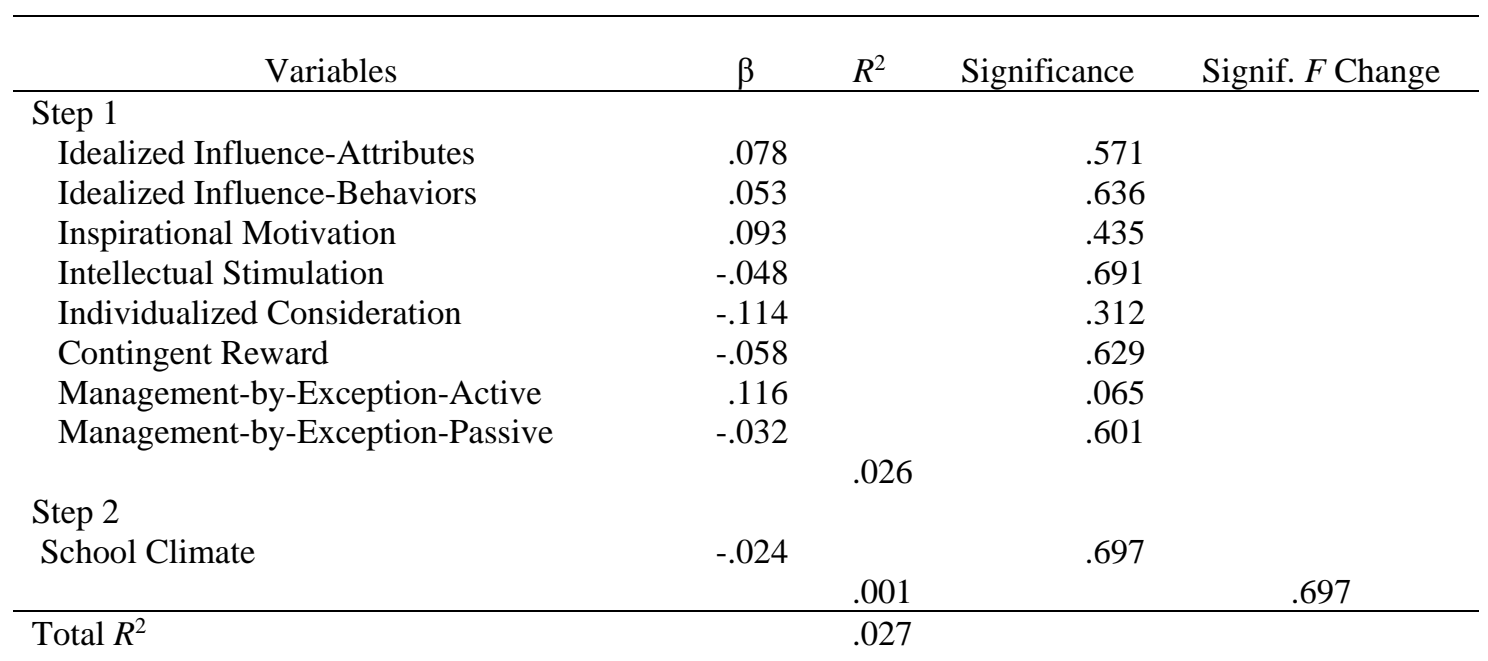

\section{Research Hypothesis 4h}

The results of the hierarchical regression analysis where $\mathrm{H}_{4 \mathrm{~h}}$ was tested demonstrated that there was no significant relationship between the school climate and science proficiency changes when controlling for the leadership variables related to transformational and transactional leadership (see Table 48). The results of the analysis in the first step, which involved the control variables, were $F(8,281)=32.421, p=.192$. The results of the analysis in the second step where school climate was included were $F(1,280)=28.819, p=.995$, and accounted for no additional variance. Consequently, Research Hypothesis 4h was not supported. 
Table 48

Summary of Hierarchical Regression Analysis for Multifactor Leadership Variables and School Climate in Predicting Science Proficiency $(N=290)$

\begin{tabular}{|c|c|c|c|c|}
\hline Variables & $\beta$ & $R^{2}$ & Significance & Signif. $F$ Change \\
\hline \multicolumn{5}{|l|}{ Step 1} \\
\hline Idealized Influence-Attributes & .100 & & .465 & \\
\hline Idealized Influence-Behaviors & .114 & & .302 & \\
\hline Inspirational Motivation & -.306 & & .010 & \\
\hline Intellectual Stimulation & -.199 & & .094 & \\
\hline Individualized Consideration & .015 & & .891 & \\
\hline Contingent Reward & .262 & & .028 & \\
\hline Management-by-Exception-Active & -.040 & & .524 & \\
\hline \multirow[t]{2}{*}{ Management-by-Exception-Passive } & -.037 & & .547 & \\
\hline & & .039 & & \\
\hline \multicolumn{5}{|l|}{ Step 2} \\
\hline \multirow{2}{*}{ School Climate } & .000 & & .995 & \\
\hline & & .000 & & .995 \\
\hline
\end{tabular}

\section{Research Hypothesis 4i}

The results of the hierarchical regression analysis where $\mathrm{H}_{4 i}$ was tested demonstrated that there was a significant negative relationship between the school climate and social studies proficiency changes $(\beta=-.177, p<.01)$ when controlling for the leadership variables related to transformational and transactional leadership (see Table 49). The results of the analysis in the first step, which involved the control variables, were $F(8,281)=109.278, p=.043$. The results of the analysis in the second step where school climate was included were $F(1,280)=147.131, p=.004$ and accounted for $2.8 \%$ of the additional variance. Consequently, Research Hypothesis $4 \mathrm{i}$ was supported. 
Table 49

Summary of Hierarchical Regression Analysis School Climate in Predicting Social Studies Proficiency $(N=290)$

\begin{tabular}{|c|c|c|c|c|}
\hline Variables & $\beta$ & $R^{2}$ & Significance & Signif. $F$ Change \\
\hline \multicolumn{5}{|l|}{ Step 1} \\
\hline Idealized Influence-Attributes & -.028 & & .836 & \\
\hline Idealized Influence-Behaviors & .179 & & .103 & \\
\hline Inspirational Motivation & .225 & & .055 & \\
\hline Intellectual Stimulation & -.196 & & .097 & \\
\hline Individualized Consideration & .062 & & .579 & \\
\hline Contingent Reward & -.152 & & .198 & \\
\hline Management-by-Exception-Active & .068 & & .269 & \\
\hline \multirow[t]{2}{*}{ Management-by-Exception-Passive } & -.007 & & .912 & \\
\hline & & $.055^{*}$ & & \\
\hline \multicolumn{5}{|l|}{ Step 2} \\
\hline \multirow[t]{2}{*}{ School Climate } & -.177 & & .004 & \\
\hline & & .028 & & .004 \\
\hline Total $R^{2}$ & & $.083 * * *$ & & \\
\hline
\end{tabular}

\section{Summary of Results}

The majority of the participants were women (72\%), Hispanic (50\%), had served at the same school site for an average of nine years. The average age of the participants was 47 years old and held a master's degree (41\%). Most of the schools studied had an enrollment between 501 and 1000 students, and the overall free and reduced lunch rate fell between $80-99 \%$. The overall ELL and disability rates were $49 \%$ and $37 \%$, respectively.

Hierarchical regression analysis revealed several substantial positive relationships. The study revealed a significant relationship between transformational leadership and reading learning gains of the lowest quartile, math proficiency, and social studies proficiency. Specifically, the tenets of Idealized Influence-Attributes and Inspirational Motivation, both indicative of transformational leadership, produced 
statistically significant relationships with reading learning gains of the lowest quartile. As well, the overall factors related to transformational leadership were found to have a significant positive relationship with math and social studies proficiency. Transactional leadership was found to have an overall significant positive relationship with both math proficiency and math learning gains. Specifically, the tenet of Contingent Reward was found to have a significant relationship with math proficiency as well as math learning gains. While all of the factors related to transactional leadership did not yield an overall significant relationship when it came to math learning gains of the lowest quartile, specifically Management-By-Exception-Active was found to be statistically significant. Overall staff climate was found to have a significant relationship with math proficiency, as well as math learning gains.

Results of the hierarchical analysis also revealed several negative significant associations. Overall, staff longevity and staff climate yielded significant negative relations to school grade. Additionally, staff climate also produced a significant negative relationship related to all the tenets associated with reading (proficiency, learning gains, and learning gains of the lowest quartile), as well as social studies proficiency.

The regression analysis additionally revealed several nonsignificant relationships. Transformational leadership, overall, was not found to be significantly linked to school grade, reading proficiency, reading learning gains, math learning gains, math learning gains of the lowest quartile, and science proficiency. Overall, transactional leadership was not significantly linked to school grade, none of the three tenets representative of reading, as well as science proficiency. Staff longevity was not linked to any of the academic factors under any specific subject. When it came to staff climate, the statistical 
analysis revealed nonsignificant relationships concerning math learning gains of the lowest quartile and science proficiency.

Chapter five addresses the results and implications related to research, theory, and practice. The chapter also provides suggestions for further research based on the findings. 


\section{CHAPTER V}

\section{SUMMARY, CONCLUSIONS, AND IMPLICATIONS}

A summary of the investigation is offered in the following chapter, accompanied by a discussion of the conclusions extracted from the findings, theoretical, and practical implications suggested by the outcomes, as well as implications for policy and research.

\section{Summary of the Study}

The following section offers a brief reiteration of the problem that the study focused upon, as well as a synopsis of the methodology utilized. It also includes a concise restatement of the specific research hypotheses tested.

The purpose of this investigation was to examine the relationships between the leadership style of principals assigned to Title I middle schools and overall school achievement. The study also analyzed the leadership styles which serve as better predictors of the academic factors related to school achievement. Principals and teachers from 30 Title I middle schools located in an urban school district in southeast Florida participated in the investigation. Staff longevity was identified by way of the demographic piece of the survey shared with the participants which asked them to identify the number of years of service at the same school site, as well as the number of years each had served in the field of education.

\section{Purpose of the Study}

The purpose of the study was to investigate the relationship between the leadership style of 30 principals assigned to Title I middle schools, staff longevity, school climate, and overall school achievement. To gauge the leadership style of each principal, teachers at each of the 30 schools, who had served at the same school for at least one year 
were invited to take the Multifactor Leadership Questionnaire (MLQ-5X). Staff climate was gauged through the staff responses on the district's School Climate Survey.

\section{Statement of the Procedures}

The process of data collection commenced after both the Institutional Review of Board Research Compliance of Florida International University and the Miami Dade County Public Schools Research Review Committee approved the study. The investigator then communicated with each principal selected for participation through a telephone conversation to fully explain the purposes associated with the study. After each leader agreed to partake in the study, the investigator also requested their assistance in ensuring the selected teachers would complete the surveys.

The MLQ-5X was transferred to an online version by the investigator utilizing the Google Survey Platform. The online surveying procedure contained two elements, the first including items related to demographic information, and the second, all the questions included on the MLQ-5X rater and leader forms. An email comprised of a description of the study, a link containing the online survey related to demographic information, and written assertion of anonymity was then distributed. Specifically, the email described was sent to all the teachers who had served for at least one year under the leadership of each of the 30 principals who agreed to participate in the study through the Miami-Dade County Public Schools email Outlook system. After one week, a reminder email was sent to participants containing all the information of the original email. A week later, an additional email was distributed to the desired participants as reminders, one week and two weeks after the initial email was distributed. The group who participated in the study consisted of 290 participants across 30 schools. Survey data was collected during the 
month of October 2018. Once the surveys were completed, correlational and hierarchical analyses were conducted through SPSS to test each hypothesis developed.

\section{Research Questions}

1. Does principal leadership that is more transformational than the norm predict a school's academic achievement level as determined by the Florida Department of Education grading system?

2. Does principal leadership that is more transactional than the norm predict a school's academic achievement level as determined by the Florida Department of Education grading system?

3. Is there a relationship between the leadership style scores of the middle school principals surveyed, and school climate in predicting overall school achievement?

4. Is there a relationship between the leadership style scores of the middle school principals surveyed, and school climate in predicting overall school achievement?

\section{Research Hypotheses}

The research hypotheses tested in the study were:

H01a: Principal leadership as determined by the results of the MLQ-5X survey that is transformational will positively predict achievement based on school grade. 
H01b: Principal leadership as determined by the results of the MLQ-5X survey that is transformational will positively predict achievement based on reading proficiency changes.

H01c: Principal leadership as determined by the results of the MLQ-5X survey that is transformational will positively predict achievement based on reading learning gains changes.

Ho1d: Principal leadership as determined by the results of the MLQ-5X survey that is transformational will positively predict achievement based on reading learning gains changes of the lowest quartile.

Ho1e: Principal leadership as determined by the results of the MLQ-5X survey that is transformational will positively predict achievement based on math proficiency changes.

H01f: Principal leadership as determined by the results of the MLQ-5X survey that is transformational will positively predict achievement based on math learning gains changes.

H01g: Principal leadership as determined by the results of the MLQ-5X survey that is transformational will positively predict achievement based on math learning gains changes of the lowest quartile.

Ho1h: Principal leadership as determined by the results of the MLQ-5X survey that is transformational will positively predict achievement based on science proficiency changes. 
H01i: Principal leadership as determined by the results of the MLQ-5X survey that is transformational will positively predict achievement based on social studies proficiency changes.

H02a: Principal leadership as determined by the results of the MLQ-5X survey that is transactional will negatively predict achievement based on school grade.

H02b: Principal leadership as determined by the results of the MLQ-5X survey that is transactional will negatively predict achievement based on reading proficiency changes.

$\mathrm{H}_{02 \mathrm{c}}$ : Principal leadership as determined by the results of the MLQ-5X survey that is transactional will negatively predict achievement based on reading learning gains changes.

H02d: Principal leadership as determined by the results of the MLQ-5X survey that is transactional will negatively predict achievement based on reading learning gains changes of the lowest quartile.

H02e: Principal leadership as determined by the results of the MLQ-5X survey that is transactional will negatively predict achievement based on math proficiency changes.

H02f: Principal leadership as determined by the results of the MLQ-5X survey that is transactional will negatively predict achievement based on math learning gains changes. 
H02g: Principal leadership as determined by the results of the MLQ-5X survey that is transactional will negatively predict achievement based on math learning gains changes of the lowest quartile.

$\mathrm{H}_{02 \mathrm{~h}}$ : Principal leadership as determined by the results of the MLQ-5X survey that is transactional will negatively predict achievement based on science proficiency changes.

H02i: Principal leadership as determined by the results of the MLQ-5X survey that is transactional will negatively predict achievement based on social studies proficiency changes.

$\mathrm{H}_{3 \mathrm{a}}$ : Staff longevity will positively predict overall school achievement based on school grade.

$\mathrm{H}_{3 \mathrm{~b}}$ : Staff longevity will positively predict reading proficiency changes.

$\mathrm{H}_{3 c}$ : Staff longevity will positively predict reading learning gains changes.

$\mathrm{H}_{3 \mathrm{~d}}$ : Staff longevity will positively predict reading learning gains changes of the lowest quartile.

$\mathrm{H}_{3}$ : Staff longevity will positively predict math proficiency changes.

$\mathrm{H}_{3 \mathrm{f}}$ : Staff longevity will positively predict math learning gains changes.

$\mathrm{H}_{3 \mathrm{~g}}$ : Staff longevity will positively predict math learning gains changes of the lowest quartile.

$\mathrm{H}_{3 h}$ : Staff longevity will positively predict science proficiency changes.

$\mathrm{H}_{3 \mathrm{i}}$ : Staff longevity will positively predict social studies proficiency changes. 
$\mathrm{H}_{4 \mathrm{a}}$ : School climate as identified by staff members will positively predict overall school achievement based on school grade.

$\mathrm{H}_{4 b}$ : School climate as identified by staff members will positively predict reading proficiency changes.

$\mathrm{H}_{4 \mathrm{c}}$ : School climate as identified by staff members will positively predict reading learning gains changes.

$\mathrm{H}_{4 \mathrm{~d}}$ School climate as identified by staff members will positively predict reading learning gains changes of the lowest quartile.

$\mathrm{H}_{4 \mathrm{e}}$ : School climate as identified by staff members will positively predict math proficiency changes.

H4f: School climate as identified by staff members will positively predict math learning gains changes.

$\mathrm{H}_{4 \mathrm{~g}}$ : School climate as identified by staff members will positively predict math learning gains changes of the lowest quartile.

$\mathrm{H}_{4 \mathrm{~h}}$ : School climate as identified by staff members will positively predict science proficiency changes.

$\mathrm{H}_{4 \mathrm{i}}$ : School climate as identified by staff members will positively predict social studies proficiency changes.

The first two research questions involved the predictability of principals who behave in either a transformational or transactional manner when it came to student achievement. Transformational leadership, as exemplified by middle school principals, did positively predict some of the academic achievement factors evaluated (e.g., reading 
learning gains changes of the lowest quartile, math proficiency changes, and social studies proficiency changes). In contrast to what was predicted, transactional leadership, as exemplified by middle school principals, also positively predicted some of the academic achievement factors evaluated (e.g., math proficiency changes, and math learning gains changes).

The results of the hierarchical multiple regression analysis to test the first series of hypotheses linked to the first research question involved investigating the unique positive contribution of transformational leadership style to student achievement. As such, the hypotheses were tested using nine academic factors. Through the performance of statistical analysis, the researcher determined that transformational leadership positively predicts reading gains changes of the lowest quartile $(p<.01)$, math proficiency changes $(p<.05)$, and social studies proficiency changes $(p<.05)$. Thus, as determined by the study, principals who inspire trust, motivate, intellectually stimulate, and treat staff members as individuals lead their schools to heightened achievement in these three areas. The study found strong correlations when it came to two specific transformational behaviors and the positive reading achievement of the lowest quartile of students, Inspirational Motivation $(p<.01)$ and Idealized Influence Attributes $(p<.05)$. Students who fall into the lowest quartile in reading are those whose scores are at the very bottom of the assessment scale, often coming to the academic table with battered esteem compounded by years of failure; it is these students who need to find motivation and influence from principal leadership (Irvin, Meltzer, \& Dukes, 2007). Overall, these results are consistent with the research of Marzano et al. (2005) who affirm that principal leadership has a direct effect on student achievement. On the other hand, these 
conclusions are in discord with the research of Ross and Gray (2006ab) who contend that principal leadership behaviors do not have a direct impact on student academic outcomes.

The results of the hierarchical multiple regression analysis to test the second series of hypotheses linked to the second research question involved the unique negative contribution of transactional leadership style to student achievement. The hypotheses were tested using nine academic factors. Through the performance of statistical analysis, the researcher determined that transactional leadership positively predicted math achievement, rather than negatively as hypothesized, based on proficiency changes $(p<$ $.05)$ and learning gains changes $(p<.05)$. Interestingly, the tenet of Contingent Reward was found to positively predict mathematics proficiency changes $(p<.05)$ and mathematics learning gains changes $(p<.05)$. When it came to the learning gains changes of the lowest quartile, overall, transactional leadership did not predict achievement, yet the specific behavior aligned with Management by Exception-Action did positively predict achievement $(p<.05)$. The conclusions reached by the statistical analysis conducted are in line with educational research on principal leadership, which affirms that leadership behaviors are linked to achievement (Marzano, Waters, \& McNulty, 2005). The results also refute some of the research which claims that the leadership actualized by principals is not linked to student achievement (Ross \& Gray, 2006ab).

The results of the hierarchical multiple regression analysis to test the third series of hypotheses linked to the third research question involved examining the unique positive contribution of staff longevity to student achievement. The hypotheses were tested using nine academic factors. Through the performance of statistical analysis, the 
researcher determined that staff longevity negatively predicted school grade $(p<.01)$. The findings suggest that the longer participants have been teaching, academic achievement decreased. This result seems incongruent with prior research where teacher longevity is linked to academic achievement (Bandura, 1993), but it may be that there is a moderating variable that might explain this relationship. Bandura (1993) suggested that teachers' sense of collective instructional efficacy can suffer with schools heavily populated with minority students with low socioeconomic status as in this research. Thus, if teachers believe their efforts to motivate and educate their minority students to learn and perform well academically are not realistic or possible, it is less likely that students will perform well either. In other words, there generally is a positive relationship between longevity and academic achievement, but in the presence of low collective instructional efficacy, this relationship can be dampened or even become negative. Future research should include a measure of collective instructional efficacy to test this notion further. It is also possible that teachers may demonstrate the highest academic gains in student achievement during the first few years in the classroom, after which performance levels off, and waning marginal outcomes are then produced (Bandura, 1993; Boyd, Grossman, Lankford, \& Wyckoff, 2009; Rice, 2018). Future research should also investigate this notion because interventions could be targeted at those with greater than twenty years in particular who have been shown to become more hardened to the latest teaching challenges thrust upon them from well-intentioned legislative and district initiatives (Bandura, 1993).

The results of the hierarchical multiple regression analysis to test the fourth series of hypotheses linked to the fourth research question involved the positive predictability of 
staff climate concerning student achievement. The hypotheses were tested using nine academic factors. Through the performance of statistical analysis, it was determined that positive staff climate positively predicted math proficiency changes $(p<.01)$, and math learning gains changes $(p<.01)$, which is in line with a large body of research linking school climate and achievement (Hoy \& Miskel, 2013). On the other hand, positive staff climate also negatively predicted school grade $(p<.01)$, all factors related to reading achievement $(p<.01)$, and social studies proficiency $(p<.01)$, which is not supported by any of the existing research. It may be that the school climate measure could stand psychometric examination and refinement, or there is an unknown moderator variable that accounts for this finding. Again, a promising moderator variable that was not measured in this research was collective instructional efficacy. Plausibly, as with longevity, if the collective instructional efficacy is low for reading and social studies, then achievement could suffer in these areas. Again, future research should be designed to test this interesting notion. 


\section{Implications}

The usefulness of the conclusions derived from educational research remains in the implications that can be developed involving theory, practice, research, and policy. The following section offers a discussion of the impact the results derived from this study may hold for each area.

\section{Theoretical Implications}

When the theory of school leadership style was first explored, transformational and transactional leadership stood distinctly at odds, on two different ends of the organizational spectrum (Burns, 1978). As the theory evolved, leaders were found to be transactional, transformational, both, or neither (Vera \& Crossa, 2004). Some researchers have uncovered that prosperous principals also possess transactional skills, and while they may be mostly transformational, transactional skills must be mastered first (Van Wart, 2003). Bass and Avolio concluded that both transactional and transformational leadership were complementary and indeed vital to the success of organizations (Avolio, Bass, \& Jung, 1999). The results of this study lend support to this perspective of leadership. As evidenced by the results of the statistical analysis, both transformational and transactional leadership behaviors can lead to heightened student achievement. Principals should not narrow their scope of influence to either transformational or transactional; instead principals should lead with a combination of both leadership perspectives. As such, the findings related to this study add to the present-day theoretical discourse centered upon the direct effect principal leadership has on student achievement. 


\section{Research Implications}

Research suggests that staff longevity typically leads to heightened achievement (Kini \& Podolsky, 2016). The longer teachers serve, the better impact they have over several cohorts of students spanning several generations; the teachers develop professionally, and they embrace an inner awareness of determination and achievement (Ridgley, 2018). High-poverty, low-achieving schools situated in urban communities often face a high degree of teacher turn-over, losing approximately one-fifth of their respective teaching force year after year (Darling-Hammond, 2010). Professional longevity is accompanied by a subset of useful abilities that can only be amassed through years of service such as trustworthiness, resolution, and resilience (Ridgley, 2018). However, the results of this study contradict this school of thought. As such, the outcomes warrant broadened research to provide viable explanations, involving more schools, more staff input, as well as collective staff efficacy.

The research has also focused on the connection between school culture and student achievement (MacNeil, Prater, \& Busch, 2009; Waters, Marzano, \& McNulty, 2003; Witzers, Bosker, \& Kruger, 2003). The concept of school climate, as some researchers claim, stands out as one of the most vital elements of any educational program (Hoyle \& Steffy, 1985). Sumner (2018), who conducted a study of 40 middle schools, found a substantial relationship between climate and achievement in literacy $(r=$ $.44, p<.05)$, social studies $(r=.37, p<.05)$, and science $(r=.33, p<.05)$. The study associated with this dissertation provided mixed results. On the one hand, the statistical analysis found a strong positive link between staff climate and math proficiency and learning gains $(p<.01)$. On the other hand, the study found a negative link between staff 
climate and school grade, all three factors associated with reading achievement, and social studies proficiency $(p<.01)$. These outcomes warrant broadened research to provide plausible explanations, including more schools and teachers, but also inclusive of all the components associated with school climate, above and beyond the single perspective presented by the staff. Expanded studies should also consider additional stakeholder perspectives as well as collective staff efficacy.

\section{Practical and Policy Implications}

Several implications related to practice can be derived from the results of this study. School principals should lead with a broadened perspective leveraging both transformational and transactional tenets. When dealing with the lowest achieving students in the area of reading, principals should practice behaviors aligned with Inspirational Motivation and Idealized Influence Attributes. Principals should also adopt a transformational approach when attempting to raise social studies proficiency. Concerning the area of mathematics proficiency solely, both a transformational/transactional approach is suggested. According to the research, when principals develop plans to impact mathematics proficiency positively and learning gains, then the tenet of Contingent Reward should be included. As well, principal training programs should focus on growing leaders able to lead schools with a broader perspective

including both transformational and transactional approaches. This idea is consistent with the research of Bass and Avolio (1994). 


\section{Suggested Further Research}

While some of the hypotheses tested were supported, additional questions developed as the study was being conducted which lead to further recommended research. Following, are suggestions that would broaden the results of the study.

\section{Recommendations for Future Research}

Based on the findings of this research, the following recommendations for future research should be considered for expanding or conducting similar studies in the area of principal leadership, teacher efficacy, and student achievement:

1. This study should be replicated and expanded to include a qualitative component, as principal and teacher interviews may provide additional information regarding perceptions and practices.

2. This study should be replicated and expanded to differentiate between Educational Transformational Office (ETO) supported schools, and non-ETO supported schools with the same variables.

3. This study should be expanded to include principals and teachers at the elementary and high school levels. Research designs and methods should be used that will allow the data from different school levels to be compared and contrasted.

4. Future research should include a larger sample size thereby allowing for more generalization.

5. This study should be replicated and expanded to include various subgroups including special education, English language learners, economically disadvantaged and subgroups identified by ethnicity. 
6. Future research should explore the effect that the principals' gender, level of education, experience, and ethnicity may have on teachers' perceptions, teacher efficacy, and student achievement.

7. Future research should be expanded to include all aspects of school climate beyond just staff perception including.

8. Additional research is suggested involving staff longevity and school climate alongside a measure of collective instructional efficacy where urban schools are concerned.

\section{Summary}

The last and final chapter of the study, chapter five, concludes with a summary of the purpose, a reiteration of the problem as well as the procedures and results. Overall, the findings revealed that principals who employ both transformational and transactional behaviors produce increased achievement in math proficiency rates. Principals who lead with more of a transformational approach produce heightened achievement respective to reading learning gains of the lowest quartile, especially by leveraging the behaviors closely associated with Idealized Influence Attributes and Inspirational Motivation. Principals who are perceived to behave in a transformational manner are linked to heightened achievement in social studies proficiency. On the other hand, all-around heightened math performance was linked to transactional behaviors, especially those closely aligned with Contingent Reward and Management by Exception Active. Staff climate was generally found to be negatively linked to many of the academic factors tested. As far as staff longevity was concerned, overall, it had a negative relationship with school grade. 
The findings suggest that principals should practice both transformational and transactional behaviors when attempting to influence specific academic factors. When attempting to positively influence the reading learning gains of the lowest quartile of students, principals should practice behaviors closely aligned to Attributable Idealized Influence coupled with Inspirational Motivation. When it comes to mathematics, the study suggests that principals should act in a transactional manner, with a particular focus on Contingent Reward and Management by Exception Active. The study also revealed that staff longevity was negatively tied to overall achievement, which may suggest that additional teacher professional development programs for more veteran teachers focusing on newer teaching techniques should be implemented. The negative association found between staff climate and school grade and all of the tenets related to reading and social studies suggests that more research is warranted before any significant conclusions can be reached, possibly in the area of collective staff efficacy. 


\section{REFERENCES}

Alexander, W. M. (1987). Toward schools in the middle: Progress and problems. Journal of Curriculum and Supervision, 2(4), 314-329.

Allensworth, E., Ponisciak, S., \& Mazzeo, C. (2009). The schools teachers leave: Teacher mobility in Chicago Public Schools. Chicago: Consortium on Chicago School Research.

Ansell, S. (2017, February 10). Achievement gap. Retrieved from Education Week: http://www.edweek.org/ew/issues/achievement-gap/index.html

Antonakis, J. (2001). The validity of the transformational, transactional, and laissez-faire leadership model as measured by the Multifactor Leadership Questionnaire $(M L Q 5 X)$. Minneapolis: Walden University.

Antonakis, J., Avolio, B., \& Sivasubramaniam, N. (2003). Context and leadership: An examination of the nine-factor Full Range of Leadership Theory using the Multifactor Leadership Questionnaire. The Leadership Quarterly, 14(3), 261-295.

Avolio, B. J. (2011). Full range of leadership development (2nd ed.). Thousand Oaks: SAGE Publications, Inc.

Avolio, B. J., \& Bass, B. (2004). Multifactor leadership questionnaire: Manual and sampler set (3rd ed.). Menlo Park: Mind Garden.

Avolio, B. J., Bass, B. M., \& Jung, D. I. (1999). Re-examining the components of transformational and transactional leadership using the Multifactor Leadership Questionnaire. Journal of Occupational and Organizational Psychology, 72, 441462.

Bakeman, J. (2018, February 16). Miami-Dade school officials sought compromise, not legal battle, on charters-and might get one. Retrieved from WLRN:

http://wlrn.org/post/miami-dade-school-officials-sought-compromise-not-legalbattle-charters-and-might-get-one

Bandura, A. (1993). Perceived self-efficacy in cognitive development and functioning. Educational Psychologist, 28(2), 117-148.

Barling, J. (2014). The science of leadership: Lessons from research for organizational leaders. New York: Oxford University Press. 
Barling, J., Slater, F., \& Kelloway, E. K. (2000). Transformational leadership and emotional intelligence: An exploratory study. Leadership \& Organizational Development Journal, 21(3), 157-161.

Bass, B. M. (1985). Leadership and performance beyond expectations. New York: The Free Press.

Bass, B. M. (1985). Transformational leadership. New York: The Free Press.

Bass, B. M. (1990). Bass and Stogdill's handbook of leadership: Theory, research and managerial applications. New York: Free Press.

Bass, B. M. (1990). From transactional to transformational leadership: Learning to share the vision. Organizational Dynamics, 18(3), 19-31.

Bass, B. M. (1997). Does the transactional-transformational leadership paradigm transcend organizational and national boundaries? American Psychologist, 52, 130-139.

Bass, B. M. (1998). Transformational leadership: Industrial, military and educational impact. Mahwah: Lawrence Erlbaum Associates.

Bass, B. M. (2000). The future of leadership in learning organizations. Journal of Leadership Studies, 7(3), 18-41.

Bass, B. M. (2006). Transformational leadership (2nd ed.). Mahwah: Lawrence Erlbaum.

Bass, B. M. (2010). Two decades of research and development in transformational leadership. European Journal of Work and Organizational Psychology, 8(1), 932.

Bass, B. M. (2016, June 3). Multifactor leadership questionnaire. Retrieved from mindgarden: tools for positive transformation: http://www.mindgarden.com/16multifactor-leadership-questionnaire

Bass, B. M., \& Avolio, B. J. (1994). Improving organizational effectiveness through transformational leadership. Thousand Oaks: Sage Publications.

Bass, B. M., \& Bass, R. (2008). The Bass handbook of leadership: theory, research, \& managerial applications (4th ed.). New York: Free Press.

Bass, B. M., \& Riggio, R. E. (2006). Transformational leadership (2nd ed.). Mahwah: Lawrence Erlbaum Associates, Publishers. 
Bass, B. M., \& Steidlmeier, P. (1999). Ethics, character, and authentic transformational leadership behavior. Leadership Quarterly, 10(2), 181-217.

Bass, B. M., Avolio, B. J., Jung, D. I., \& Berson, Y. (2003). Predicting unit performance by assessing transformational and transactional leadership. Journal of Applied Psychology, 88(2), 207-218.

Becker, B., \& Luthar, S. (2002). Social-emotional factors affecting achievement outcomes among disadvantaged students: Closing the achievement gap. Educational Psychologist, 37(4), Taylor \& Francis.

Belknap, M. L. (2004). The real significance of Brown V. Board of Education: The genesis of the Warren Court's quest for equality. The Wayne Law Review, 863, Wayne State University Law School.

Bennis, W. G. (1959). Leadership theory and administrative behavior: the problem of authority. Administrative Science Quarterly, 4, 259-260.

Bernhardt, V. L. (2003). No schools left behind. Educational Leadership, 60(5), 26-30.

Bierly, C., \& Shy, E. (2013). Building pathways: How to develop the next generation of transformational school leaders. Boston: Bain \& Company.

Bobeck, B. L. (2002). Teacher resiliency: A key to career longevity. The Clearing House, 75(4), 202-205.

Bottoms, G., \& O'Neill, K. (2001). Preparing a new breed of school principals: It's time for action. Atlanta: Southern Regional Education Board.

Boyd, D. J., Grossman, P. L., Lankford, S., \& Wyckoff, J. (2009). Teacher preparation and student achievement. Educational Evaluation and Policy Analysis, 31(4), 416-440.

Boyd, D., Lankford, H., Loeb, S. R., \& Wyckoff, J. (2011). The effect of school neighborhoods on teacher retention decisions. In G. Duncan, \& R. Murnane, Whither opportunity? Rising inequality, schools, and children's life chances. New York: Russell Sage Foundation Press.

Bradbury, B., Corak, M., Waldfogel, J., \& Washbrook, E. (2015). Too many children left behind: The U.S. achievement gap in comparative perspective. New York: Russell Sage Foundation.

Brooks, M. (2009). The relationship of leadership styles, gender and years of experience of middle school principals in North Carolina on achievement and growth trends on the end of grade exams (Doctoral dissertation). Retreived from 
https://search.proquest.com/openview/3fe235c39a01c8930d35cdfbd05bcd5b/1?pq -origsite $=$ gscholar $\&$ cbl $=18750 \&$ diss $=y$

Brooks, R. L. (1996). Integration or separation: A strategy for racial equality. Cambridge: Harvard University Press.

Bulach, C. R., Lunenburg, F., \& Potter, L. (2011). Creating a culture for high-performing schools (2nd ed.). Lanham: Rowman \& Littlefield Education.

Bulach, C., Malone, B., \& Castleman, C. (1995). An investigation of variables related to student achievement. Mid-western Educational Researcher, 8(2), 23-29.

Burns, J. M. (1978). Leadership. New York: Harper \& Row.

Camera, L. (2018, March 5). Gains in reading for Hispanic students overshadowed by achievement gap. Retrieved from U.S. News and World Report: https://www.usnews.com/news/blogs/data-mine/2016/03/28/hispanic-studentsgains-overshadowed-by-achievement-gaps

Cardno, C. (2012). Managing effective relationships in education. London: Sage Publications Ltd.

Carnevale, A. P. (2010). Projections of jobs and education requirements through 2018. Washington: Georgetown University.

Caro, D. H. (2012). Measuring family socioeconomic status: An illustration using data from PIRLS 2006. IERI Monograph Series: Issues and Methodologies, 5, 9-33.

Carvalho, A. M. (2017, November 20). DATA/COM presentation. Miami, FL, United States.

Cashman, K. (2017). Leadership from the inside out: Becoming a leader for life. Oakland: Berret-Koehler Publishers, Inc.

Chauldhry, A. Q., \& Javed, H. (2012). Impact of transactional and laissez-faire leadership style on motivation. International Journal of Business and Social Science, 50(2), 258-264.

Church, A. H., \& Waclawski, J. (2017). Designing and using organizational surveys. New York: Routledge.

Cisneros, F. (2010). Successful school turnarounds using transformational leadership: Keys to success in creating a foundation for a successful school. Houston: University of Houston. 
Clark, D., Martorell, P., \& Rockoff, J. (2009). School principals and school performance. Washington: Calder, The Urban Institute.

Cohen, J., McCabe, E. M., Michelli, N. M., \& Pickeral, T. (2009). School climate: Research, policy, practice, and teacher education. Teachers College Record, 111(1), 180-213.

Colby, S. L., \& Ortman, J. M. (2015). Projections of the size and composition of the U.S. population: 2014 to 2060. Washington: U.S. Department of Commerce.

Cotton, K. (2003). Principals and student achievement: What the research says. Alexandria: Association for Supervision and Curriculum Development.

Creswell, J. W. (2009). Research design: Qualitative, quantitative, and mixed methods approaches (3rd ed.). Thousand Oaks: Sage Publications, Inc.

Daresh, J., Ganter, M., K., D., \& Hvizdak, M. (2000). Words from "the trenches:" Principals' perspectives on effective school leadership characteristics. Journal of School Leadership, 10(1), 69-83.

Darling-Hammond, L. (2004). The color line in American Education: Race, resources, and student achievement. Du Boise Review: Social Science Research on Race, $1(2), 213-246$.

Darling-Hammond, L. (2010). Teacher education and the American future. Journal of Teacher Education, 61(1-2), 36-37.

Darling-Hammond, L. (2010). The flat world and education: How America's commitment to equity will determine our future. New York: Teachers College Press.

Darling-Hammond, L., Bae, S., Cook-Harvey, C. M., Lam, L., Mercer, C., Podolsky, A., \& Stosich, E. L. (2016). Pathways to new accountability through the Every Student Succeeds Act. Palo Alto: Learning Policy Institute.

Day, C., Gu, Q., \& Sammons, P. (2016). The impact of leadership on student outcomes: How successful leaders use transformational and instructional strategies to make a difference. Education Administration Quarterly, 52(2), 221-258.

Delpit, L. (2006). Other people's children: Cultural conflict in the classroom. New York: The New Press.

Den Hartog, D. N., Van Muijen, J. J., \& Koopman, P. L. (1997). Transactional versus transformational leadership: An analysis of the MLQ. Journal of Occupational and Organizational Psychology, 70, 19-34. 
Di Schiena, R., Letens, G., Van Aken, E., \& Farris, J. (2013). Relationship between leadership and characteristics of learning organizations in deployed military units: An exploratory study. Administrative Sciences, 3(13), 143-165.

Dickinson, T. S. (2001). Reinventing the middle school. New York: Routledge.

Dillman, D. A. (2014). Improving response to household surveys using mail contact to request responses over the Internet: Results from a series of experiments. Pullman: Washington State University.

DiPaola, M., \& Hoy, W. K. (2012). Principals improving instruction: Supervision, evaluation, and professional development. Charlotte: Information Age Publishing Inc.

Dufour, R. \&. (2011). Leaders of learning: How district, schools, and classroom leaders improve student achievement. Bloomington: Solution Tree Press.

Duncan, G., \& Magnuson, K. (2005). Can family socioeconomic resources account for racial and ethnic test score gaps? Future Child, 15(1), 35-54.

Eagley, A. H., Johannesen-Scmidt, M. C., \& Van Engen, M. L. (2003). Transformational, transactional, and laissez-faire leadership styles: A meta-analysis comparing men and women. Psychological Bulletin, 129(4), 569-591.

Eberts, R., Hollenbeck, K., \& Stone, J. (2002). Teacher performance incentives and student outcomes. The Journal of Human Resources, 37(4), 913-927.

Education Cities (2016). Education in America: Comparing the achievement gap across schools, cities, and states. Memphis: Education Cities

Edwards, S., \& Kemp, A. T. (2014). The middle school philosophy: Do we practice what we preach or do we preach something different? Current Issues in Middle Level Education, 19(1), 13-19.

Eyal, O., \& Roth, G. (2011). Principal's leadership and teacher's motivation: SelfDetermination Theory analysis. Educational Administration, 49(3), 256-275.

Fernet, C., Trepanier, S., Austin, S., \& Levesque-Cote. (2016). Committed, inspiring, and healthy teachers: How do school environment and motivational factors facilitate optimal functioning at career start? Teacher and Teacher Education, 59, 481-491.

Florida Department of Education (2016). School grades learning gains calculation for 2015-16. Tallahassee: Florida Department of Education. 
Florida Department of Education (2016). Understanding Florida standards assessment reports . Tallahassee: Office of Assessment.

Florida Department of Education (2016, March 16). Florida school grades. Retrieved from fldoe.org: http://schoolgrades.fldoe.org/

Florida Department of Education (2016, December 10). K-12 student assessment. Retrieved from Florida Department of Education: http://www.fldoe.org/accountability/assessments/k-12-studentassessment/fsa.stml

Florida Department of Education (2017). Free/reduced lunches by district. Tallahassee: Florida Department of Education.

Florida Department of Education (2017, May 15). Florida standards. Retrieved from Florida Department of Education: http://www.fldoe.org/academics/standards/florida-standards/about.stml

Florida Department of Education (2017, December 1). Florida school accountability reports. Retrieved from Florida Department of Education: http://www.fldoe.org/accountability/accountability-reporting/school-grades/

Florida Department of Education (2017, December 15). 2017 School grades overview. Retrieved from Florida Department of Education: http://www.fldoe.org/core/fileparse.php/18534/urlt/SchoolGradesOverview17.pdf

Florida Department of Education (2018, February 10). K-12 student assessment. Retrieved from Florida Department of Education: http://www.fldoe.org/accountability/assessments/k-12-studentassessment/fsa.stml

Florida Department of Education (2018, August 25). Florida school accountability reports. Retrieved from Florida Department of Education: http://www.fldoe.org/accountability/accountability-reporting/school-grades/

Florida Department of Education (2018, November 19). 2016-17 Guide to Calculating School and District Grades. Retrieved from http://www.fldoe.org/core/fileparse.php/18534/urlt/schoolgradescalcguide17.pdf

Florida Senate (2017). The Florida Senate 2017 summary of legislation passed committee on education. Talahassee: Florida Senate.

Fry, R. (2008). The role of schools in the English Language Learner achievement gap. Washington: Pew Hispanic Center. 
Fryer, R. G., \& Levitt, S. D. (2004). Understanding the Black-White test score gap in the first two years of school. The Review of Economics and Statistics, 86(2), 447-464.

Fullan, M. (2001). Leading a culture of change. San Francisco: Jossey-Bass.

Fullan, M. (2002). Beyond instructional leadership. Educational Leadership, 59(8), 1621.

Gabarro, J. (1987). The dynamics of taking charge. Boston: Harvard Business School Press.

Gill, R. (2006). Theory and practice of leadership. London: SAGE Publications.

Gillespie, N., \& Mann, L. (2004). Transormational leadership and shared values: The building blocks of trust. Journal of Managerial Psychology, 19(6), 588-607.

Giroux, H. A. (2016). Schooling and the struggle for public life: Democracy's promise and education's challenge. New York: Paradigm Publishers.

Givens, R. J. (2008). Transformational leadership: The impact on organizational and personal outcomes. Emerging Leadership Journeys, 1(1), 4-24.

Goddard, R. D., Hoy, W. K., \& Hoy, A. (2000). Collective teacher efficacy: Its meaning, and impact on student achievement. American Educational Research Journal, 37(2), 479-507.

Gooden, M. A. (2004). A history of Black achievement as impacted by federal court decisions in the last century. The Journal of Negro Education, 73(3), 230-238.

Granello, D. H., \& Wheaton, J. E. (2004). Online data collection: Strategies for research. Journal of Counseling and Development, 82(4), 387-394.

Gray, L., Taie, S., \& O'Rear, I. (2015). Public school teacher attrition and mobility in the first five years: Results from the first through fifth waves of the 2007-08 beginning teacher longitudinal study. Washington: U.S. Department of Education; National Center for Education Statistics.

Green, S. (1991). How many subjects does it take to do a regression analysis? Multivariate Behavioral Research, 26, 449-510.

Griffith, J. (2004). Relation of principal transformational leadership to school staff job satisfaction, staff turnover, and school performance. Journal of Educational Administration, 42(3), 333-356. 
Groves, R. M., Fowler, R. M., Couper, M., Lepkowski, J., Singer, J., \& Tourangeau, R. (2009). Survey Methodology. Hoboken: John Wiley \& Sons, Inc.

Gurney, K., \& Clark, K. M. (2017, July 26). Miami schools move toward joining lawsuit against state education law. Retrieved from Miami Herald:

http://www.miamiherald.com/news/local/education/article163837083.html

Hair, J. F., \& Black, W. C. (2010). Multivariate data analysis (7th ed.). Upper Saddle River: Prentice Hall.

Hallinger, P., \& Heck, R. H. (2010). Collaborative leadership and school improvement: understanding the impact on school capacity and student learning. School Leadership and Management, 30(2), 95-110.

Hardman, B. K. (2011). Teacher's perception of their principal's leadership style and the effects on student achievement in improving and non-improving schools. Tampa: University of South Florida.

Hayes, A. F. (2018). Introduction to mediation, moderation, and conditional process analysis: A regression-based approach (2nd ed.). New York: The Guilford Press.

Heck, T. (2014). The promise of transformational leadership for closing the achievement gap. San Diego: University of California.

Heinitz, K., Liepmann, D., \& Felfe, J. (2005). Examining the factor structure of the MLQ. European Journal of Psychological Assessment, 21, 182-190.

Herold, D. M., Fedore, D. B., Caldwell, S., \& Liu, Y. (2008). The effects of transformational and change leadership on employees' commitment to a change: A multilevel study. Journal of Applied Psychology, 93(2), 346-357.

Horng, E. L., Klasik, D., \& Loeb, S. (2010). Principals' time use and school effectiveness. American Journal of Education, 116(4), 491-523.

Houlfort, N., Koestner, R., Joussemet, M., Nantel-Vivier, A. \& Lekes, N. (2002). The impact of performance-contingent rewards on perceived autonomy and competence. Motivation and Emotion, 26(4), 279-295.

Hoy, A., \& Hoy, W. (2003). Instructional leadership: A learning-centered guide. Boston: Allyn and Bacon.

Hoy, W. K., \& Miskel, C. G. (2013). Educational administration: Theory, research, and practice. New York: McGraw-Hill. 
Hoy, W. K., Smith, P. A., \& Sweetland, S. (2003). The development of the organizational climate index for high schools: Its measures and relationship to faculty trust. High School Journal, 86(2), 38-50.

Hoyle, J. R., \& Steffy, B. E. (1985). Skills for successful leaders. Arlington: American Association of School Administrators.

Humes, K. R. (2011). Overview of race and Hispanic origin: 2010. Washington: United States Census Bureau.

Irvin, J., Meltzer, J., \& Dukes, M. (2007). Taking action on adolescent lkiteracy: An implementation guide for school leaders. Alexandria: Association for Supervision and Curriculum Development.

Jackson, A. W., \& Davis, G. A. (2000). Turning points 2000: Educating adolescents in the 21st century. New York: Teachers College Press.

Jennings, J. (2016). Fifty years of federal aid to school: Back into the future? Education Law \& Policy Review, 3, 1-30.

Jensen, E. (2017, March 17). How poverty affects classroom engagement. Retrieved from Reading to Learn/Learning for Life: http://reading4all.com/entries/page/1156

Johnson, B., \& Christensen, L. (2017). Educational research: Quantitative, qualitative, and mixed approaches (6th ed.). Thousand Oaks: SAGE.

Kelley, R., Thornton, B., \& Daugherty, R. (2005). Relationships between measures of leadership and school climate. Education, 126(1), 17-25.

Kini, T., \& Podolsky, A. (2016). Does teaching experience increase teacher effectiveness? A review of the research. Palo Alto: Learning Policy Institute.

Kirkbride, P. (2006). Developing transformational leaders: The full range of leadership model in action. Industrial and Commercial Training, 38(1), 23-32.

Kohlberg, L., \& Hersh, R. H. (1977). Moral development: A review of the theory. Theory Into Practice, 16(2), 53-59.

Kouzes, J., \& Posner, B. (2002). The leadership challenge. San Francisco: Jossey-Bass.

Kuhnert, K. W., \& Lewis, P. (1987). Transactional and transformational leadership: A constructive/developmental analysis. Academy of Management Review, 12(4), 648-657. 
Landson-Billings, G. (2006). From the achievement gap to the education debt:

Understanding achievement in U.S. schools. Educational Researcher, 35(7), 3-12.

Lashway, L. (2018, January 11). The strategies of a leader. Retrieved from Eric Digest: https://www.ericdigests.org/1997-4/leader.htm

Lefever, S., Dal, M., \& Matthiasdottir, A. (2007). Online data collection in academic research: Advantages and limitations. British Journal of Educational Technology, 38(4), 574-582.

Lehr, C. A., \& Christenson, S. L. (2002). Best practices in promoting a positive school. In A. Thomas, \& J. Grimes, Best practices in school psychology IV (pp. 929-947). Bethesda: National Association of School Psychologists.

Leithwood, K. (1992). Transformational leadership: Where does it stand? The Education Digest, 58(3), 17-20.

Leithwood, K. (1992). The move toward transformational leadership. Educational Leadership, 49(5), 8-12.

Leithwood, K., \& Riehl, C. (2003). What we know about successful school leadership. Philadelphia: Temple University.

Leithwood, K., Day, C., Sammons, P. \& Hopkins, D. (2006). Successful school leadership: What it is and how it influences pupil learning. Nottingham: University of Nottingham: National College for School Leadership.

Leithwood, K., \& Wahlstrom, K. (2004). How leadership influences student learning. New York: Wallace Foundation.

Leithwood, K., \& Duke, D. L. (1998). Mapping the conceptual terrain of leadership: A critical point of departure for cross-cultural studies. Peabody Journal of Education, 73(2), 31-50.

Leithwood, K., \& Jantzi, D. (2009). Transformational leadership. In B. Davies, The Essentials of School Leadership (pp. 37-52). Thousand Oaks: SAGE.

Leithwood, K., \& Montgomery, D. (1982). The role of the elementary principal in program improvement. Review of Educational Research, 52(3), 309-339.

Leithwood, K., Louis, K. S., Anderson, S., \& Wahlstrom, K. (2004). How leadership influences student learning. The Wallace Foundation. 
Lowe, K. K. (1996). Effectiveness correlates of transformational and transactional leadership: A meta-analytic review of the MLQ literature. Leadership Quarterly, $7(3), 385-425$.

Lowndes, J., Novkov, J., \& Warren, D. T. (2008). Race and American political development. New York: Routledge.

MacNeil, A. J., Prater, D. L., \& Busch, S. (2009). The effects of school culture and climate on student achievement. International Journal of Leadership in Education, 12(1), 73-84.

Mahdinezhad, M., Saudi, T. B., Silong, A. D., \& Omar, Z. B. (2013). Transformational, transactional leadership styles and job performance of academic leaders. International Education Studies, 6(11), 29-34.

Marquardt, M. J. (2011). Building the learning organization: Achieving strategic advantage through a commitment to learning. Boston: Nicholas Brealey Publishing.

Marzano, R. J., Waters, T., \& McNulty, B. A. (2005). School leadership that works. Alexandria: Association for Supervision and Curriculum Development.

Mathis, W. J., \& Trujillo, T. M. (2016). Lessons from NCLB for the Every Student Succeeds Act. Boulder: National Education Policy Center.

McCall, M. (2016). Overview, intention, history, and where we are now. In H. \&. Jiao, The Next Generation of Testing: Common Core Standards, Smarter-Balanced, PARCC, and the Nation (pp. 19-27). Charlotte: Information Age Publishing .

McCleskey, J. A. (2014). Situational, transformational, and transactional leadership and leadership development. Journal of Business Studies Quarterly, 5(4), 117-130.

McGuinn, P. (2012). Stimulating reform: Race to the Top, competitive grants and the Obama education agenda. Educational Policy, 26(1), 136-159.

McGuinn, P. (2016). From No Child Left Behind to the Every Student Succeeds Act: Federalism and the education legacy of the Obama Administration. Publius: The Journal of Federalism, 46(3), 392-415.

Mendels, P. (2012). The effective principal. Oxford: Learning Forward.

Meyer, P. (2011). The middle school mess: If you love bungee jumping, you're the middle school type. Education Next, 11(1), 40-47. 
Miami-Dade County Public Schools (2016, May 15). Title I administration. Retrieved from Dadeschools.net: Giving our students the world: http://title1.dadeschools.net/titleI.asp

Miami-Dade County Public Schools. (2017, November 10). Title I administration 20172018 Participating Schools. Retrieved from Dadeschools.net: giving our students the world: http://title1.dadeschools.net/pdfs18/participating_schools.pdf

Miami-Dade County Public Schools (2018, January 5). Legislative updates. Retrieved from Office of Intergovernmental Affairs: http://gafla.dadeschools.net/pdf/MDCPS_17-18_Budget_Changes.pdf

Miami-Dade County Public Schools Office of Assessment, R. A. (2018, January 6). ARDA: Assessment, research, and data analysis. Retrieved from Miami-Dade County Public Schools: http://oada.dadeschools.net/

Miami-Dade County Public Schools (2018, Feburary 3). Middle schools. Retrieved from Miami-Dade County Public Schools: http://www.dadeschools.net/schools/schoolinformation/?type=2\#list

Miami-Dade County Public Schools: Assessment, R. (2018, April 14). 2014-2015 School climate results: District results summary. Retrieved from Miami-Dade County Public Schools: http://drs.dadeschools.net/SchoolClimateSurvey/201415/2014-15_ClimateSurvey_DistrictSummary_Results_V2.pdf

Miami-Dade County Public Schools (2018, April 15). School climate surveys: District results 2011-2012. Retrieved from Miami-Dade County Public Schools: http://drs.dadeschools.net/SchoolClimateSurvey/201112/climate\%20report\%202011-12.pdf

Miami-Dade County Public Schools (2018, April 16). Annual climate survey. Retrieved from Miami-Dade County Public Schools: http://drs.dadeschools.net/SchoolClimateSurvey/SCS.asp

Michelman, B. (2016, October 1). The never-ending story of ESEA reauthorization. Retrieved from ASCD Learn. Teach. Lead.: http://www.ascd.org/publications/newsletters/policy_priorities/vol18/num01/The_ Never-Ending_Story_of_ESEA_Reauthorization.aspx

Miller, R. B. (1971). Development of a taxonomy of human performance: Design of a systems task vocabulary. Fort Belvoir: Defense Technical Information Center.

Mills, J. L. (2017). The meaning of "equal": Evolution of racial equality in the United States. Florida Journal of International Law, 29(1), 1-15. 
Mitchell, C., \& Castle, J. B. (2005). The instructional role of elementary school principals. Canadian Journal of Education, 28(3), 409-433.

Moore, L. \&. (2006). Leadership styles of current extension leaders. Journal of Agricultural Education, 47(1), 6-16.

Morrow, M. I. (2008). Self-Determination Theory: Increasing motivation in middle school students. Denver: Regis University.

Muenjon, N., \& Armstrong, A. (2008). Evaluating the structural validity of the Multifactor Leadership Questionnaire (MLQ), capturing the leadership factors of transformational-transactional leadership. Contemporary Management Research, $4(1), 3-14$.

N.A. (2018, January 17). The nation's main K-12 law: A timeline of the ESEA. Retrieved from Education Week: https://www.edweek.org/ew/section/multimedia/thenations-main-k-12-law-a-timeline.html

N.A. (2018, April 29). Sample size calculator. Retrieved from Calculator.net: https://www.calculator.net/sample-sizecalculator.html type $=1 \& \mathrm{cl}=95 \& \mathrm{ci}=5 \& \mathrm{pp}=50 \& \mathrm{ps}=3000 \& \mathrm{x}=120 \& \mathrm{y}=18$

National Center for Education Statistics (2003). Overview and inventory of state education reforms: 1990 to 2000. Washington: U.S. Department of Education.

National Center for Education Statistics (2013). NAEP 2012: Trends in acacdemic progress. Washington: U.S. Department of Education.

National Center for Education Statistics (2015). School composition and the Black-White achievement gap. Washington: U.S. Department of Education.

National Center for Education Statistics (2016). The condition of education 2016. Washington: U.S. Department of Education.

National Center for Education Statistics (2017, November 10). Characteristics of children's families. Retrieved from National Center for Education Statistics: https://nces.ed.gov/programs/coe/indicator_cce.asp

National Center for Education Statistics (2017, December 15). Digest of education statistics. Retrieved from National Center for Education Statistics: https://nces.ed.gov/programs/digest/d16/tables/dt16_203.50.asp

National Center for Education Statistics (2018, January 1). Fast facts. Retrieved from IES/NCES: https://nces.ed.gov/fastfacts/display.asp?id=372 
National Center for Education Statistics (2018, January 1). NAEP data explorer. Retrieved from National Center for Education Statistics: https://nces.ed.gov/nationsreportcard/lttdata/report.aspx

National Policy Board for Educational Administration (2015). Professional standards for educational leaders 2015. Reston: National Policy Board for Educational Administration

Newman, I., Newman, C., Brown, R., \& McNeely, S. (2005). Conceptual statistics for beginners (3rd ed.). New York: University Press of America, Inc.

Nguni, S., Sleegers, P., \& Denessen, E. (2006). Transformational and transactional leadership effects on teachers' job satisfaction, organizational citizenship behavior in primary schools: The Tanzanian case. School Effectiveness and School Improvement, 17(2), 145-177.

Nielson, K., Randall, R., Yarker, J., \& Brenner, S.-O. (2008). The effects of transformational leadership on followers' perceived work characteristics and psychological well-being: A longitudinal study. Work \& Stress, 22(1), 16-32.

Noguera, P. (2003). City schools and the American dream: Reclaiming the promise of public education. New York: Teachers College Press.

Norton, S. (2002). Let's keep our quality school principals on the job. High School Journal, 86(50), 50-57.

Nunnally, J. C., \& Bernstein, I. H. (1994). Psychometric theory. New York: McGrawHill.

Odumeru, J. A. (2013). Transformational vs. transactional leadership theories: Evidence in literature. International Review of Management and Business Research, 2(1), 355-361.

Office of the Assistant Secretary for Planning and Evaluation (2016, November 10). 2015 Poverty guidelines. Retrieved from U.S. Department of Health \& Human Services: https://aspe.hhs.gov/2015-poverty-guidelines

Office of the Under Secretary (2002, September). No Child Left Behind Act: A desktop reference 2002. Washington, D.C.: Education Publications Center.

Orfield, G. (2009). Reviving the goal of an integrated society: A 21 st Century challenge. Los Angeles: The Regents of the University of California.

Orfield, G. \& Frankenberg, E. (2014). Increasingly segregated and unequal schools as courts reverse policy. Education Administration Quarterly, 50(5), 718-734. 
Oregon School Boards Association (2016, September 20). Motivating teachers to improve instruction. Retrieved from Oregon School Boards Association: http://www.osba.org/Resources/Article/Employee_Management/Motivating_Teac hers_to_Improve_Instruction.aspx

Organization, S. D. (2016, May 10). Self-Determination theory. Retrieved from sdt/SelfDetermination Theory: http://selfdeterminationtheory.org/theory/

Ozaralli, N. (2003). Effects of transformational leadership on empowerment and team effectiveness. Leadership \& Organization Development Journal, 24(6), 335-344.

Pantaleon, S. (2015). The full-range of leadership. Kalmar: Linnaeus University.

Principals, N. A., \& Principals, N. A. (2013). Leadership matters: What the research says about the importance of principal leadership. Reston: National Association of Secondary School Principals; National Association of Elementary School Principals.

Public Impact (2018). Closing achievement gaps in diverse and low poverty schools: An action guide for district leaders. Retrieved from http://publicimpact.com/pi/wpcontent/uploads/2018/08/Closing_Achievement_Gaps_in_Diverse_and_LowPoverty_Schools.pdf

Rabinovitz, J. (2016). Local education inequities across U.S. revealed in new Stanford data set. Stanford: Stanford University Communications.

Rada, D. (1999). Transformational leadership and urban renewal. Journal of Leadership \& Organizational Studies, 6(3-4), 18-33.

Ravitch, D. (1995). National standards in American education: A citizen's guide. Washington: The Brookings Institution.

Reardon, S. (2003). Sources of educational inequality; the growth of racial/ethnic and socioeconomic test score gaps in kindergarten and first grade (Working Paper No. 03-05R). Philadelphia: Population Research Institute.

Reardon, S. F. (2011). The widening academic achievement gap between the rich and the poor: New evidence and possible explanations. Stanford: Stanford University.

Reardon, S. F. (2013). Left behind? The effect of No Child Left Behind on academic achievement gaps. Stanford: Stanford University. 
Reardon, S. F., \& Galindo, C. (2006). Patterns of Hispanic students' math and English literacy test scores in the early elementary grades. Washington: National Task Force for Early Childhood Education for Hispanics.

Research, H. (2014). Improving student achievement and closing the achievement gap. Arlington: Hanover Research.

Rice, J. (2018, December 10). The impact of teacher experience: Examining the evidence and policy implications. Retrieved from Urban Institute National Center for Analysis of Longitudincal Data in Educational Research: https://www.urban.org/sites/default/files/publication/33321/1001455-The-Impactof-Teacher-Experience.PDF

Ridgley, J. (2018, April 9). A qualitative analysis of factors influencing the professional longevity of high school science teachers in Florida (Dissertation). Retrieved from The Aquila Digital Community:

https://aquila.usm.edu/cgi/viewcontent.cgi?referer=https://www.google.com/\&htt psredir $=1 \&$ article $=1907 \&$ context $=$ dissertations

Rierson, S. L. (1994). Race and gender discrimmination: A historical case for equal treatment under the Fourteenth Amendment. Duke Journal of Gender \& Law Policy, 1(1), 89-117.

Robinson, M. A., \& Boies, K. (2016). Different ways to get the job done: comparing the effects of intellectual stimulation and contingent reward leadership on task-related outcomes. Journal of Applied Psyhology, 46(6), 336-353.

Robinson, V. (2011). Student-centered leadership. San Francisco: Jossey-Bass.

Rockoff, J. E., \& Lockwood, B. B. (2010). Stuck: How and why middle schools harm student achievement. Education Next, 10(4), 68-75.

Rodriguez, C. (2016). The relationship of the parental involvement of Latino immigrant parents of middle school students and student academic achievement. Miami: Florida International University.

Ross, J., \& Gray, P. (2006a). School leadership and student achievement: The mediating effects of teacher beliefs. Canadian Journal of Education, 29(3), 798-822.

Ross, J., \& Gray, P. (2006b). Transformational leadership and teacher commitment to organizational values: The mediating effects of collective teacher efficacy. School Effectiveness and School Improvement, 17(2), 179-199.

Rothstein, R. (2013). Why our schools are segregated. Educational Leadership, 70(8), 50-55. 
Rothstein, R. (2017, April 29). For public schools, segregation then, segregation since: Education and the unfinished march. Retrieved from Economic Policy Institute: http://www.epi.org/publication/unfinished-march-public-school-segregation/

Rumberger, R., \& Arellano, B. (2004). Understanding and addressing the California Latino achievement gap in early elementary school. Santa Barbara: University of California Linguistic Minority Research Institute.

Saultz, A., Fusarelli, L. D., \& McEachin, A. (2017). The Every Student Succeeds Act, the decline of the federal role in education policy, and the curbing of executive authority. Publius: The Journal of Federalism, 47(3), 426-444.

Schaefer, M., \& Malu, K. F. (2016). An historical overview of the middle school movement, 1963-2015. 39(5), Research in Middle Level Education.

Schein, E. H. (2010). Organizational culture and leadership (4th ed.). San Francisco: John Wiley \& Sons, Inc.

Schwerdt, G., \& West, M. (2017, May 10). The middle school plunge. Retrieved from Education Next: http://educationnext.org/the-middle-school-plunge/

Seashore-Louis, K., Leithwood, K., Wahlstrom, K. L., \& Anderson, S. E. (2010). Investigating links to improved student learning. Miineapolis: The University of Minnesota.

Sellers, K. B. (2018, April 8). The effect of teacher retention on student achievement in third grade reading/language arts (Dissertation). Retrieved from The University of Southern Mississippi:

https://aquila.usm.edu/cgi/viewcontent.cgi? article=1444\&context=dissertations

Sergiovanni,T. J. (1995). The principlaship: A reflective practice perspective. Massachusetts: Allyn and Bacon.

Sergiovanni, T. J. (2007). Rethinking leadership: A collection of articles (2nd ed.). Thousand Oaks: Corwin Press.

Skogstad, A., Einarsen, S., Torsheim, T., Schanke, A. M., \& Hetland, H. (2007). Destructiveness of laissez-faire leadership behavior. Journal of Occupational Health Psychology, 12(1), 80-92.

Smith, J. P. (1984). Race and human capital. The American Economic Review, 74(4), 685-698. 
Smith, K. K., Matkin, G. S., \& Fritz, S. (2004). A review of gender and full-range leadership research and suggestions for future research. Journal of Leadership Education, 3(2), 52-68.

Sparks, S. D. (2016, March 15). New research uncovers little improvement in achievement gap. Retrieved from PBS Newshour:

http://www.pbs.org/newshour/rundown/new-research-uncovers-littleimprovement-in-achievement-gap/

Sprinthall, R. C. (2012). Basic statistical analysis (9th ed.). Needham Height: Allyn \& Bacon, Inc.

Stone, A. G., Russell, R. F., \& Patterson, K. (2004). Transformational versus servant leadership: A difference in leader focus. The Leadership \& Organization Development Journal, 25(4), 349-361.

Street, P. (2005). Segregated schools; educational apartheid in Post-Civil Rights America. New York: Routledge, Taylor \& Francis Group.

Stronge, J. H., Richard, H. B., \& Catano, N. (2008). Qualities of effective principals. Alexandria: Association for Supervision and Curriculum Development.

Sumner, M. (2018, April 7). Climate and student performance in Tennessee middle schools (Doctoral Dissertation). Retrieved from University of Tennessee: http://trace.tennessee.edu/utk_graddis/1875

Sun, J., \& Leithwood, K. (2015). Leadership effects on student learning mediated by teacher emotions. Societies, 5(3), 566-582.

Thapa, A., Cohen, J., Gugffey, S., \& Higgins-D'Alessandro, A. (2013). A review of school climate research. Review of Educational Research, 83(3), 357-385.

The National Commission on Excellence in Education (1983). A Nation at Risk: The imperative for educational reform. Washington, D.C.: U.S. Government Printing Office.

The Carnegie Corporation Task Force on Education of Young Adolescents (1990). Turning points: Preparing American youth for the 21 st century:

Recommendations for transforming middle grade schools. Washington: Carnegie Council

The Education of Blacks in the South, 1860-1935. (1988). Anderson, James D. Chapel Hill: The University of North Carolina Press. 
Theobald, N. D. (2000). Balancing local control and state responsibility for K-12 education: 2000 yearbook of the American Education Finance Association. New York: Routledge.

Thomas, J. Y., \& Brady, K. P. (2005). The Elementary and Secondary Education Act at 40: Equity, accountability, and the evolving federal role in public education. Review of Research in Education, 29(1), 51-67.

Thoroughgood, C. N., Tate, B. W., Sawyer, K. B., \& Jacobs, R. (2012). Bad to the bone: Empirically defining and measuring destructive leader behavior. Journal of Leadership \& Organizational Studies, 19(2), 230-255.

Travis, S. (2017, December 17). Middle school isn't working. Here's how South Florida is fixing it. Retrieved from SunSentinel: http://www.sunsentinel.com/news/education/fl-broward-middle-schools-20171212-story.html

Tschannen-Moran, M. (2013). Becoming a trustworthy leader. The Jossey-Bass Reader on Educational Leadership (3rd ed.), 40-54. San Francisco: Jossey-Bass.

United States Congress (2017, September 2). PUBLIC LAW 107-110-JAN. 8, 2002115 STAT. 1425. Retrieved from U.S. Department of Education: https://www2.ed.gov/policy/elsec/leg/esea02/107-110.pdf

United States Department of Education (2002). No Child Left Behind Act of 2001. Washington: U.S. Department of Education.

United States Department of Education (2008). A nation accountable: Twenty-five years after A Nation at Risk. Washington: U.S. Department of Education.

United States Department of Education (2008). Total U.S. expenditures for elementary and secondary education. Washington: U.S. Department of Education.

United States Department of Education (2016, June 16). U.S. Department of Education. Retrieved from U.S. Department of Education: http://www2.ed.gov/about/overview/fed/role.html

United States Department of Education (2016, September 6). Improving basic programs operated by local educational agencies (Title I, Part A) . Retrieved from U.S. Department of Education: http://www2.ed.gov/programs/titleiparta/index.html

United States Department of Education (2016, October 15). NCLB overview. Retrieved from U.S. Department of Education: http://www2.ed.gov/nclb/overview/intro/guide/guide_pg12.html 
United States Department of Education (2016, November 1). Title I, Part A. Retrieved from U.S. Department of Education:

http://www2.ed.gov/programs/titleiparta/index.html

United States Department of Education (2016, November 20). Every Student Succeeds Act (ESSA). Retrieved from U.S. Department of Education:

http://www.ed.gov/ESSA

United States Department of Education (2016, December 1). Title I-improving the academic achievement of the disadvantaged. Retrieved from U.S. Department of Education: http://www2.ed.gov/policy/elsec/leg/esea02/pg1.html

United States Department of Education (2017, March 12). Law \& guidancelelementary \& secondary education. Retrieved from www2.ed.gov:

https://www2.ed.gov/policy/elsec/leg/esea02/pg1.html

United States Department of Education (2017, December 17). Estimated ESEA Title I

LEA allocations-FY 2017. Retrieved from U.S. Department of Education:

https://www2.ed.gov/about/overview/budget/titlei/fy17/index.html

United States Department of Education (2018). Title I, Part A. Retrieved from https://www2.ed.gov/programs/titleiparta/index.html

Van Wart, M. (2003). Public-sector leadership theory: An assessment. Public Administration Review, 214-228.

Vera, D., \& Crossa, M. (2004). Strategic leadership and organizational learning. Academy of Management Review, 29(2), 222-240.

Vinovskis, M. (2015). From a Nation at Risk to No Child Left Behind: National education goals and the creation offederal education policy. New York: Teachers College Press.

Wagner, C., \& Masden-Copas, P. (2002). An audit of the culture starts with two handy tools. Journal of Staff Development, 23(3), 42-53.

Wahlstrom, K., Louis, K., Leithwood, K., \& Anderson, S. (2010). Investigating the links to improved student learning. New York: The Wallace Foundation.

Waldman, D. A. (1990). Adding to contingent-reward behavior: The augmenting effect of charismatic leadership. Group \& Organizational Management, 15(4), 381-394.

Walker, N. J. (2009). The relationship between principal longevity and school performance in a large urban school district. Macon: Mercer University Press. 
Wallace Foundation (2013). The school principal as leader: Guiding schools to better teaching and learning. New York: The Wallace Foundation.

Waters, J. T., Marzano, R. J., \& McNulty, B. A. (2003). Balanced leadership: What 30 years of research tells us about the effect of leadership on student achievement. Aurora: Waters, J. T., Marzano, R. J., \& McNulty, B. A. (Eds.).

Weber, M. (1974). Max Weber: The theory of social and economic organization. New York: The Free Press.

Whitehead, B. M., Boschee, F., \& Decker, R. H. (2013). The principal: Leadership for a global society. Thousand Oaks: SAGE.

Wilson, W. J. (2009). More than just race: Being black and poor in the inner city. Poverty \& Race, 18(3), 1-15.

Witzers, B., Bosker, R. J., \& Kruger, M. L. (2003). Educational leadership and student achievement: The elusive search for an association. Education Administration Quarterly, 39(3), 398-425.

Yammarino, F. J., \& Dubinsky, A. J. (1994). Transformational Leadership Theory: Using levels of analysis to determine boundary conditions. Personnel Psychology, 47, 787-811.

Yecke, C. P. (2005). Mayhem in the middle: How middle schools have failed America-and how to make them work. Washington: Thomas B. Fordham Institute.

Yisrael, S. (2012). The 12 laws of urban school leadership: A principal's guide for initiating effective change. Plymouth: Rowman \& Littlefield Education.

Yukl, G. (2012). Leadership in organizations (8th ed.). Upper Saddle River: Pearson. 
VITA

ANNA L. RODRIGUEZ

Born, West Palm Beach, Florida

1994

B.A., History and Latin American Studies

University of Miami

Coral Gables, Florida

1994-1996

Teacher

Palm Beach County Public Schools

West Palm Beach, Florida

$1996-2000$

Teacher

Miami-Dade County Public Schools

Miami, Florida

1999

M.S., Educational Leadership

Florida International University

Miami, Florida

2000-2006

Assistant Principal

Miami-Dade County Public Schools

Miami, Florida

2006-2013

Principal

Miami-Dade County Public Schools

Miami, Florida

2013-Present

Administrative Director

Miami-Dade County Public Schools

Miami, Florida

Summer 2010- Spring 2019

Doctoral Candidate

Educational Administration and Supervision Florida International University

Miami, Florida 


\section{PRESENTATIONS}

Rodriguez, A.L. (2015). MDCPS Leadership Development Initiatives. National presentation at the American Association of School Administrators (AASA) Conference. San Diego, CA

Rodriguez, A.L. (2014). Instructional Rounds and MDCPS. Presentation at a Regional American Association of School Administrators (AASA) Conference. New Orleans, LA

Rodriguez, A.L. (2014). MDCPS and Lead Strong Program. Presentation for National award recipients. Washington, D.C. 